NATIONAL LABORATORY

MANAGED BY UT-BATTELLE

FOR THE DEPARTMENT OF ENERGY

\title{
Integrated Analysis of Market Transformation Scenarios with HyTrans
}

June 2007

David L. Greene

Paul N. Leiby

Oak Ridge National Laboratory

David Bowman

EconoTech

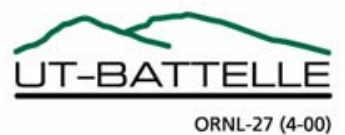




\title{
DOCUMENT AVAILABILITY
}

Reports produced after January 1, 1996, are generally available free via the U.S. Department of Energy (DOE) Information Bridge.

Web site http://www.osti.gov/bridge

Reports produced before January 1, 1996, may be purchased by members of the public from the following source.

\author{
National Technical Information Service \\ 5285 Port Royal Road \\ Springfield, VA 22161 \\ Telephone 703-605-6000 (1-800-553-6847) \\ TDD 703-487-4639 \\ Fax 703-605-6900 \\ E-mail info@ntis.gov \\ Web site http://www.ntis.gov/support/ordernowabout.htm
}

Reports are available to DOE employees, DOE contractors, Energy Technology Data Exchange (ETDE) representatives, and International Nuclear Information System (INIS) representatives from the following source.

Office of Scientific and Technical Information

P.O. Box 62

Oak Ridge, TN 37831

Telephone 865-576-8401

Fax 865-576-5728

E-mail reports@osti.gov

Web site http://www.osti.gov/contact.html

This report was prepared as an account of work sponsored by an agency of the United States Government. Neither the United States Government nor any agency thereof, nor any of their employees, makes any warranty, express or implied, or assumes any legal liability or responsibility for the accuracy, completeness, or usefulness of any information, apparatus, product, or process disclosed, or represents that its use would not infringe privately owned rights. Reference herein to any specific commercial product, process, or service by trade name, trademark, manufacturer, or otherwise, does not necessarily constitute or imply its endorsement, recommendation, or favoring by the United States Government or any agency thereof. The views and opinions of authors expressed herein do not necessarily state or reflect those of the United States Government or any agency thereof. 
ORNL/TM-2007/094

Engineering Science and Technology Division

\title{
INTEGRATED ANALYSIS OF MARKET TRANSFORMATION SCENARIOS WITH HYTRANS
}

\author{
David L. Greene \\ Paul N. Leiby \\ Oak Ridge National Laboratory \\ Oak Ridge, Tennessee \\ David Bowman \\ EconoTech \\ Oak Ridge, Tennessee 37831
}

June 2007

\author{
Prepared by \\ OAK RIDGE NATIONAL LABORATORY \\ P.O. Box 2008 \\ Oak Ridge, Tennessee 37831-6285 \\ managed by \\ UT-Battelle, LLC \\ for the \\ U.S. DEPARTMENT OF ENERGY \\ under contract DE-AC05-00OR22725
}





\section{CONTENTS}

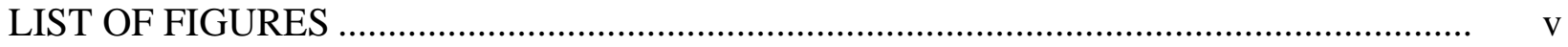

LIST OF TABLES ......................................................................................................... vii

ACKNOWLEDGEMENTS ............................................................................................... ix

ABSTRACT

1. PURPOSE AND PREMISES.................................................................................... 1

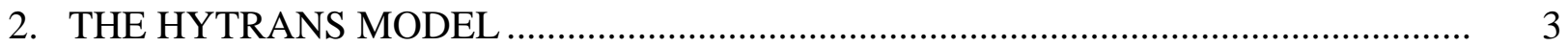

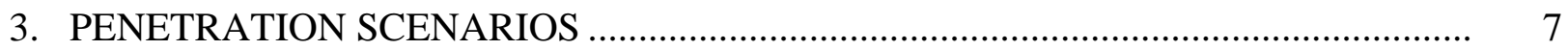

4. FUEL CELL VEHICLE COSTS .............................................................................. 13

5. HYDROGEN PRODUCTION PATHWAYS.............................................................. 17

6. ALTERNATIVE FUTURES AND POLICY CASES ....................................................... 19

7. IMPACTS AND EFFECTIVENESS OF THE THREE EARLY TRANSITION SCENARIOS AND THE LONG-TERM TRANSITION TO HYDROGENPOWERED VEHICLES ……………................................................................. 21

7.1 TOTAL MOTOR FUEL USE ………………………………………………..... 25

7.2 HYDROGEN PRODUCTION AND DELIVERY PATHWAYS ........................... 26

8. COSTS OF THE EARLY TRANSITION ................................................................... 31

8.1 COST SHARES BORNE BY GOVERNMENT (THREE SCENARIOS COUPLED WITH THREE POLICY CASES)...................................................... 32

8.2 IMPLIED CASH FLOW FOR VEHICLE MANUFACTURERS ............................. 37

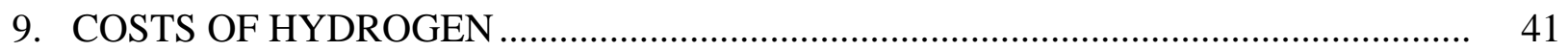

10. THE NEED FOR EARLY TRANSITION POLICIES ………………………................... 45

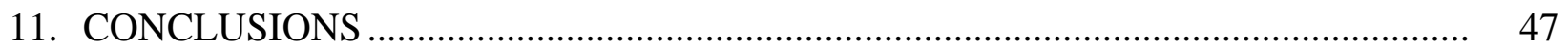

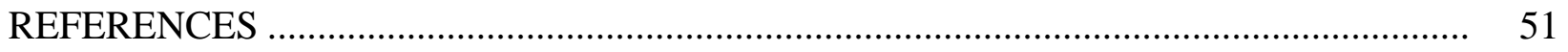




\section{LIST OF FIGURES}

Figure

Page

1 Components of the Hydrogen Vehicle and Fuel Market Integrated in HyTrans .......... 4

2 New York Metropolitan Area and High and Low Fuel Demand Density Regions in the Northeast ...............................................................................................

3 Number of Hydrogen Vehicles Sold Per Year by Region in Scenario 1 1.................... 9

$4 \quad$ Number of Hydrogen Vehicles Sold Per Year by Region in Scenario 2 ..................... 9

$5 \quad$ Number of Hydrogen Vehicles Sold Per Year by Region in Scenario 3 ..................... 10

$6 \quad$ Total Hydrogen Refueling Stations by Year: Los Angeles .......................................... 10

7 Total Hydrogen Refueling Stations by Year: Rest of U.S....................................... 11

8 Total Hydrogen Refueling Stations by Year: All of U.S....................................... 11

$9 \quad$ Fuel Economy Estimates for Advanced Technologies by Rousseau et al. (2005) ....... 12

10 Scale and Learning as a Function of the Stock of Vehicles and Production Volume .. 14

11 Fuel Cell Vehicle Cost in Scenarios 1, 2, and 3, Compared with a Central Tendency of OEM Estimates............................................................................................ 115

12 Close-up View of Fuel Cell Vehicle Production Costs in Three Scenarios ................ 15

13 Diversity of Fuel Cell Vehicle Choice (\# of Nameplates) by Scenario ....................... 16

14a Vehicle Technology Market Shares: No Transition Policy, No C Policy (Future \#1)

14b Vehicle Technology Market Shares: No Transition Policy, C Policy (Future \#5) ........

15 Light-duty Vehicle Fuel Demand in Billions of Gallons of Gasoline Equivalent:

Future \#1.....

16 Vehicle Technology Market Shares in Scenario 1 (Future \#2).................................. 23

17 Vehicle Technology Market Shares in Scenario 2: No C Policy (Future \#3).............. 23

18 Vehicle Technology Market Shares in Scenario 3: No C Policy (Future \#4).............. 24

19 Vehicle Technology Shares, Scenario 3, Technology Shortfall (Future \#9) ................ 24

20 Vehicle Technology Shares, Scenario 3, Technology Success, Reference Case Oil

Prices (Future \#10)................................................................................................ 25

21 Light-duty Vehicle Fuel Use by Type: Scenario 3, No C Policy (Future \#4) ............. 26

22 Hydrogen Production Pathways: All U.S., Scenario 3, Technology Success,

No C Policy (Future \#4).

23 Hydrogen Production Pathways: Medium Density Rest of U.S., Scenario 3, No C Policy (Future \#4)........................................................................................... 27

24 Hydrogen Production Pathways: All U.S., Scenario 3, With C Policy (Future \#8) ..... 28

25 Impacts of Carbon Policy and FCV Market Success on $\mathrm{CO}_{2}$ Emissions from Light-duty Vehicles (Futures \#5, \#8, \#4).

26 Vehicle Technology Shares, \$10/kWh Storage Costs Scenario 3 (Future \#12) .......... 30

27a, b Cost to Government of Policy Case 1 in Scenario 1, Annual and Cumulative ............ 32

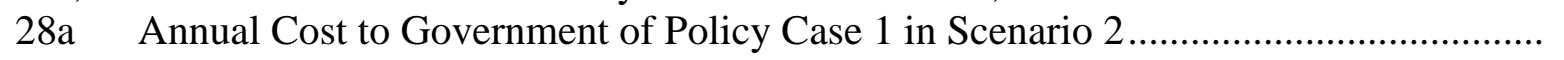

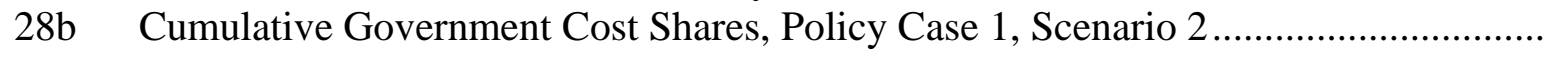

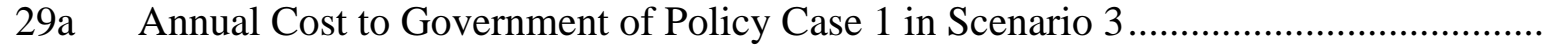

29b Cumulative Government Cost Shares, Policy Case 1, Scenario 3..............................

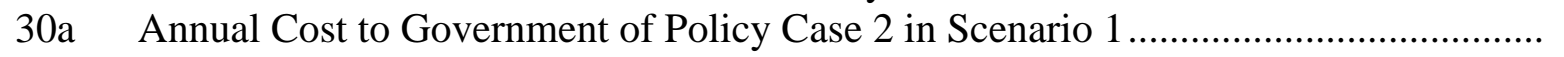

30b Cumulative Government Cost Shares, Policy Case 2, Scenario 1..............................

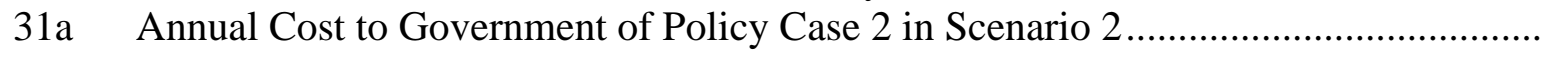

31b Cumulative Government Cost Shares, Policy Case 2, Scenario 2 ............................. 35 
32a Annual Cost to Government of Policy Case 2 in Scenario 3................................... 35

32b Cumulative Government Cost Shares, Policy Case 2, Scenario 3............................. 35

33a Annual Cost to Government of Policy Case 3, Scenario 1 ....................................... 36

33b Cumulative Government Cost Shares, Policy Case 3, Scenario 1............................. 36

34a Annual Cost to Government of Policy Case 3, Scenario 2 ...................................... 36

34b Cumulative Government Cost Shares, Policy Case 3, Scenario 2 ............................ 36

35a Annual Cost to Government of Policy Case 3, Scenario 3 ...................................... 37

35b Cumulative Government Cost Shares, Policy Case 3, Scenario 3............................ 37

36 Simulated Industry Cash Flow from Sales of FCVs: No Policy Case....................... 38

37 Simulated Industry Cash Flow from Sales of FCVs: Policy Case 1 1......................... 38

38 Simulated Industry Cash Flow from Sales of FCVs: Policy Case 2 ......................... 39

39 Simulated Industry Cash Flow from Sales of FCVs: Policy Case 3......................... 40

40 Hydrogen Production Costs in Future \#4, U.S. Average .......................................... 41

41 Hydrogen Production Costs in Future \#4, Los Angeles ........................................... 42

42 Cost of Hydrogen at the Refueling Station, Excluding Tax and Subsidy................... 42

43 Retail Fuel Cost for Hydrogen Fuel Cell Vehicles, Adjusted for their Greater Efficiency and Including All Taxes and Subsidies .................................................. 43

44 Retail Fuel Cost for Hydrogen Fuel Cell Vehicles, Adjusted for Energy Efficiency and Including Taxes and Subsidies 


\section{LIST OF TABLES}

1 Models and Projections Used in HyTrans ........................................................................ 3

2 Deployment of Hydrogen Fuel Cell Vehicles by Region and Year................................... 8

3 DOE FCV Program Goals for 2015 and Lesser Achievements Evaluated by Rousseau et al. (2005)........................................................................................... 11

4 DOE 2015 Vehicle Technology Goals for Peak Energy Efficiency of Advanced Powertrains ..................................................................................................... 11

5 Hydrogen Production Pathways in HyTrans............................................................. 18

6 Early Transition Futures: Scenarios plus Policy Cases.................................................... 19

$7 \quad$ Hydrogen Fuel Cell Vehicle and Infrastructure Policy Cases ........................................... 32 


\section{ACKNOWLEDGEMENT}

The authors gratefully acknowledge the leadership and support of Sig Gronich, U.S. Department of Energy. This report tries to capture his vision of the transition to a hydrogen powered transportation system. The HyTrans model could not have been constructed had we not been able to take advantage of the excellent analytical modeling done by other researchers, especially the DOE H2A models, the PSAT and ASCM models, the GREET model and the NEMS model. We thank the automobile manufacturers and their staff who assisted us in developing useful representations of the costs of future fuel cell vehicles as a function of scale, learning by doing and R\&D dependent technological progress. We are also grateful to Philip Patterson, U.S. DOE, and to our colleagues Steve Plotkin (Argonne National Laboratory) and Sujit Das (Oak Ridge National Laboratory) for their comments on an earlier draft of this report. Any remaining errors or deficiencies are the authors' responsibility. 


\begin{abstract}
This report presents alternative visions of the transition of light-duty vehicle transportation in the United States from petroleum to hydrogen power. It is a supporting document to the U.S. Department of Energy's Summary Report, “Analysis of the Transition to a Hydrogen Economy and the Potential Hydrogen Infrastructure Requirements” (U.S. DOE, 2007). Three alternative early transition scenarios were analyzed using a market simulation model called HyTrans. The HyTrans model simultaneously represents the behavior of fuel suppliers, vehicle manufacturers and consumers, explicitly recognizing the importance of fuel availability and the diversity of vehicle choices to consumers, and dependence of fuel supply on the existence of market demand. Competitive market outcomes are simulated by means of non-linear optimization of social surplus through the year 2050. The three scenarios specify different rates and geographical distributions of market penetration for hydrogen fuel cell vehicles from 2012 through 2025. Scenario 1 leads to 2 million vehicles on U.S. roads by 2025, while Scenarios 2 and 3 result in 5 million and 10 million FCVs in use by 2025, respectively. The HyTrans model "costs out" the transition scenarios and alternative policies for achieving them. It then tests whether the scenarios, together with the achievement of the DOE's technology goals for fuel cell vehicles and hydrogen infrastructure technologies could lead to a sustainable transition to hydrogen powered transportation. Given the achievement of DOE's ambitious technology goals, all three scenarios appear to lead to a sustainable transition to hydrogen. In the absence of early transition deployment effort, no transition is likely to begin before 2045. The cumulative costs of the transition scenarios to the government range from $\$ 8$ billion to $\$ 45$ billion, depending on the scenario, the policies adopted and the degree of cost-sharing with industry. In the absence of carbon constraining policies, the transition to hydrogen achieves about the same reduction in $\mathrm{CO}_{2}$ emissions as a transition to advanced gasoline-electric hybrid vehicles. With significant carbon policy, drastic reductions in well-to-wheel $\mathrm{CO}_{2}$ emissions are possible. Energy transition modeling is a newly evolving field and much remains to be done to improve the utility of models like HyTrans.
\end{abstract}




\section{PURPOSE AND PREMISES}

Transforming the automotive market from petroleum to hydrogen powered vehicles will require fervent and sustained commitment by hydrogen producers, transporters and retailers, vehicle manufacturers, consumers and governments. The costs and benefits of early market transformation policies, and ultimately the success of the transformation itself will depend on the interaction of these agents in the marketplace. The transition to hydrogen-powered transportation faces imposing economic barriers. These include driving a new and different power-train technology down the learning curve, simultaneously building a supporting fuel infrastructure and developing a market of vehicles to utilize it, and achieving both economies of scale in production and diversity of make and model choice for consumers. The up-front costs will be large and the rewards enormous but delayed. Such a profound market transformation is likely to require careful planning and strong policy incentives.

This report presents the results of integrated market-based simulations of alternative market transformation plans and compares them with a no-policy scenario. In general, all the futures explored assume major progress in fuel cell and other advanced drive train technologies. Most futures assume that the technology goals of the Department of Energy's (DOE's) FreedomCar and Vehicle Technologies Program (U.S. DOE/EERE, 2006) and Hydrogen Fuel Cells and Infrastructure Technologies (HFCIT) Program (U.S. DOE/EERE, 2005) will be met. Three early transformation scenarios are evaluated assuming three different policy cases. The policy cases reflect alternative strategies for sharing the costs of the transformation between private industry and government and providing incentives to consumers. The scenarios and policy cases are evaluated with respect to their effectiveness in achieving a sustainable market transformation and their costs to government and private industry. No recommendations are being made or are intended with respect to which scenarios or policies should be adopted.

Analyses extending twenty to fifty years into the future, involving critical assumptions about technological progress and consumer behavior, are replete with uncertainties.

- Uncertainty about the extent and rate of technological progress for hydrogen fuel cell vehicles and competing vehicle technologies.

- Uncertainty about future energy market conditions, especially the prices of petroleum and feedstocks for producing hydrogen.

- Uncertainty about the response of feedstock costs to the additional demand for hydrogen production.

- Uncertainty about the values consumers attach to fuel and vehicle attributes, including fuel availability and the diversity of choice among makes and models.

- Uncertainty about how both market and policy risks will affect the investment decisions of vehicle manufacturers, hydrogen producers and retailers, and consumers.

It is important that these (and other) uncertainties be acknowledged lest we deceive ourselves into thinking we know all the answers. Still, in a project as complex and important as the transition to hydrogen powered transportation, envisioning and planning are essential. Integrated market analysis is critical for the development of a coherent and credible vision of the transition, and could become an essential tool in the development of feasible plans. The assessments presented here are intended to contribute to progress towards those goals. 


\section{THE HYTRANS MODEL}

The U.S. DOE developed the HyTrans Model (Leiby et al., 2005) to simulate the market response to advanced hydrogen technologies and alternative policies to promote the market transformation to hydrogen vehicles. HyTrans directly incorporates the important market barriers that hinder transition to a radically different fuel and vehicle technology: (1) lack of availability of the alternative fuel, (2) lack of a market for the alternative fuel, (3) the need to achieve scale economies in vehicle production, (4) the need to reduce fuel cell power train costs via learning by doing, and (5) lack of diversity of choice in vehicle products for early buyers. To represent the key components of the hydrogen market, HyTrans incorporates simplified representations of several other models developed by the DOE (Table 1).

Table 1. Models and Projections Used in HyTrans

\begin{tabular}{l}
\hline DOE H2A Model \\
Hydrogen Production \\
Hydrogen Delivery \\
PSAT \& ASCM Vehicle Performance and Cost Estimates \\
2010/2015 cost and performance goals \\
Fuel economy \\
ORNL Vehicle Choice Model \\
Fuel availability \\
Make \& model diversity \\
Price, fuel economy, etc. \\
ORNL Advanced Vehicle Manufacturing Cost Model \\
Scale Economies \\
Learning-by-doing \\
Time-Dependent Technological Change \\
GREET GHG Emissions Model \\
NEMS AEO 2006 Calibration Through 2030 \\
High Oil Price Case \\
Reference Oil Price Case
\end{tabular}

HyTrans is a dynamic, non-linear optimization model that simulates the functioning of competitive markets through the year 2050 by maximizing producers' profits and consumers' welfare. The key agents in the hydrogen transition are represented: (1) fuel producers, distributors and retailers, (2) vehicle manufacturers, and (3) motor vehicle purchasers and users (Figure 1). Government policies can also be simulated. It is assumed that the key actors behave as rational, optimizing economic agents with full information and foresight. The non-linearity of the model allows for more accurate representation of key processes such as consumers' choices among alternative vehicle technologies and scale economies. The challenge of finding optimal solutions is increased by the important positive feedback mechanisms of learning by doing, scale economies and fuel and vehicle availability. This limits the feasible size of the model in terms of the number of variables that can be included in the model and the detail with which it can represent geographical regions, vehicle types, and market segments.

The three early market transformation scenarios are implemented in HyTrans as constraints. For each geographic region, fuel demand density subregion, and time period from 2012 to 2025 the sales of hydrogen vehicles (and hydrogen fuel use) are required to follow the trajectories specified by the three early transition scenarios. After 2025 through 2050 a competitive market 
outcome is determined. HyTrans calculates the costs of satisfying the required sales volumes for vehicles and fuels during the early scenario period. Excess costs above the costs of the null scenario imply that someone, fuel producers, manufacturers, consumers, or the government, had to subsidize the transition. Three policy cases explore different allocations of these start-up costs between the private sector and the government.

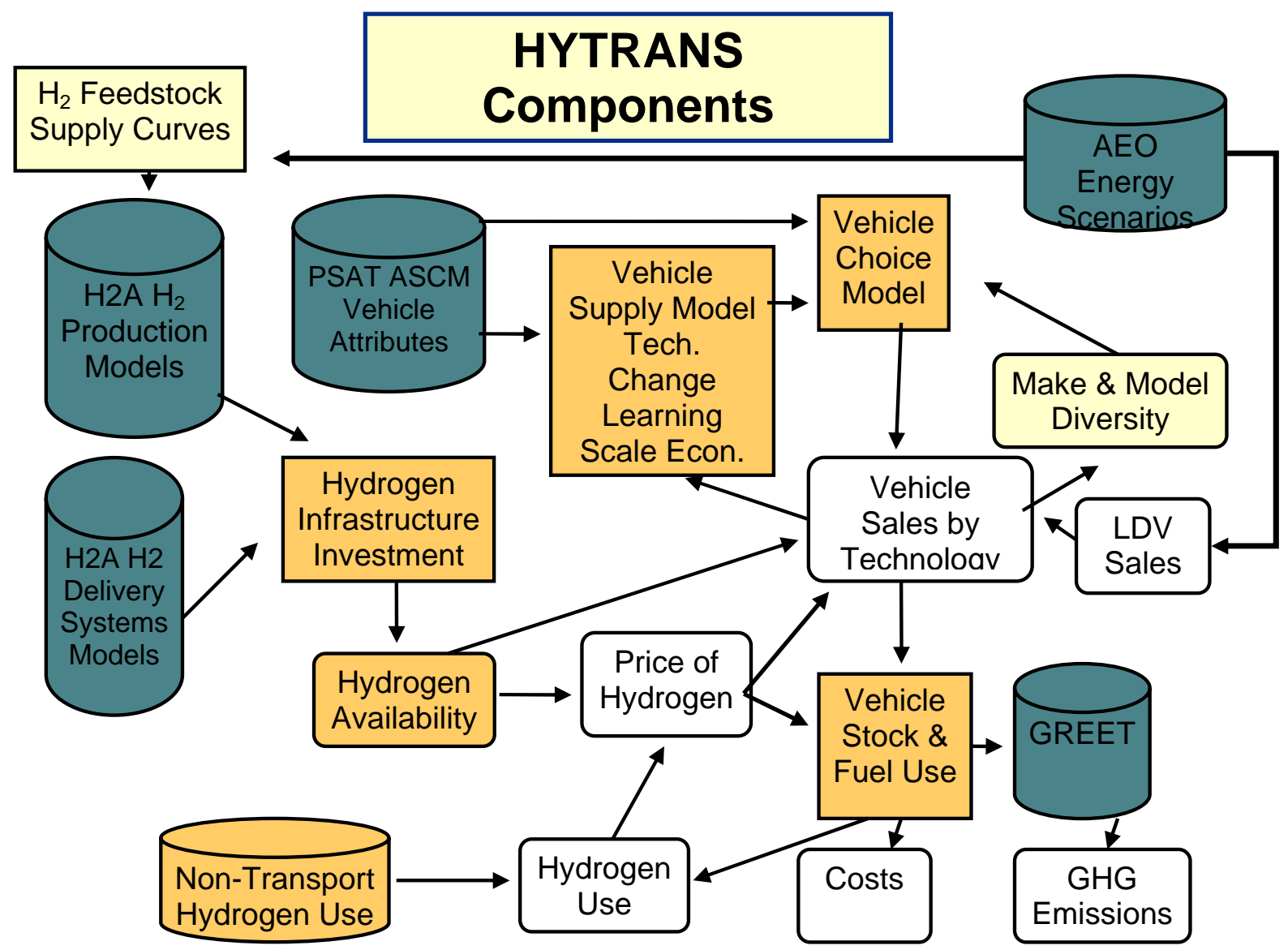

Figure 1. Components of the Hydrogen Vehicle and Fuel Market Integrated in HyTrans

Two regions, the Pacific Coast and the Northeastern United States are the initial focal points of the early transition scenarios. In these two regions, HyTrans separately represents the two major "lighthouse" cities: Los Angeles and New York. The remainder of each region is divided into high and low fuel demand density areas. For example, the New York Metropolitan Area, high fuel demand density areas and the remaining low density areas in the Northeast Region are shown in Figure 2. Similarly, the rest of the United States is divided into high, medium and low fuel demand density areas. Vehicle sales and stocks, hydrogen production and consumption are predicted and tracked for each region and subregion. Regions are interdependent, however, because while hydrogen availability in one's own region may matter the most, hydrogen availability in all regions has some value to car buyers. 


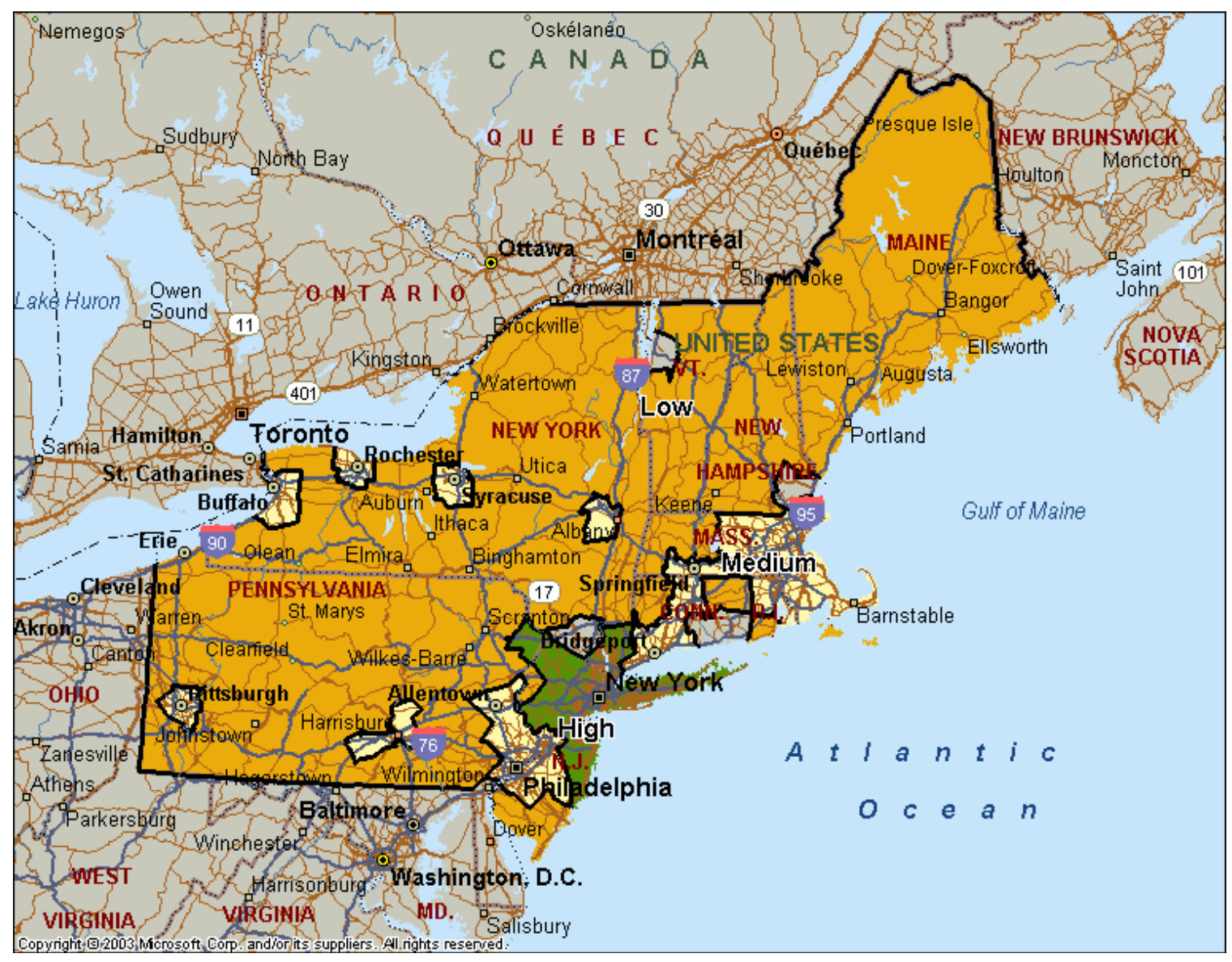

Figure 2. New York Metropolitan Area and High (yellow) and Low (orange) Fuel Demand Density Regions in the Northeast

A crucial contribution of HyTrans is to assess the longer-run (post 2025) competitive market outcomes after the completion of each of the early market transformation scenarios. During the "Scenario" or startup period, learning is gained, unit costs are reduced and regional fuel production and delivery infrastructure is developed. A key question is whether the scenarios establish the conditions and prices under which a substantial transition to hydrogen vehicles and fuels could then occur and be economically sustainable. From 2025 to 2050 HyTrans is run in unconstrained mode to evaluate the long-run market response to the early transition scenarios. 


\section{PENETRATION SCENARIOS}

Three early penetration scenarios plus a no-policy scenario were analyzed under differing assumptions about, (1) energy market conditions driven by oil prices, (2) the progress of advanced vehicle technologies, and (3) carbon emissions and biomass fuels policy. Scenario 1 is the most cautious of the three. It begins in 2015, three years later than the other two scenarios (Table 2). By 2025, nearly 2 million fuel cell vehicles (FCVs) are on the road, more than half of them in California or New York (Figure 3).

Scenarios 2 and 3 begin cautiously in 2012 at 500 vehicles per year but jump to 30,000 vehicles per year in 2015. Three OEMs are assumed to be involved in this phase until 2017, then it is assumed that 5 vehicle manufacturers are producing the cars. The two scenarios track each other closely until 2019, when Scenario 3 begins a more aggressive expansion to areas outside of the Pacific and Northeast regions (Figures 4 and 5).

The deployment of forecourts and liquid hydrogen delivery directly follows the deployment of hydrogen vehicles. Each forecourt has a nominal capacity of $1,500 \mathrm{~kg} / \mathrm{d}$ and is assumed to have a $70 \%$ utilization rate, implying 1,050 kg/d of hydrogen dispensed. In Scenario 3 nearly 8000 stations are needed to supply the 10 million fuel cell vehicles on the road, implying an average rate of hydrogen use of $0.8 \mathrm{~kg} / \mathrm{d}$ for the newer and therefore relatively more intensively used fuel cell vehicles.

Scenario 1 establishes 400 refueling outlets in each lighthouse city, with the rest of the country sharing an equal number (about 800). Scenarios 2 and 3 induce the same number of stations through 2017 but after that date there are far more stations in Scenario 3, especially outside of the major lighthouse cities of Los Angeles and New York (Figure 6). While Scenarios 2 and 3 place similar numbers of stations in L.A. and N.Y., Scenario 3 places 6,000 refueling outlets in other cities across the United States while Scenario 2 establishes only 2,000 stations outside of the main lighthouse regions of LA and New York (Figures 7 and 8). ${ }^{1}$

A key premise of this integrated market analysis is that the technology goals of the DOE's HFCIT and FreedomCAR programs will be met, although sensitivity cases test the potential reaction of markets to falling short those goals. The technology goals for hydrogen production pathways, as represented in the H2A Production and Delivery models, were also incorporated as reduced form equations in HyTrans.

\footnotetext{
${ }^{1}$ The total vehicle sales paths and station deployment rates in the HyTrans scenarios described here, both for the United States as a whole and for large regions, match those described by Melendez and Milbrandt (2007) in a companion report. There are, however, some differences in the detailed regional distribution of vehicles and stations by city, since the HyTrans runs are based on an earlier draft of the National Renewable Energy Laboratory (NREL) work. For example, the newer geographically based demand and infrastructure analysis by NREL indicates a larger share of the fuel-cell vehicles in Scenarios 3 may be effectively deployed in New York City by 2025 (see Table 4 of Melendez and Milbrandt). These differences in scenario spatial detail will be harmonized in future HyTrans work, but it is not expected that the revisions will alter any of the fundamental results or insights.
} 
Table 2. Deployment of Hydrogen Fuel Cell Vehicles by Region and Year (thousands)

\begin{tabular}{|c|c|c|c|c|c|c|c|c|c|c|c|c|c|c|}
\hline \multicolumn{15}{|c|}{ Deployment of Hydrogen Fuel Cell Vehicles by Scenario (thousands) } \\
\hline & 2012 & 2013 & 2014 & 2015 & 2016 & 2017 & 2018 & 2019 & 2020 & 2021 & 2022 & 2023 & 2024 & 2025 \\
\hline Scenario 1 & 0.0 & 0.0 & 0.0 & 3.0 & 4.8 & 7.2 & 50 & 100 & 150 & 200 & 250 & 300 & 400 & 500 \\
\hline Scenario 1 Cumulative & 0.0 & 0.0 & 0.0 & 3.0 & 7.8 & 15.0 & 65 & 165 & 315 & 515 & 765 & 1,065 & 1,465 & 1,965 \\
\hline Scenario 2 & 0.5 & 1.0 & 1.0 & 30.0 & 60.0 & 60.0 & 200 & 300 & 400 & 500 & 600 & 700 & 900 & 1,000 \\
\hline Scenario 2 Cumulative & 0.5 & 1.5 & 2.5 & 32.5 & 92.5 & 152.5 & 353 & 653 & 1,053 & 1,553 & 2,153 & 2,853 & 3,753 & 4,753 \\
\hline Scenario 3 & 0.5 & 1.0 & 1.0 & 30.0 & 60.0 & 60.0 & 300 & 500 & 750 & 1,000 & 1,200 & 1,500 & 2,000 & 2,500 \\
\hline Scenario 3 Cumulative & 0.5 & 1.5 & 2.5 & 32.5 & 92.5 & 152.5 & 453 & 953 & 1,703 & 2,703 & 3,903 & 5,403 & 7,403 & 9,903 \\
\hline
\end{tabular}




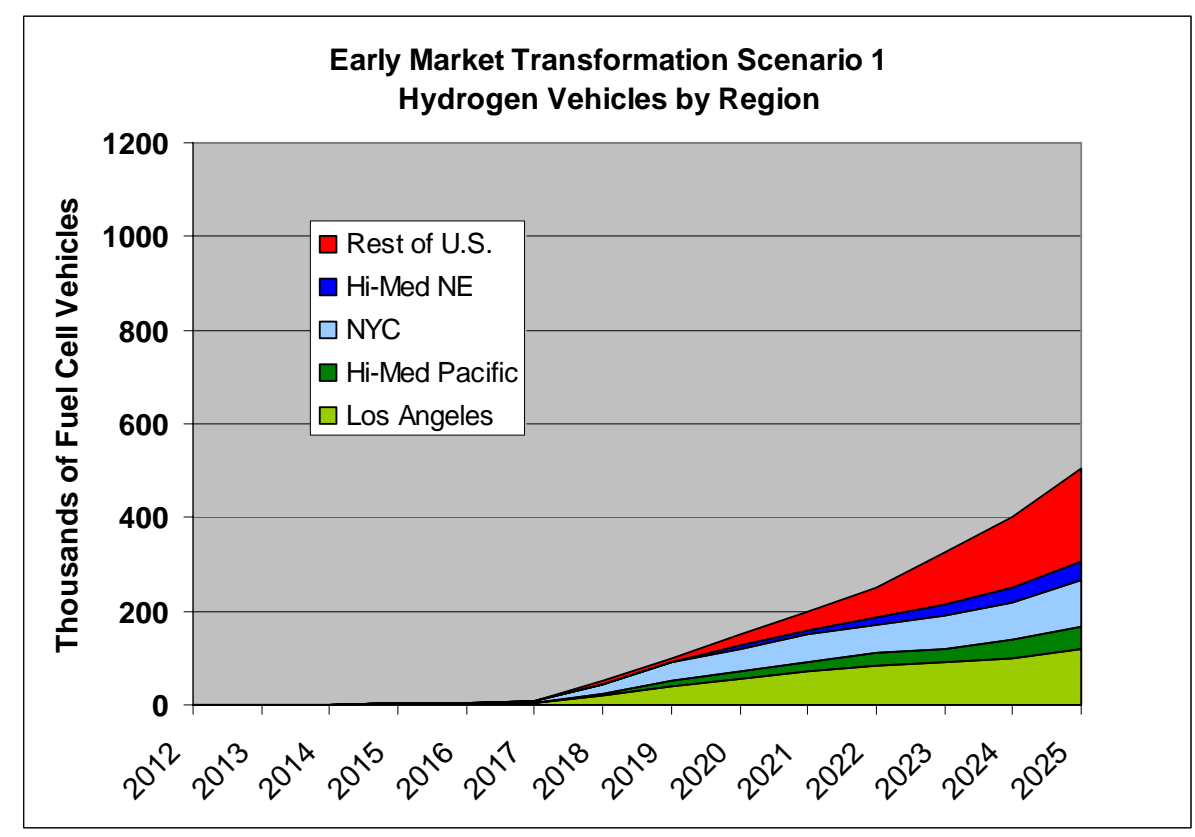

Figure 3. Number of Hydrogen Vehicles Sold Per Year by Region in Scenario 1

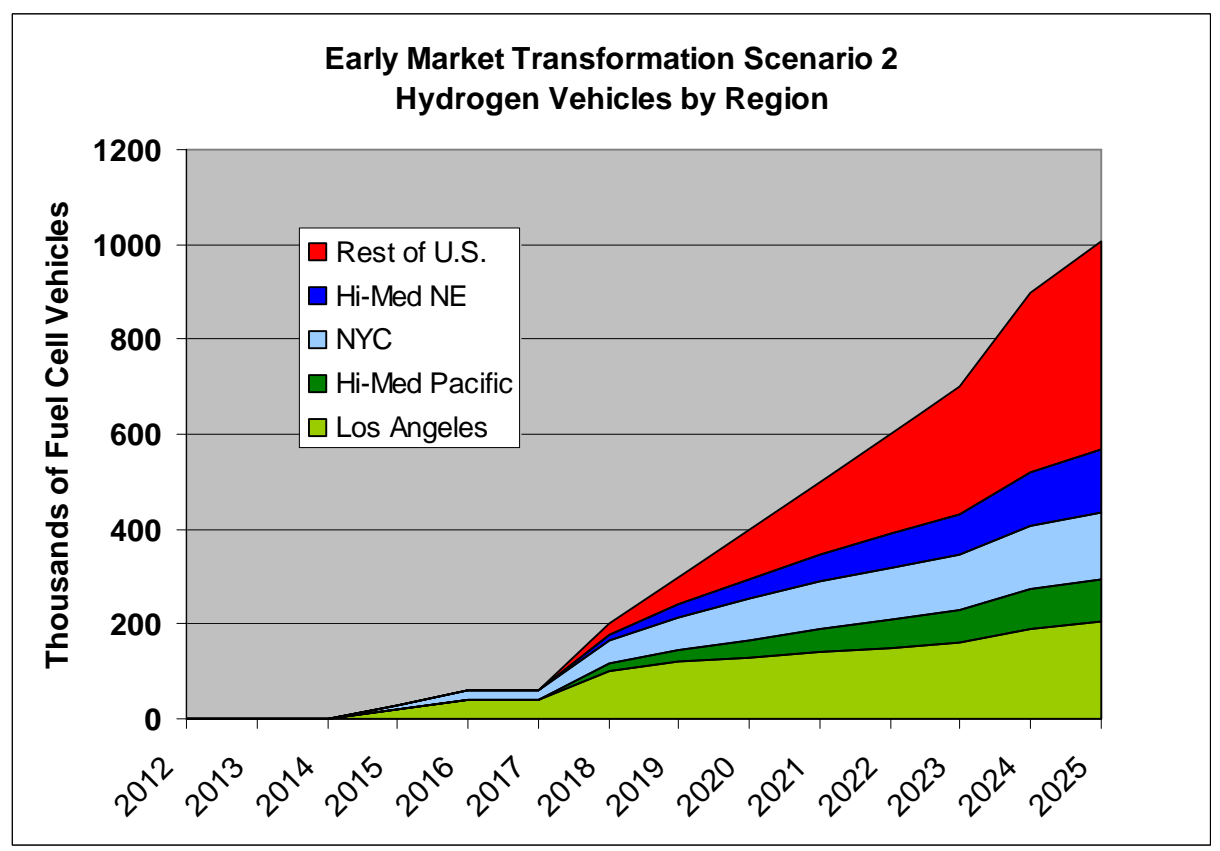

Figure 4. Number of Hydrogen Vehicles Sold Per Year by Region in Scenario 2 


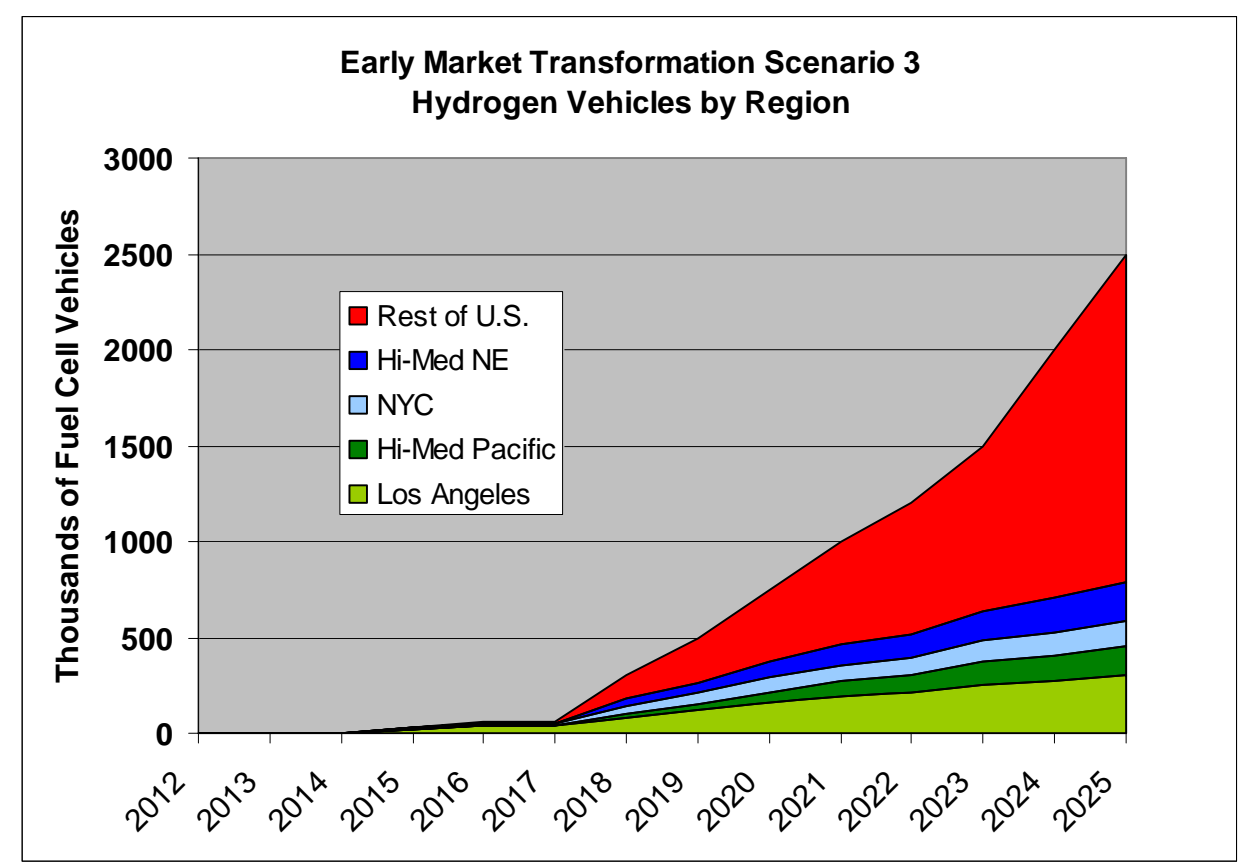

Figure 5. Number of Hydrogen Vehicles Sold Per Year by Region in Scenario 3

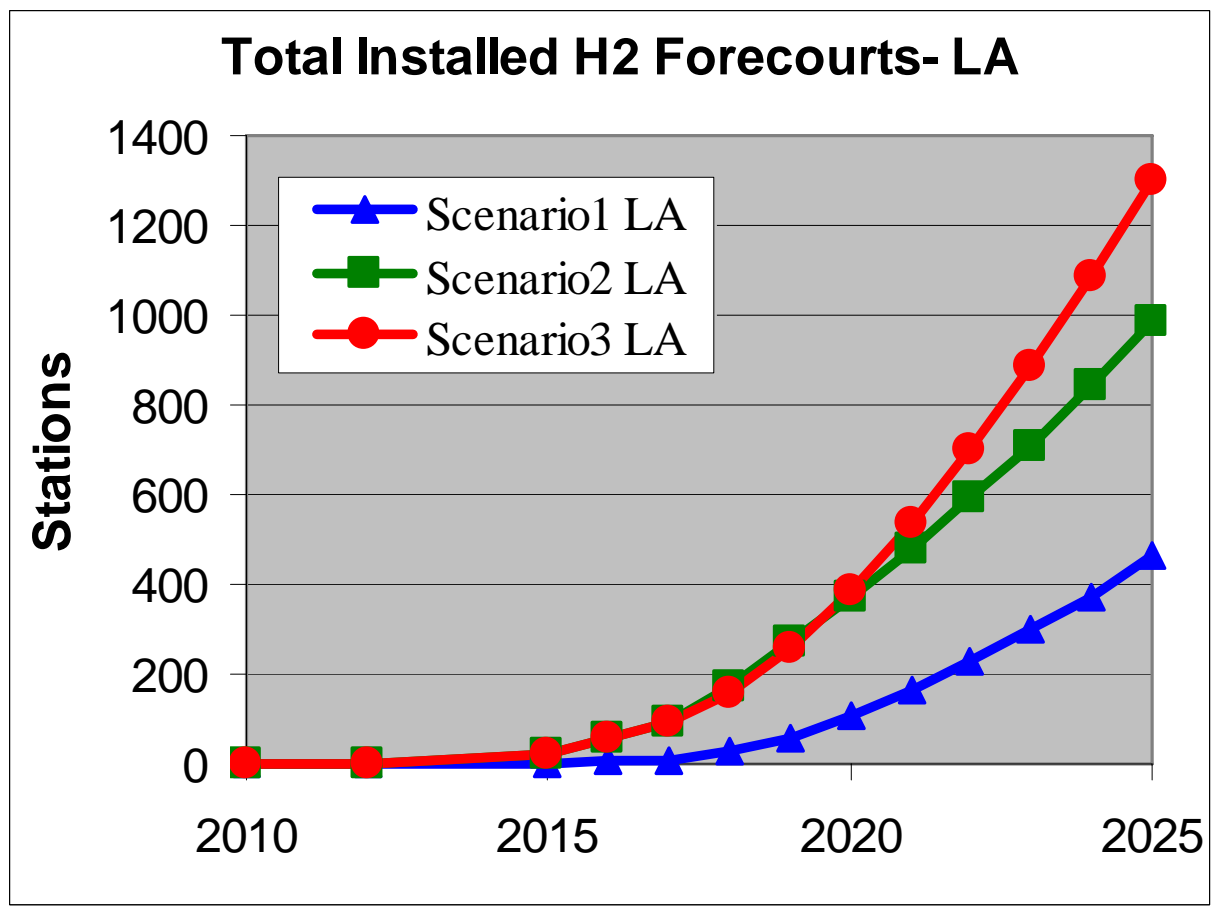

Figure 6. Total Hydrogen Refueling Stations by Year: Los Angeles 


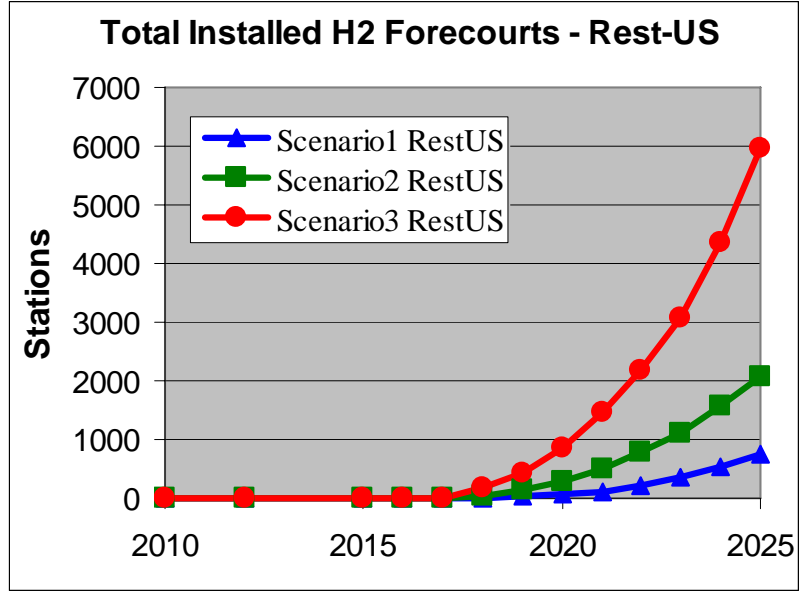

Figure 7. Total Hydrogen Refueling Stations by Year: Rest of U.S.

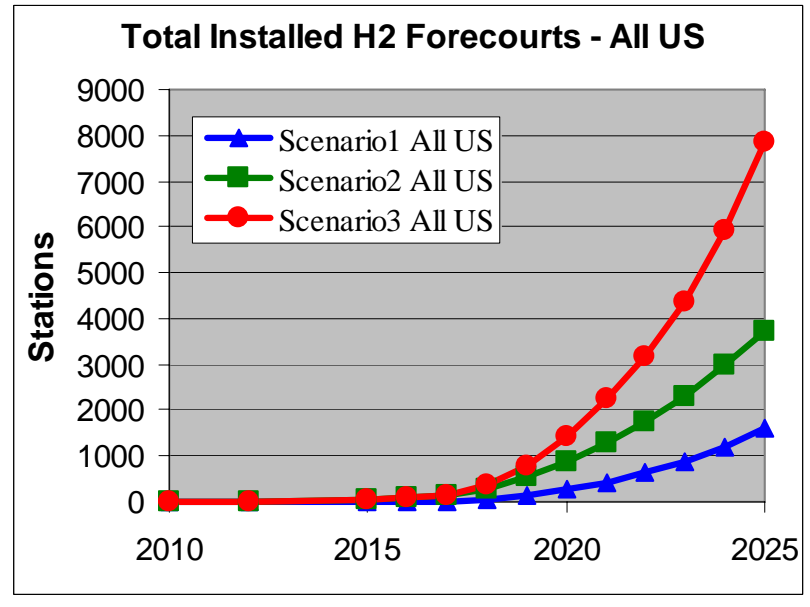

Figure 8. Total Hydrogen Refueling Stations by Year: All of U.S.

The DOE's vehicle technology goals are reflected in the cost and fuel economy performance of hydrogen FCVs and a set of other advanced technology vehicles with which they must compete. The cost goals for key fuel cell and hybrid vehicle components, as well as the costs of advanced gasoline and diesel engines are shown in Table 3. Key energy efficiency assumptions are shown in Table 4.

Table 3. DOE FCV Program Goals for 2015 and Lesser Achievements Evaluated by Rousseau et al. (2005)

\begin{tabular}{lcc}
\hline & DOE Goals & Technology Shortfall \\
\hline Fuel Cell System $(\$ / \mathrm{kW})$ & $\$ 30$ & $\$ 60$ \\
On-Board H2 Storage $(\$ / \mathrm{kWh})$ & $\$ 2$ & $\$ 8$ \\
Motor $(\$ / \mathrm{kW})$ & $\$ 4$ & $\$ 4.50$ \\
Batteries $(\$ / \mathrm{kWh})$ & $\$ 20$ & $\$ 25$ \\
Gasoline ICE Engine Only $(\$ / \mathrm{kW})$ & $\$ 21$ & $\$ 22$ \\
Diesel ICE Engine Only $(\$ / \mathrm{kW})$ & $\$ 21$ & $\$ 24$ \\
\hline
\end{tabular}

Note: Fuel cell systems include not only an integrated fuel cell stack subsystem, but on-board storage as well. Electric motor and ICE costs shown in this table include respectively the motor or engine only. The corresponding electric propulsion system cost would be $\$ 12 / \mathrm{kW}$ and the full ICE powertrain cost for the DOE goals would be $\$ 30 / \mathrm{kW}$.

Table 4. DOE 2015 Vehicle Technology Goals for Peak Energy Efficiency of Advanced Powertrains

\begin{tabular}{lcc}
\hline Technology & DOE Goals & Technology Shortfall \\
\hline Fuel Cell & $60 \%$ & $57.5 \%$ \\
Gasoline ICE & $38 \%$ & $36.5 \%$ \\
Diesel ICE & $45 \%$ & $42.5 \%$ \\
\hline
\end{tabular}


The DOE program goals were used by researchers at Argonne and Oak Ridge National Laboratories to define the performance and costs of advanced vehicle technologies (Rousseau et al., 2005) using the Powertrain Systems Analysis Toolkit (PSAT) and Automotive System Cost Model (ASCM). Their technology characterizations are used in HyTrans to represent the achievement of DOE program goals for an average light-duty vehicle (passenger cars and light trucks) under the technology assumptions termed "Success." Rousseau et al. also defined a case based on a slower rate of technological progress and an "average" of the Success and "slower" cases. We use the average as our technology "Shortfall" case. The fuel economy numbers calculated by Rousseau et al. are shown in Figure 9. ${ }^{2}$

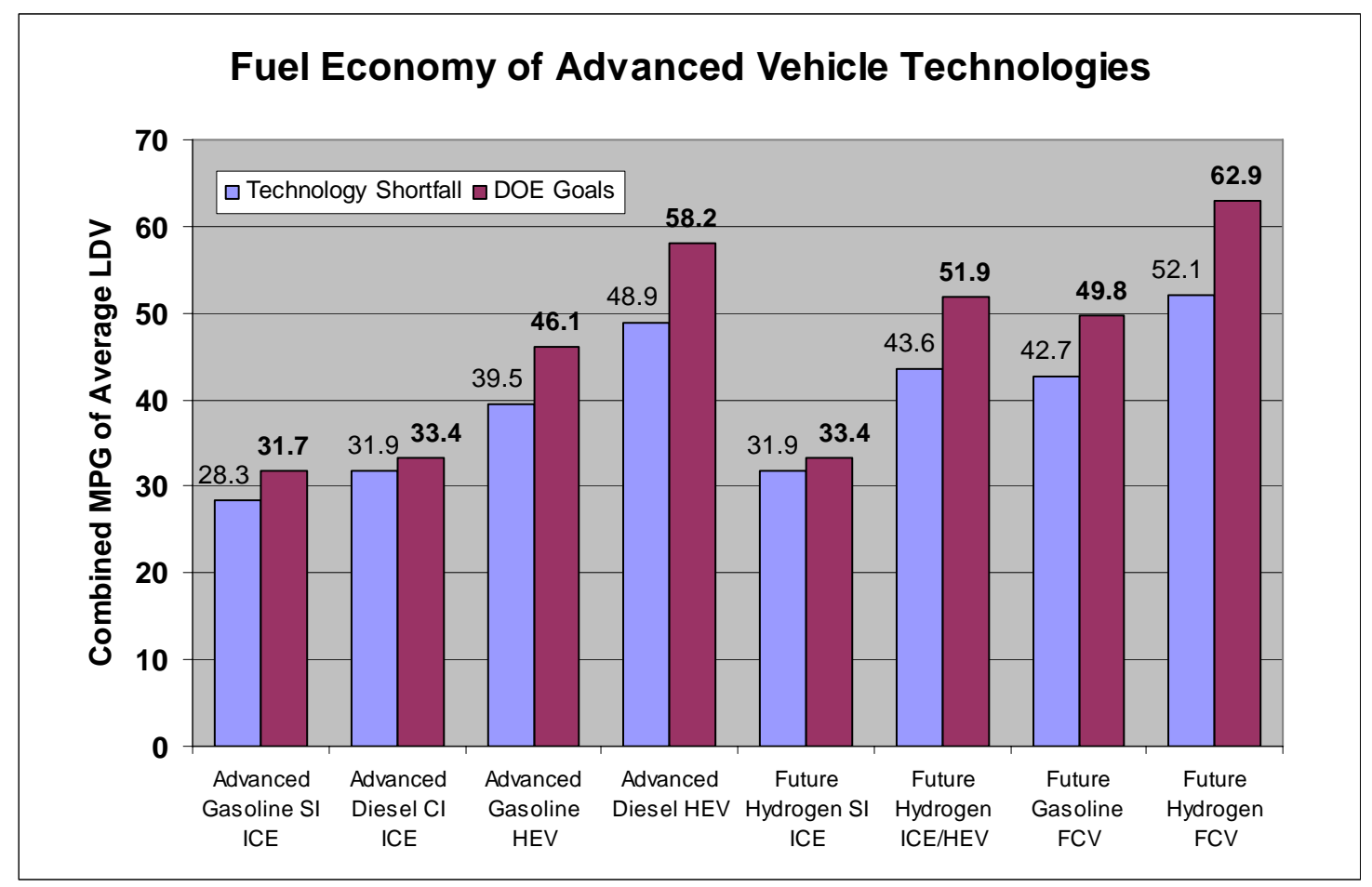

Figure 9. Fuel Economy Estimates for Advanced Technologies by Rousseau et al. (2005)

${ }^{2}$ A third "Mixed Success" set of assumptions was defined in which the FCVs meet the DOE program goals but all other technologies shown in Figure 9 achieve the "shortfall" targets. Sensitivity analysis determined that there was almost no difference between the Success and Mixed Success assumptions, chiefly because the shortfalls for non-hydrogen technologies are not large (Table 3 and 4). Accordingly, the subsequent analysis discusses only the technology "Success" and "Shortfall" cases. 


\section{FUEL CELL VEHICLE COSTS}

Today, FCVs are not ready to compete in the marketplace with conventional gasoline internal combustion engine vehicles or gasoline-electric hybrid vehicles. Both cost reductions and performance improvements are needed. DOE's program goals for hydrogen vehicles represent the combined judgment of experts from industry, government and academia with respect to the cost and performance targets that will be required for market success and that might be achievable in the near future (U.S. DOE/EERE, 2006). Vehicle technologies also improve by learning-by-doing and, in addition, their costs are sensitive to the scale of production. DOE program goals refer to commercial vehicle technology costs after successful $R \& D$ and given production at large scale by a mature industry.

In HyTrans, the total cost of an average light-duty vehicle is the sum of drive train and glider costs. Glider costs are the same for all technology types and are assumed to be a constant $\$ 20,000$ over time. ${ }^{3}$ The cost of the advanced vehicle drive train for each technology is the product of a long-run potential cost based on achieving DOE's program goals and three factors representing: (1) time-dependent technological change, (2) economies of scale, and (3) learningby doing.

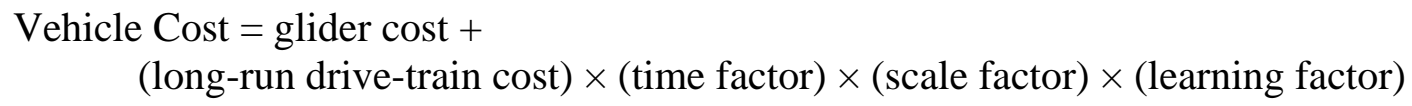

The time-dependent technological change factor represents progress "in the lab" toward achieving the program goals. Advances in the lab are available for implementation in production vehicles five years later, representing a time lag between laboratory discovery and implementation in a mass produced product. The technological progress factor decreases exponentially to a value of 1 five years after DOE's goals are assumed to be met in the lab and thereafter declines asymptotically to 0.98. For most advanced and hybrid vehicle technologies, DOE laboratory goals are set for 2010. For hydrogen fuel cell vehicles, DOE has set additional technology goals for 2015. These call for a reduction in the cost of the hydrogen fuel cell power train (including on-board hydrogen storage) to $\$ 30 / \mathrm{kW}$ by 2015 from $\$ 45 / \mathrm{kW}$ in 2010 . The 2015 goals reduce the cost of a $70 \mathrm{~kW}$ fuel cell vehicle drive train by $\$ 1,050$ versus the 2010 goal. Again, the FCV goals are assumed to be met in the laboratory by 2015 and to be available for use in production vehicles by 2020.

Functions representing learning-by-doing and scale economies were calibrated with the assistance of six major original equipment manufacturers. Once vehicle technologies fully achieve technological advances, scale economies and learning by doing, all three of those multiplicative cost factors decline to 1.0 and the DOE program goals are realized in production vehicles. Three manufacturers, GM, Ford and DaimlerChrysler provided proprietary estimates of the costs of FCVs at specific future dates and production volumes. A set of central tendency estimates were then developed by judgment. The central tendency estimates do not match any

${ }^{3}$ A strong argument can be made that the hydrogen fuel cell power train will permit a radical redesign not only of the power train but also of the automobile's glider, permitting not only greater flexibility in design but lower costs through greater economies of scale ( e.g., http://money.cnn.com/2002/01/08/autos/auto tech/ ). By assuming equal glider costs, we believe we are probably overestimating the cost of the fuel cell vehicle, conditional on the other technology and cost assumptions. 
individual manufacturer's estimates, but were reviewed by manufacturers for reasonability. In terms of timing, the central tendency estimates were assumed to be consistent with market transformation Scenario 2, thereby providing estimates of cumulative FCV production at each point in time. It was additionally assumed that by 2025 in Scenario 2 full learning would be achieved. For each vehicle technology type, learning-by-doing was modeled by an asymptotic exponential function of extant vehicle stock, while scale economies were represented by a constant elasticity function of current-year production volume per vehicle platform. These functions were fitted to the central tendency estimates by non-linear least squares. The estimated scale elasticity was -0.25 , assuming a reference for full scale economies of 250,000 units for a vehicle platform. The resulting cost surface over production volume and the stock of FCVs is illustrated in Figure 10.

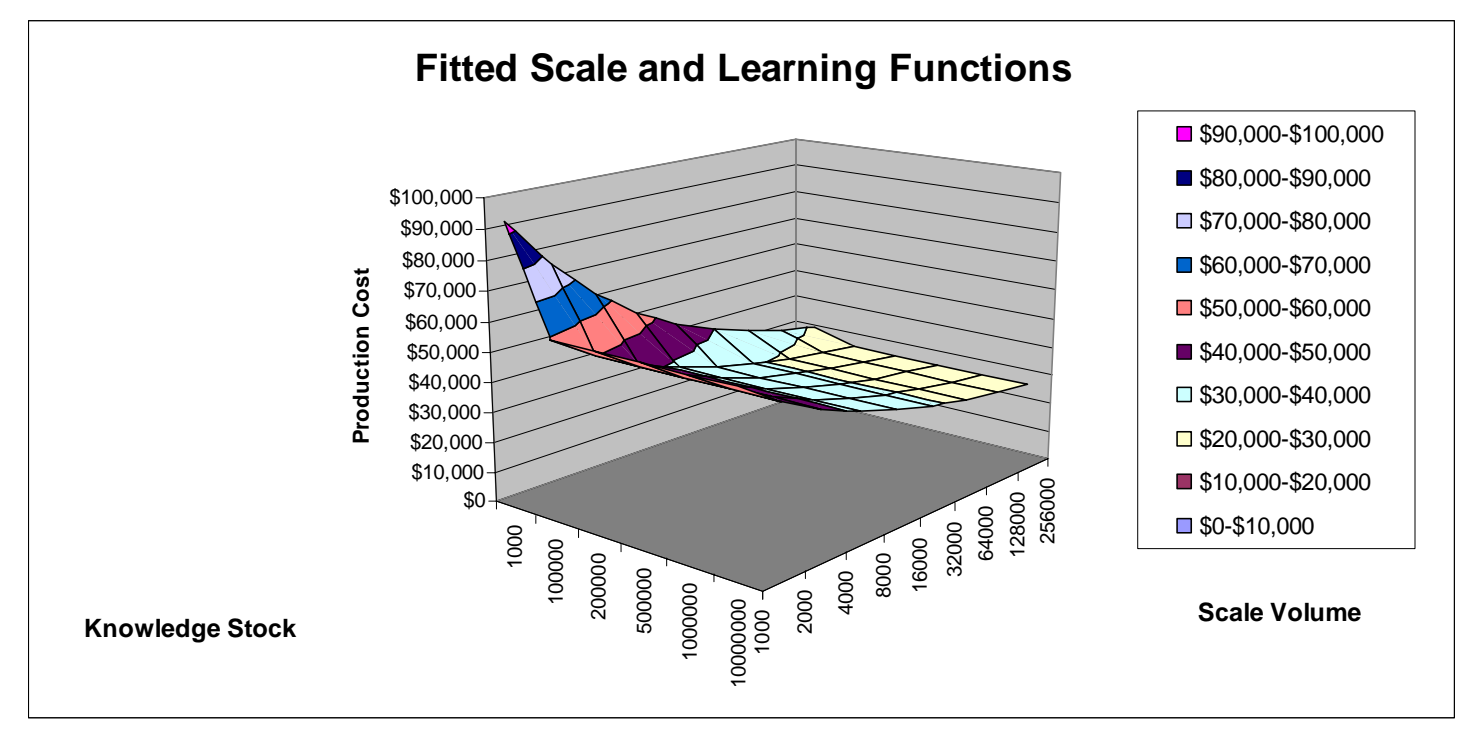

Figure 10. Scale and Learning as a Function of the Stock of Vehicles and Production Volume

The costs of FCVs in each of the three transformation scenarios are shown in Figure 11, along with the central tendency cost estimate. Initial FCV costs are very high, on the order of $\$ 350,000$ per vehicle in 2012. The cost of a FCV during the transition period is much higher in Scenario 1 than in Scenarios 2 and 3 due to the lower production volumes and smaller vehicle stocks. 


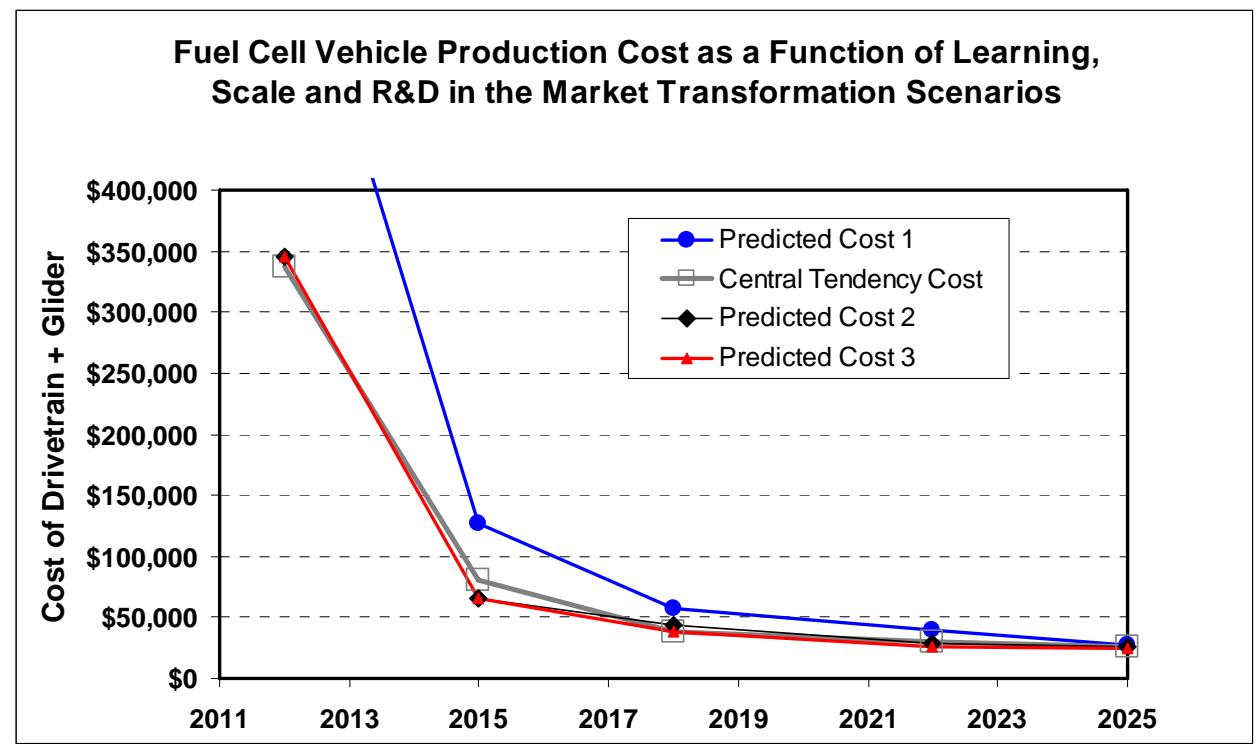

Figure 11. Fuel Cell Vehicle Cost in Scenarios 1, 2, and 3, Compared with a Central Tendency of OEM Estimates

The scale in Figure 11 obscures very important differences among the three scenarios in later years. As the close-up view in Figure 12 shows, in Scenario 2 FCVs cost \$4,000 more in 2022 than they do in Scenario 3. In Scenario 1 they are almost $\$ 15,000$ more costly to manufacture. These differences have important implications for the costs of the three scenarios and especially for the cash flows of vehicle manufacturers, as will be seen below.

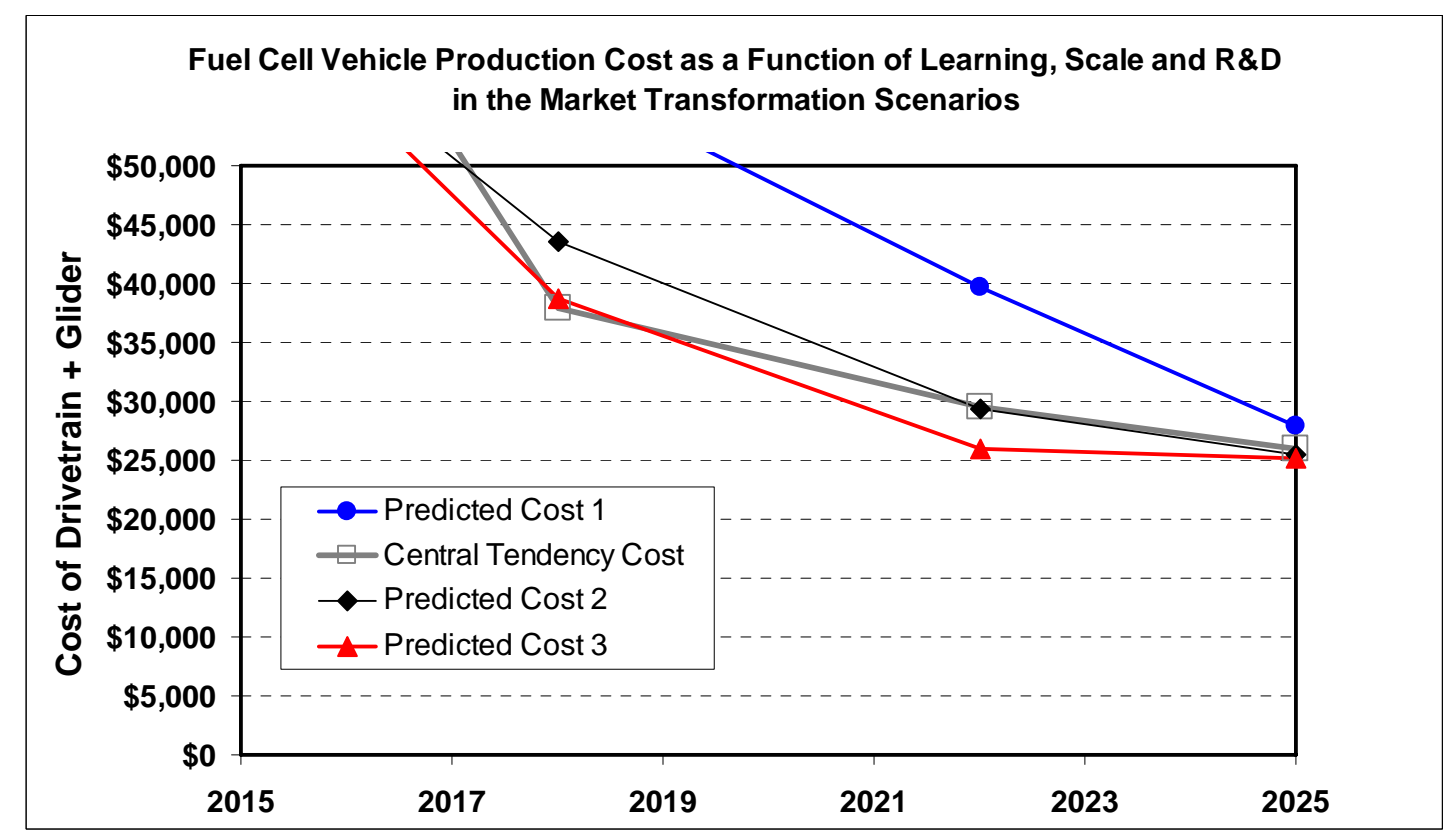

Figure 12. Close-up View of Fuel Cell Vehicle Production Costs in Three Scenarios

In addition to lower vehicle platform costs, the greater numbers of vehicles sold in Scenarios 2 and 3 also induce manufacturers to offer a more diverse choice of makes and models. HyTrans measures scale economies by vehicle platform rather than make and model. In 2005, there are 
assumed to be a total of 60 different vehicle platforms in production. Sixty platforms at 250,000 per platform, the volume at which full scale economies are assumed to be reached in the HyTrans vehicle production model, corresponds to total sales of 15,000,000 units per year, approximately the total volume of light-duty vehicle sales in the United States. Considering unique nameplates (e.g., Camry, Impala, Fusion, Accord, etc.) rather than body styles or trim variants (e.g., Camry Sedan, Camry Solara, Camry Solara Convertible), there are about 275 makes and models available. Of these, about 25 are rare brands such as Ferrari, Bentley and Maybach. Deleting these rare brands implies approximately four nameplates per platform, on average. Given these assumptions, the numbers of nameplates available for car buyers to choose from for each scenario are shown in Figure 13. The greater diversity of FCV makes-and-models in the larger scenarios (2 and 3 ) provides value to consumers, further reducing the effective cost of the new FCV technology. It is possible that fuel cell systems will be able to achieve scale economies across vehicle platforms and therefore benefit from even greater scale economies than assumed here.

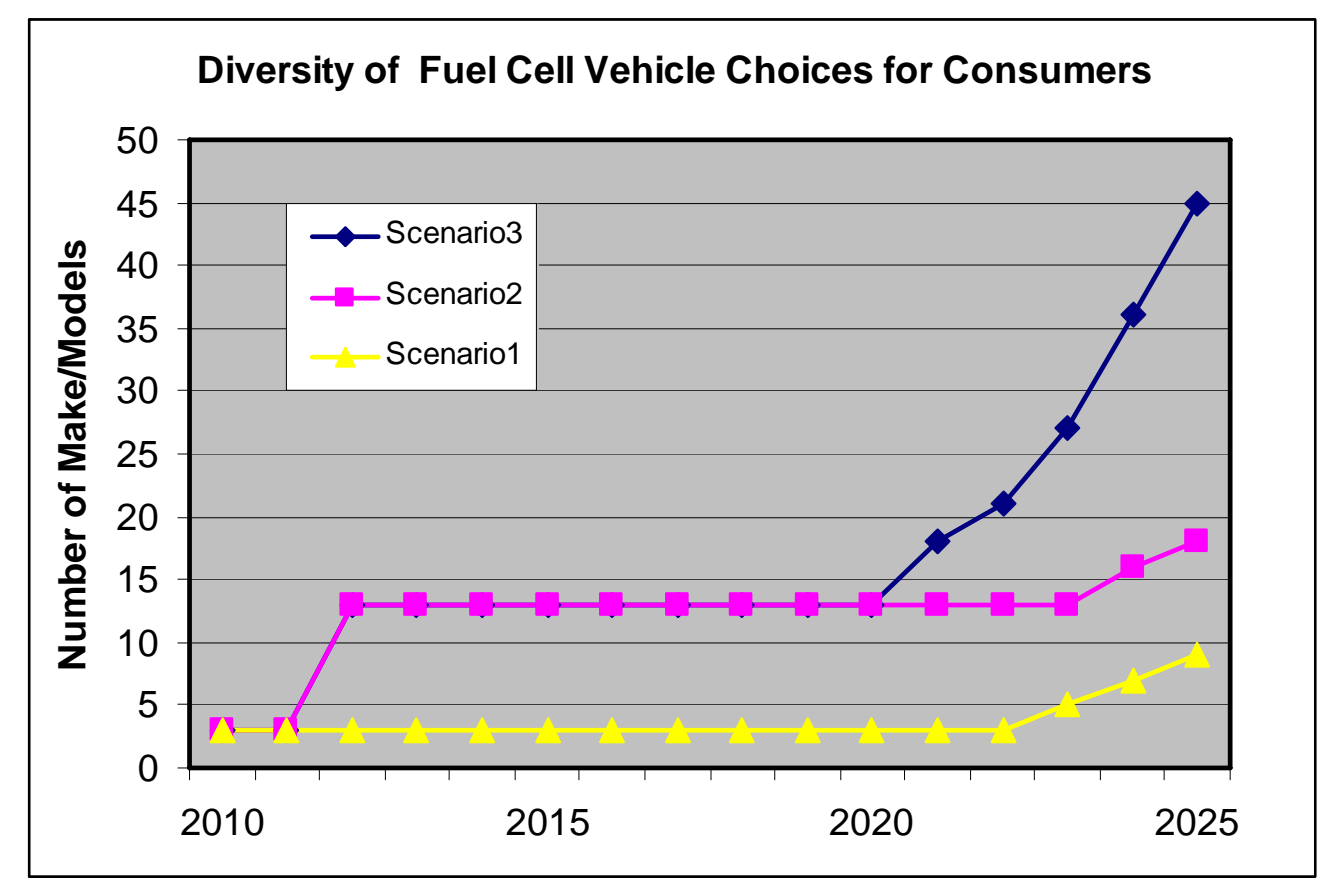

Figure 13. Diversity of Fuel Cell Vehicle Choice (\# of Nameplates) by Scenario 


\section{HYDROGEN PRODUCTION PATHWAYS}

Hydrogen production pathways are comprised of a production process, a delivery mode and a forecourt type (Table 5). Production processes may be central, or distributed (i.e., hydrogen produced at the forecourt). Carbon emissions may be sequestered or not. Central hydrogen production can be delivered to forecourts in gaseous form by tube trailer trucks or by pipelines. Liquid hydrogen is delivered by cryogenic trucks. There are two types of forecourts, those that store hydrogen as a compressed gas and those that store it in liquid form. There are two types of distributed production at forecourts: steam methane reforming (SMR) and electrolysis.

HyTrans uses the H2A models for both production and delivery. In general, the H2A production models provide three technology generations: 2005, 2015 and 2030. Two generations of delivery technology are described in the H2A delivery models: Current and "future." In HyTrans, the future technology, including advanced compressed gas, becomes available by 2010. Advanced compressed gas truck delivery is far more economical than current compressed gas delivery. This mode turns out to be important for serving lower fuel demand density areas. All delivery modes play important roles in different environments at different times, depending on the volume and spatial density of demand.

The pathways shown in Table 5 are not intended to be an exhaustive list of all possible hydrogen production pathways. It should not be inferred that in the future hydrogen will be produced by only or by all of these pathways. Rather, these pathways are representative of economical and potentially clean processes for hydrogen production. There are more potential hydrogen production pathways than HyTrans can practically manage. Any central production process in Table 5 can be matched with any delivery mode and forecourt type. Thus, there are 42 potential production pathways plus two onsite production technologies. A complete list of possible production and delivery options for hydrogen would be far longer. To keep manageable HyTrans' solution time, the limited set of pathways in Table 5 is used in the scenario analyses presented in this chapter. Previous model runs have demonstrated that these pathways can deliver hydrogen at low cost and with minimal carbon emissions, if required by carbon mitigation policies.

Distributed SMR is the only production pathway for which learning-by-doing is currently implemented in HyTrans. ${ }^{4}$ All distributed SMR facilities are assumed to have a nominal capacity of $1,500 \mathrm{~kg} / \mathrm{d}$ and a utilization rate of $70 \%$. Cost begins at the H2A "today's technology" level in 2005 and declines with installed capacity, reaching the H2A 2030 level in 2025 in Scenario 3.

HyTrans relies heavily on the H2A model for production costs and the HDSAM delivery portion of H2A system for delivery costs. In the HyTrans cases described here, the forecourt size and scale of distributed production was taken as $1500 \mathrm{~kg} /$ day. A useful comparison is DTI's (2007) HyPro analysis which focuses on the development of hydrogen production and delivery

${ }^{4}$ While learning-by-doing may play a role for other pathway technologies, distributed SMR is a particularly promising candidate, due to the anticipated off-site manufacture of large numbers of SMR units. It is also the only technology for which H2A guidance on anticipated learning rates was readily available (see "Forecourt-Specific Assumptions and Ground Rules for H2A Analyses," October 2005, p. 10, available at www.hydrogen.energy.gov/pdfs/h2a_forecourt_assumptions.pdf). 
infrastructure. DTI's HyPro analysis considers $1500 \mathrm{~kg} /$ day forecourts as well as a $100 \mathrm{~kg} /$ day size at much higher costs. In HyTrans and the DTI analysis the dominant pathway for production in the early years, after the utilization of excess $\mathrm{H} 2$ production capacity from existing refineries or merchants, is endogenously chosen to be distributed SMR. DTI's HyPro and HyTrans agree closely on the cost of that process in DTI's pessimistic case. DTI's optimistic case for distributed SMR has a cost well below that used by these HyTrans runs. The two models also agree on the posited scale of centralized production by type, and produce close estimates of production costs in 2030 for most methods. The low cost central production methods are coal gasification and SMR, with costs ranging from $\$ 1 / \mathrm{kg}$ to $\$ 1.5 / \mathrm{kg}$. One distinction is that while coal gasification is the lowest cost $\mathrm{H} 2$ production method for both HyTrans and HyPro, DTI's costs are even lower (about \$1.05/kg versus \$1.15). Also, the costs of production by biomass are higher in HyPro. Comparing delivery costs in the two approaches must be done with care, because they depend on demand density (distance) and delivered volume. These factors vary endogenously by region and time in HyTrans. The studies agree that pipeline delivery is the lowest cost option for high fuel demand regions in 2030 and beyond, although the cost estimates used by HyTrans are somewhat higher $(\$ 1.10 / \mathrm{kg}$ delivery cost in LA in 2030 , versus $\sim 0.75 / \mathrm{kg}$ in HyPro). While liquid delivery is a higher cost option than pipeline once a dense market has developed, in HyTrans it proves a cost-effective delivery mode over the long distances in lower volume dispersed markets of ex-urban and rural United States.

Table 5. Hydrogen Production Pathways in HyTrans

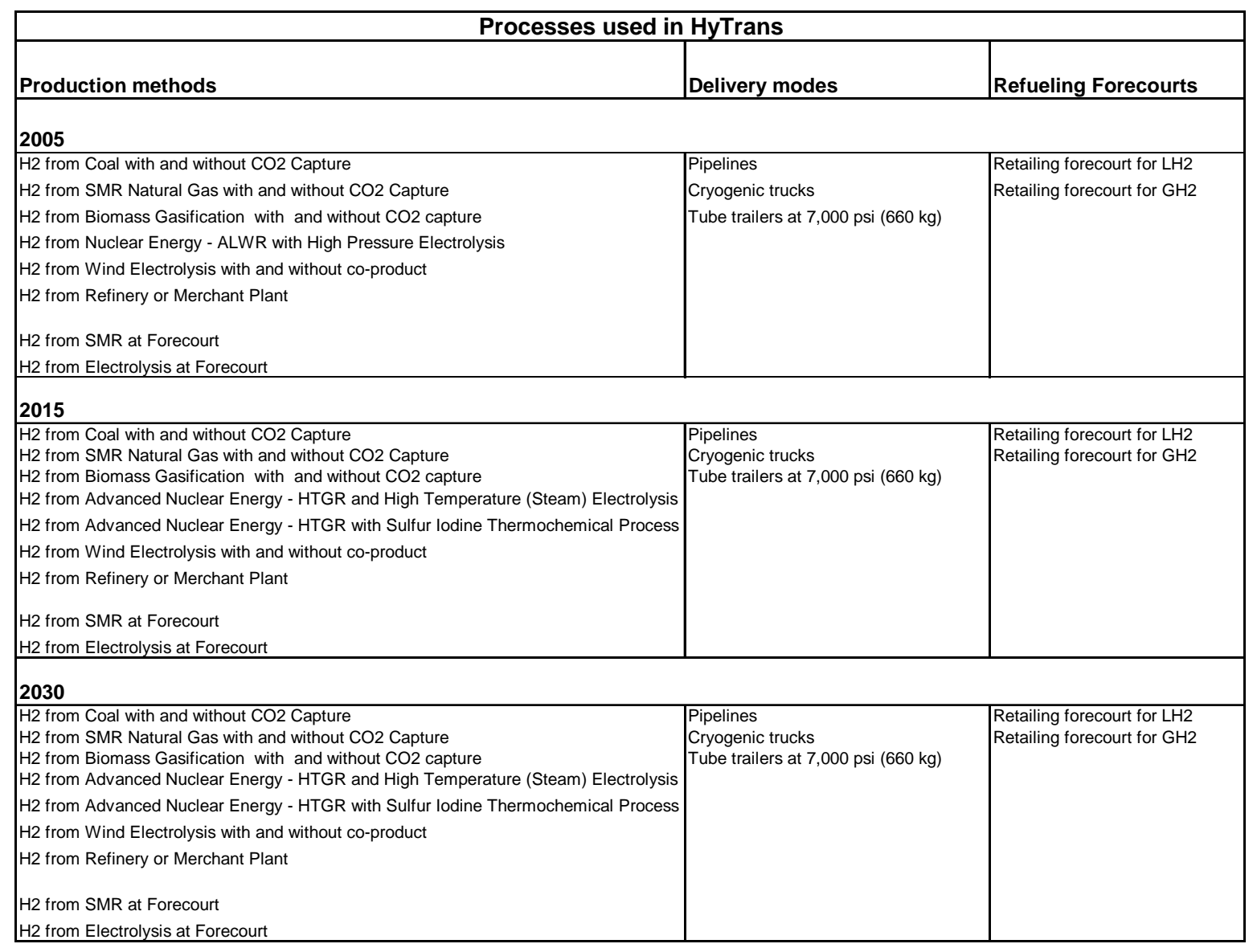




\section{ALTERNATIVE FUTURES AND POLICY CASES}

The HyTrans model was calibrated to either the 2006 Annual Energy Outlook's (U.S. DOE/EIA, 2006) Reference Case or the High World Oil Price Case vehicle sales, vehicle use, energy use and (non-hydrogen) energy prices. In most cases, the Energy Information Administration's (EIA's) High Oil Price Projection is assumed to be the energy market environment in which the market transformations take place. The High Oil Price Projection is consistent with the depletion of limited conventional oil resources and continued OPEC reluctance to dramatically expand production. In general, the alternative futures evaluated assume technological progress in both hydrogen and conventional vehicle technologies consistent with the achievement of the DOE's program goals. However, alternative cases consider what impacts lower oil prices and slower rates of technological progress might have on the transformation scenarios and the sustainability of the transition to hydrogen. In addition, the role of carbon emissions policy on the choice of hydrogen pathways and the resulting emissions of carbon dioxide is also examined. None of the futures considered include any policy initiatives to promote FCVs and hydrogen after 2025.

Combining assumptions about technology success, oil prices, carbon and biomass policies with the three early transition scenarios, we have defined the 13 alternative futures shown in Table 6. The first eight futures explore the importance of early transition policies without and with carbon constraining policy. They combine the technology success assumptions (full achievement of technology goals for all advanced technologies, and high world oil prices) with the three early penetration scenarios plus a "No Policy" scenario. The "No Policy" scenario places no constraints on FCV production or hydrogen sales. Market agents, however, are assumed to have complete foresight and so are fully aware of the eventual technological success of hydrogen fuel cell technology. The question is whether the future private-sector rewards will justify the cost of overcoming the barriers to transition.

Table 6. Early Transition Futures: Scenarios Plus Policy Cases

\begin{tabular}{|c|c|c|c|c|c|c|c|}
\hline Future & $\begin{array}{l}\text { Vehicle Tech } \\
\text { Success } \\
\text { Assumptions }\end{array}$ & $\begin{array}{l}\text { AEO } 2006 \\
\text { Oil Price } \\
\text { Case }\end{array}$ & $\begin{array}{c}\mathrm{CO} 2 \\
\text { Constraints } \\
\text { Equal to a } \\
\text { Carbon Tax }\end{array}$ & $\begin{array}{l}\text { BioFuels } \\
\text { Program }\end{array}$ & $\begin{array}{c}\text { Fuel Cell } \\
\text { Vehicle and } \\
\text { Hydrogen } \\
\text { Station Early } \\
\text { Transition } \\
\text { Scenario }\end{array}$ & $\begin{array}{c}\text { Early } \\
\text { Transition } \\
\text { (2012-2025) } \\
\text { Policy Cases }\end{array}$ & $\begin{array}{c}\text { Post-2025 } \\
\text { Policies to } \\
\text { Promote } \\
\text { Hydrogen and } \\
\text { Fuel Cell } \\
\text { Vehicles }\end{array}$ \\
\hline 1. & $\begin{array}{l}\text { Technology } \\
\text { Success }\end{array}$ & High & No & No & 0 & All 3 cases & None \\
\hline 2. & Success & High & No & No & 1 & All 3 cases & None \\
\hline 3. & Success & High & No & No & 2 & All 3 cases & None \\
\hline 4. & Success & High & No & No & 3 & All 3 cases & None \\
\hline 5. & Success & High & Yes & No & 0 & All 3 cases & None \\
\hline 6. & Success & High & Yes & No & 1 & All 3 cases & None \\
\hline 7. & Success & High & Yes & No & 2 & All 3 cases & None \\
\hline 8. & Success & High & Yes & No & 3 & All 3 cases & None \\
\hline 9. & $\begin{array}{l}\text { Technology } \\
\text { Shortfall }\end{array}$ & High & Yes & No & 3 & Case 2 & None \\
\hline 10. & Success & Reference & Yes & No & 3 & Case 2 & None \\
\hline 11. & Success & High & Yes & Yes & 3 & Case 2 & None \\
\hline 12. & $\begin{array}{l}\text { Success but } \\
\$ 10 / \text { kwh storage }\end{array}$ & High & Yes & No & 3 & Cases 2 and 3 & None \\
\hline
\end{tabular}


Futures \#1 through \#4 assume no constraints on $\mathrm{CO}_{2}$ emissions. The same futures are repeated in \#5 - \#8 but with greenhouse gas policy equivalent to a $\mathrm{CO}_{2}$ tax beginning at $\$ 10$ in 2010 and increasing linearly to $\$ 25$ per ton in 2025. As it turns out, the carbon constraint policies have little impact on the market success of FCV technology but are essential to insuring that the transformation to hydrogen significantly reduces well-to-wheel greenhouse gas emissions. ${ }^{5}$

Futures \#9 and \#12 test the importance of achieving the DOE technology goals for FCVs and other advanced power-train technologies. In Future \#9, all technologies are assumed to meet the average goals defined by Rousseau et al. (2005) rather than the high DOE 2010/2015 goals. As Table 3 shows, this puts the FCV at a greater disadvantage than the other technologies. Future \#12 considers the possibility that DOE goals for on-board hydrogen storage may not be met $(\$ 2 / \mathrm{kWh})$ and that storage may cost as much as $\$ 10 / \mathrm{kWh}$.

Future \#10 tests importance of high oil prices to the hydrogen transition by substituting the Annual Energy Outlook 2006 (U.S. DOE/EIA, 2006b) Reference Case oil price projection for the High World Oil price projection. The price of oil reaches \$90/barrel in 2030 in the High oil price projection but only $\$ 50 /$ barrel in the Reference projection. ${ }^{6}$

Future \#11 considers the impact of expanded use of biofuels on the availability of biomass feedstock for hydrogen production.

${ }^{5} \mathrm{~A} \mathrm{CO}_{2}$ tax which is roughly comparable to the cost of decarbonization/sequestration of hydrogen production does not substantially alter the market incentives for or against hydrogen, since both hydrogen and gasoline essentially would bear the full burden of the tax. A larger $\mathrm{CO}_{2} \operatorname{tax}$ (e.g. $\$ 50 / \mathrm{MT} \mathrm{CO}_{2}$ ) would tilt the market toward hydrogen, increasing gasoline cost by the full tax ( $\sim 0.50 /$ gallon), but increasing the hydrogen cost by only the smaller cost of decarbonization.

${ }^{6}$ Note that in these two oil price projections the 2030 delivered gasoline price, excluding tax, is $\$ 2.60$ and $\$ 1.90 /$ gallon respectively (higher is certain regions). 


\section{IMPACTS AND EFFECTIVENESS OF THE THREE EARLY TRANSITION SCENARIOS AND THE LONG-TERM TRANSITION TO HYDROGEN-POWERED VEHICLES}

Without any early transition policies, no transition to hydrogen powered light-duty vehicles occurs, even assuming technology success and high world oil prices (Figure 14a). Adding carbon constraining policy has no perceptible effect on this outcome (Figure 14b). The transition barriers appear to be too large for market forces unaided by significant, direct policy intervention to overcome. Advanced hybrid vehicles, on the other hand, face much smaller barriers to market acceptance. They are already well down their learning curve with more than half a million vehicles on the road by the end of 2005 and a dozen makes and models in the market place in 2007. The advanced hybrids, which are superior to hybrid vehicles available today, need no new refueling infrastructure, deliver $40 \%$ better fuel economy than advanced ICE vehicles and, when they meet DOE goals, cost two hundred dollars less than advanced conventional gasoline vehicles. In little more than a decade, ICE gasoline-electric hybrids come to dominate the automotive market in the no-policy future.

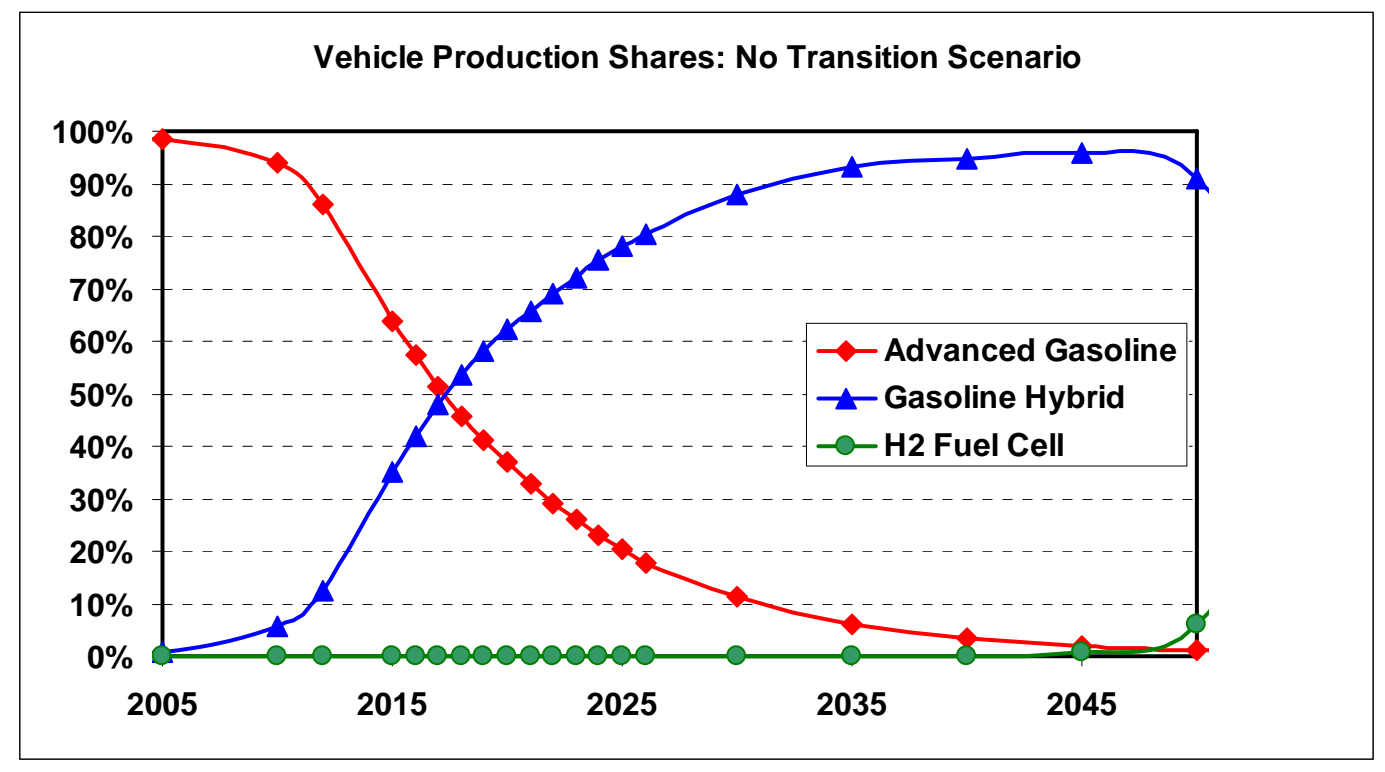

Figure 14a. Vehicle Technology Market Shares: No Transition Policy, No C Policy (Future \#1) 


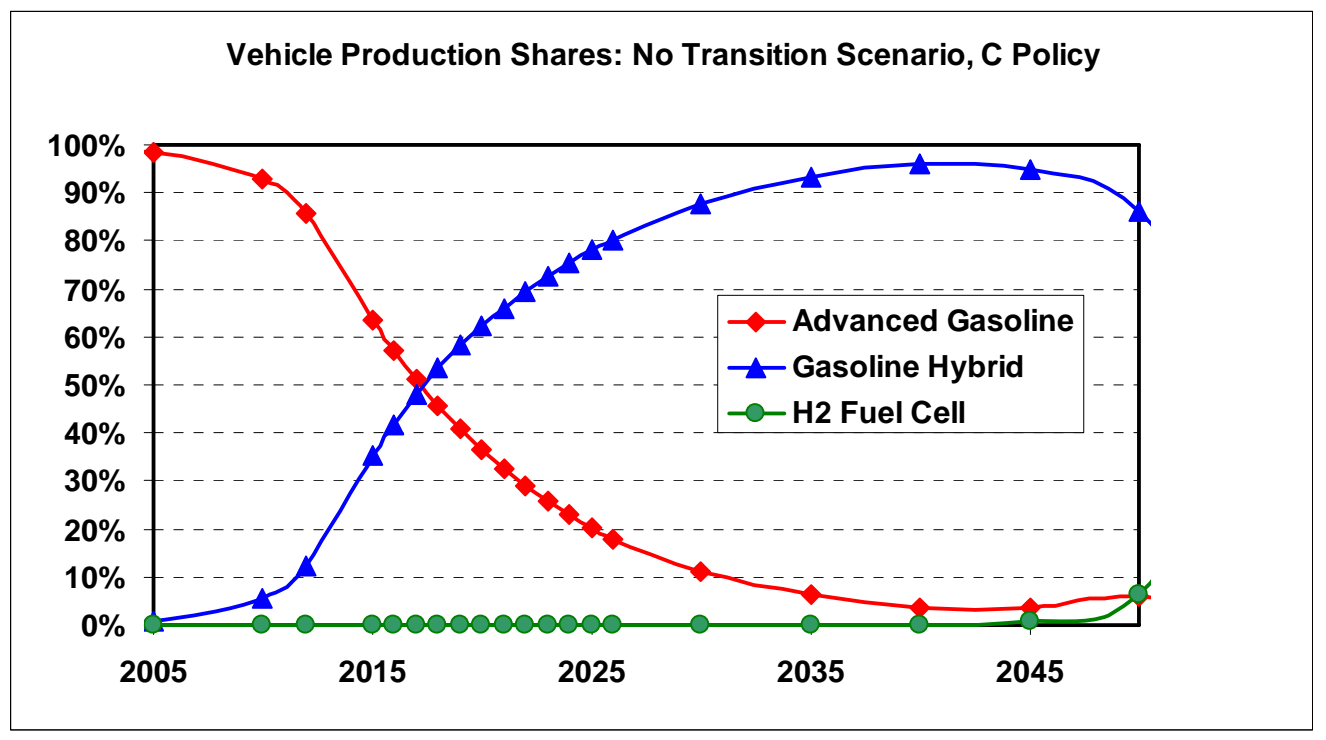

Figure 14b. Vehicle Technology Market Shares:

No Transition Policy, C Policy (Future \#5)

The success of hybrid vehicles has a dramatic impact on light-duty vehicle fuel demand (Figure 15). The rapid market penetration of more fuel efficient hybrid vehicles causes total fuel demand to decrease gradually from just after 2015 until 2040. Even in 2050, light-duty vehicle fuel demand is no greater than it was in 2005. Adding carbon policies equivalent to a carbon price of $\$ 25 / \mathrm{CO}_{2}$ has little effect on light-duty vehicle fuel use in the HyTrans simulations.

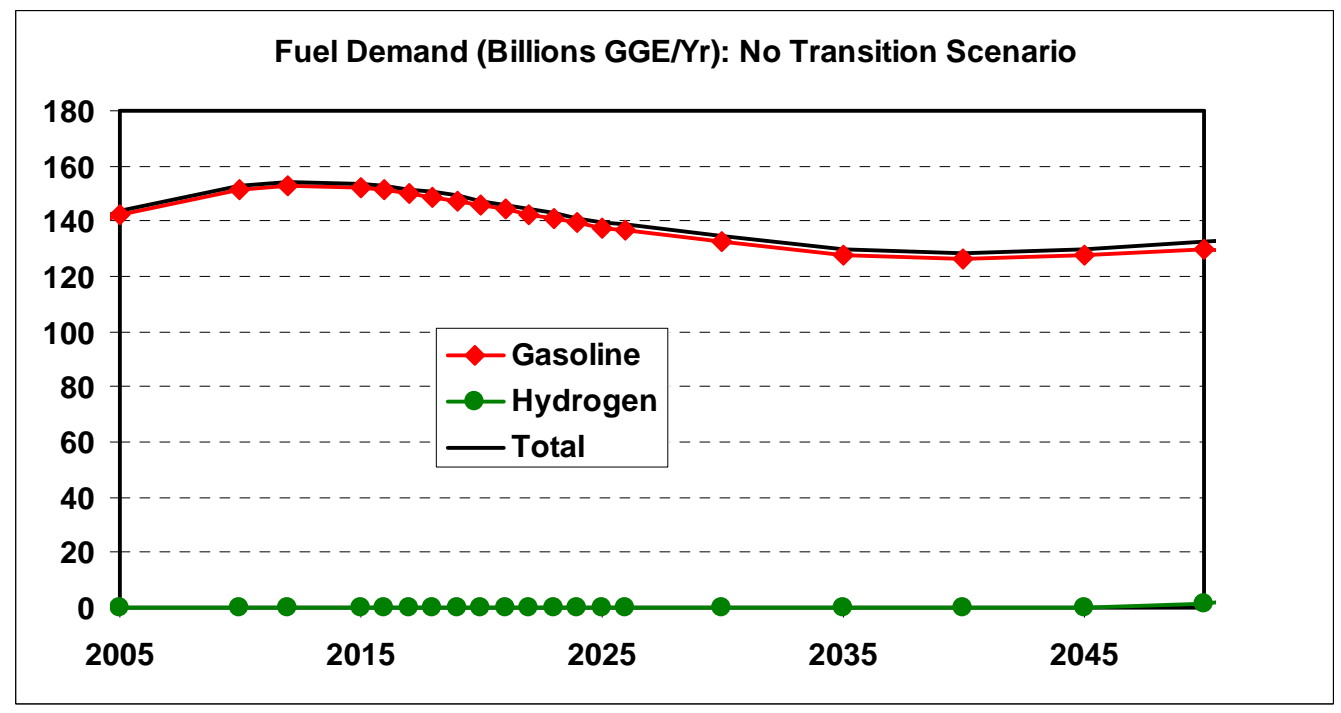

Figure 15. Light-duty Vehicle Fuel Demand in Billions of Gallons of Gasoline Equivalent: Future \#1

The HyTrans market simulations indicate than any one of the three market transformation scenarios is able to accomplish a sustainable transition to hydrogen powered vehicles (Figures 16-18). The more aggressive the scenario, the more quickly and completely hydrogen FCVs come to dominate the light-duty vehicle market. The success of each of the scenarios can be 
explained by the fact that all three scenarios are able to move production costs almost all the way down the learning curve, and to achieve substantial economies of scale (see, Figure 11). On the vehicle side, most of the transition costs have been paid by 2025. From that point in time, private investment in hydrogen vehicles looks like a profitable decision.

The scenarios differ with respect to the extent of hydrogen infrastructure in place and the cost of hydrogen, as well as the diversity of makes and models of FCVs in the market. In Scenario 3, 7,900 hydrogen stations are already in place, about 5\% of total refueling outlets. Only 3,700 outlets are extant in Scenario 2, and only 1,600 in Scenario 1, 1\% of total U.S. refueling stations. Despite the lack of nationwide fuel availability, private decision-makers with foresight know that hydrogen will eventually succeed and are willing to make the remaining upfront investments. This result should be interpreted with caution, however, since real-world agents do not possess accurate foresight and are likely to view investments in hydrogen infrastructure as risky. The degree to which the greater achievements of Scenarios 2 and 3 reduce the risk of further investments could be of great importance and has not been evaluated in this study.

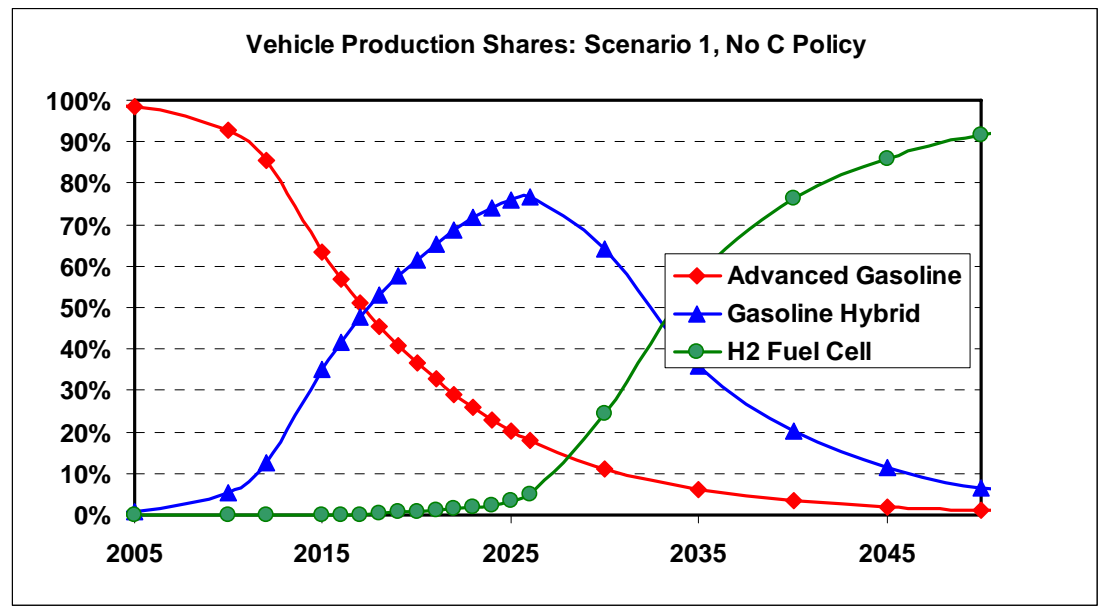

Figure 16. Vehicle Technology Market Shares in Scenario 1 (Future \#2)

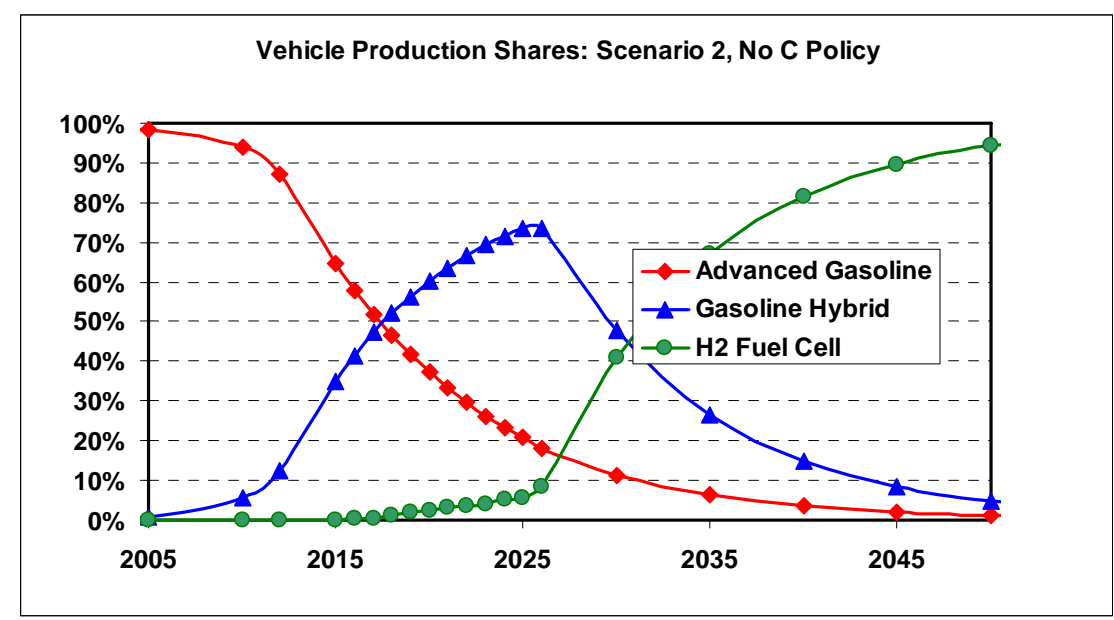

Figure 17. Vehicle Technology Market Shares in Scenario 2: No C Policy (Future \#3) 


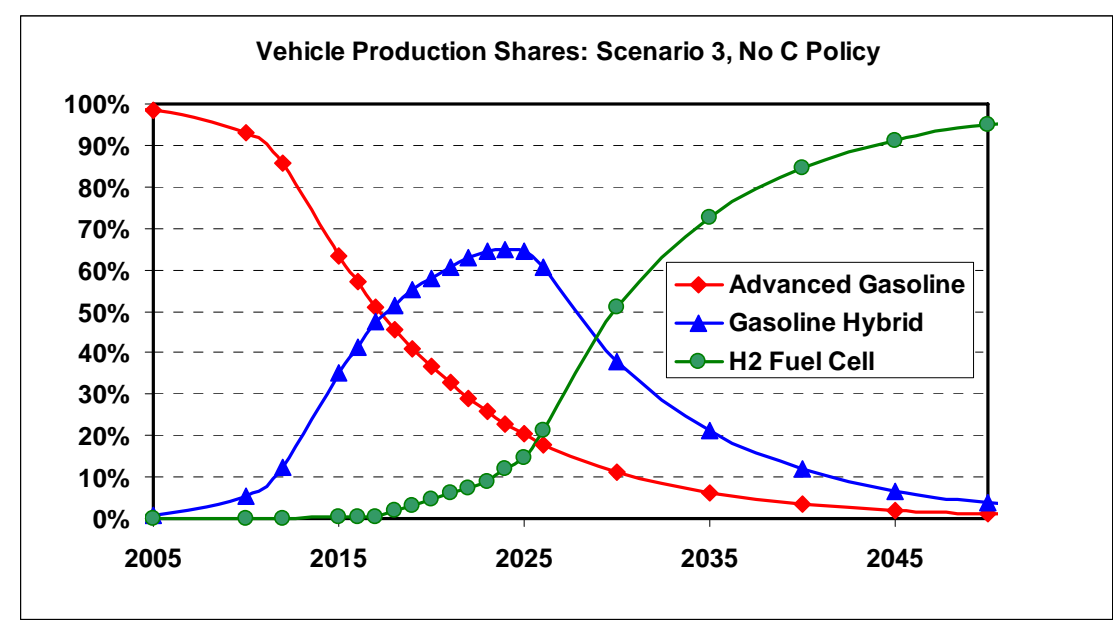

Figure 18. Vehicle Technology Market Shares in Scenario 3: No C Policy (Future \#4)

If all technologies succeed, assuming high oil prices and with or without strong carbon policy, a sustainable transition to hydrogen appears to be achievable in scenarios 1, 2 and 3. But if all technologies achieve only the average goals, the transition does not go to completion by 2050 (Figure 19). After 2025, hydrogen vehicles increase their market share to almost $45 \%$ but then decline slightly and gasoline-powered hybrids rebound slightly. Towards 2050, fuel cell vehicles increase their market share to $50 \%$, possibly as a result of increasing petroleum prices. The two technologies are very competitive, however, so this result should in no way be considered definitive. Rather it indicates the importance of fully achieving the DOE program goals to insuring a full and sustainable market transformation.

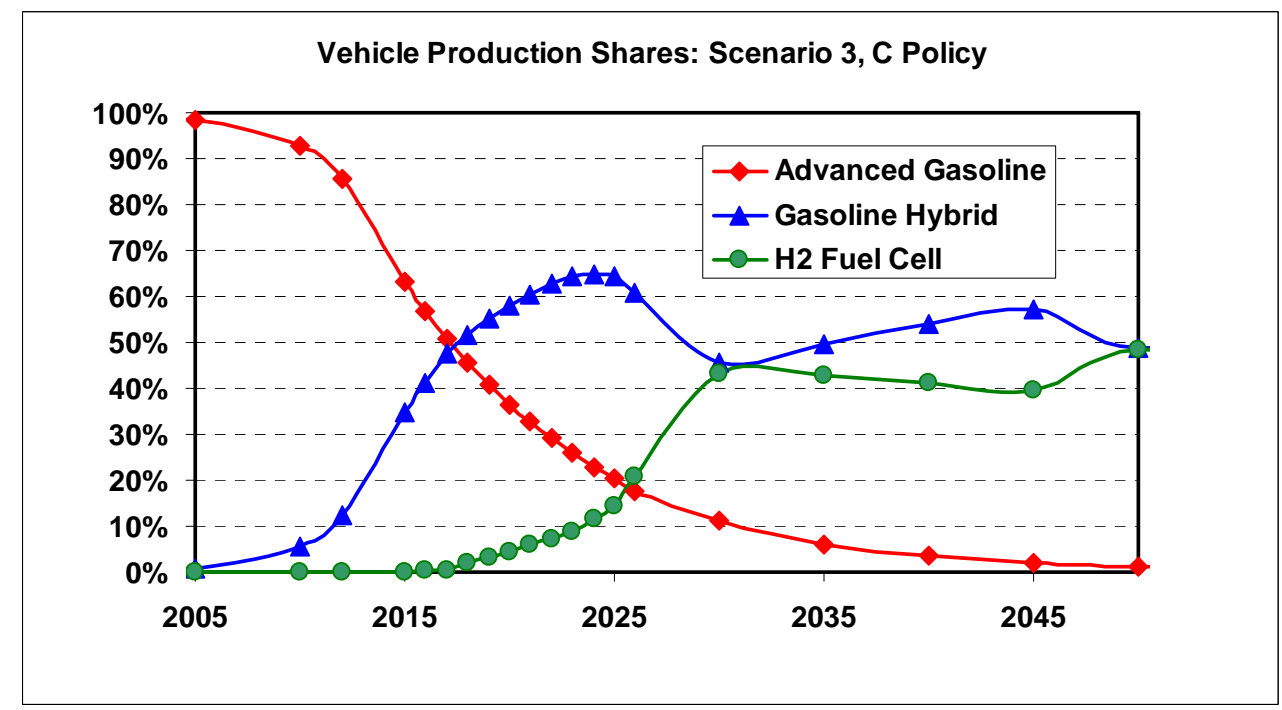

Figure 19. Vehicle Technology Shares, Scenario 3, Technology Shortfall (Future \#9)

The price of petroleum also affects the transition. At AEO 2006 Reference Case oil prices (\$50/barrel in 2030) the transformation to hydrogen proceeds rapidly to a $70 \%$ market share and then stalls for a decade. After 2040 it appears headed slowly toward completion (Figure 20). Higher oil prices are clearly helpful but may not be essential to a sustainable transition. 


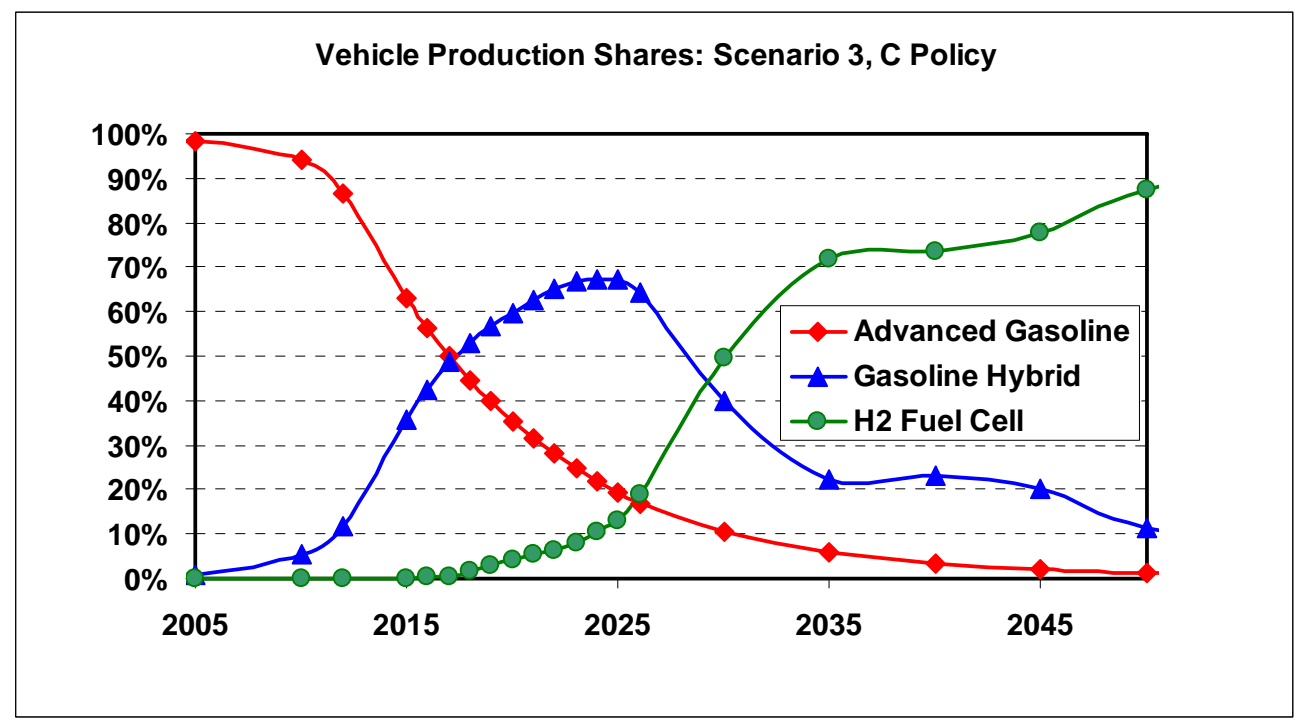

Figure 20. Vehicle Technology Shares, Scenario 3, Technology Success, Reference Case Oil Prices (Future \#10)

\subsection{TOTAL MOTOR FUEL USE}

The transition to hydrogen powered light-duty vehicles dramatically reduces petroleum use and significantly decreases overall energy use by light-duty vehicles. In the AEO Reference Case projection, light-duty vehicle energy use grows at $1.4 \%$ per year through 2030 . Our extrapolation to 2050 implies an $85 \%$ increase in light-duty vehicle energy use by 2050 in the absence of advanced vehicle technologies, nearly all of the energy being supplied by petroleum fuels. With advanced vehicle technologies but without a transition to hydrogen fuel cell vehicles, gasoline demand is no higher in 2050 than in 2005 due to the market dominance of highly efficient advanced gasoline hybrid-electric vehicles (Figure 15). Market success of fuel cell vehicles further reduces total energy use by 40 billion gallons gasoline equivalent energy per year (Figure 21). Petroleum use is reduced to less than 30 billion gallons per year by 2050 , and is on its way towards zero. 


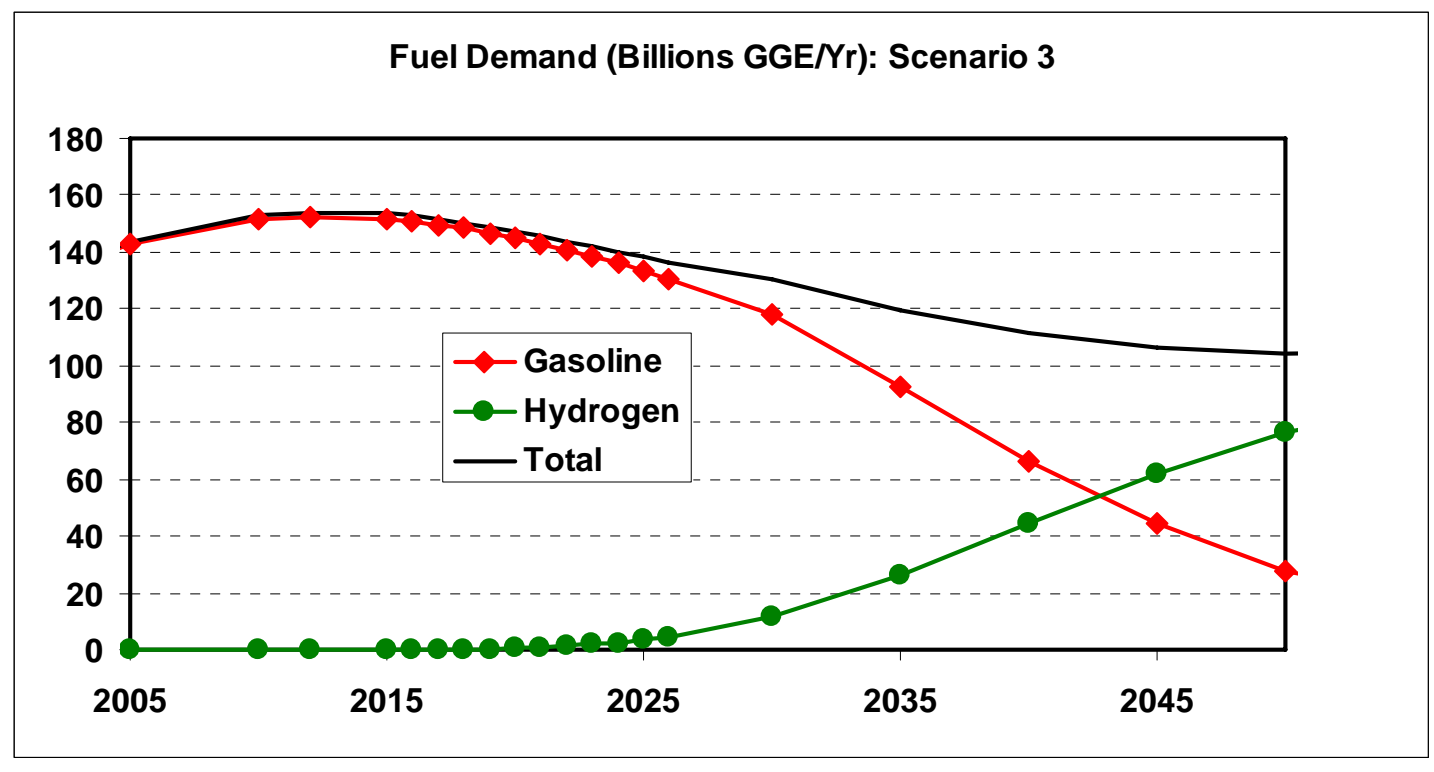

Figure 21. Light-duty Vehicle Fuel Use by Type: Scenario 3, No C Policy (Future \#4)

\subsection{HYDROGEN PRODUCTION AND DELIVERY PATHWAYS}

In the twelve scenarios examined, hydrogen production pathways differ by region and over time as the size of the hydrogen market and the density of hydrogen demand grow. Pathways also change dramatically when carbon constraining policy is imposed. Because many production and delivery processes are ultimately quite close in cost, exactly which pathways are chosen is not as important or definitive as the general picture of how production is likely to vary over space and time and in response to strong carbon policy. The actual mix of production methods and delivery modes is likely to include greater diversity than the results shown here for two reasons: local variations in regional price and availability of feedstocks or fuels will alter the least cost choice; and risk and uncertainty will mean that the least unit-cost pathway is not always selected, particularly if it involves greater fixed investment or technological risk.

The earliest production comes from distributed SMR supplemented by a small amount of hydrogen available from existing merchant hydrogen plants, delivered by tube trailer. When Scenario 3 expands rapidly after 2015 distributed SMR takes off, followed after 2025 with about a 5-year lag by central production from coal without sequestration. The latter is delivered via pipeline. As the market grows and expands into less dense regions, delivery by advanced compressed gas trucks becomes significant. Production from biomass enters late even without the stimulus of carbon constraining policy. Very minor amounts are produced by other methods and a small quantity is delivered by cryogenic truck in lower fuel demand density regions. Again, it should be emphasized that several production pathways are close in cost according to the H2A model. Thus small changes in assumptions could change production pathways from central coal to central SMR or central biomass. The important pattern illustrated in Figure 22 is the tendency for centralized production distributed via pipeline to supplement distributed SMR as the hydrogen market matures. 


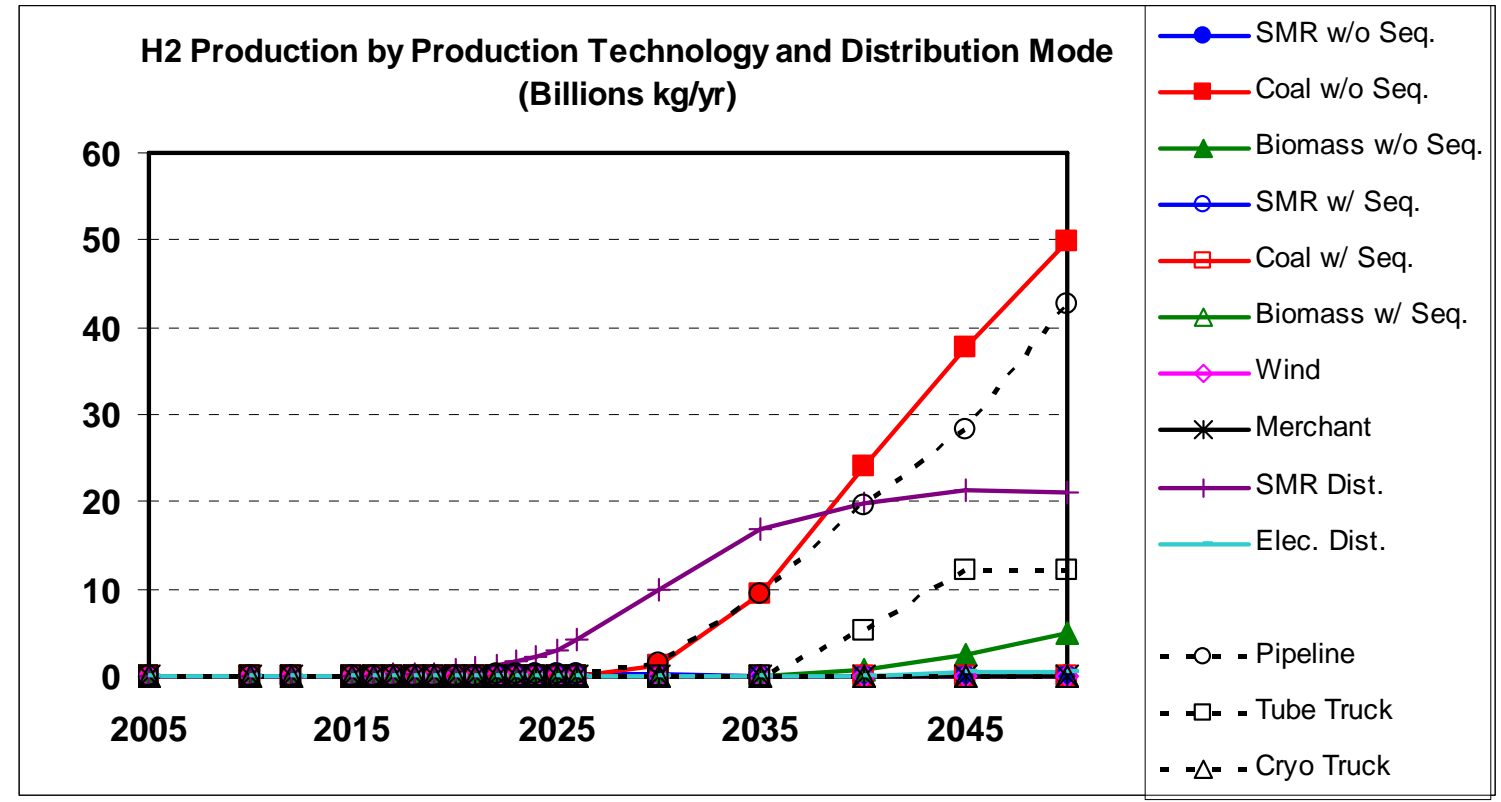

Figure 22. Hydrogen Production Pathways: All U.S., Scenario 3, Technology Success, No C Policy (Future \#4)

Methods of production and delivery also vary considerably by region. In Los Angeles, early production by distributed SMR is overtaken by central production distributed via pipeline after 2025. In the least dense areas of region 9 (Pacific), distributed SMR remains the dominant hydrogen producer through 2050. Its total contribution to U.S. hydrogen supply levels off at about 20 billion kilograms between 2035 and 2040. In the medium density areas outside of the Pacific Coast and the Northeast, distributed SMR declines after 2035. The growing demand is filled by production from coal distributed by advanced compressed gas trucks, with pipeline distribution and biomass gasification increasing in the later years (Figure 23).

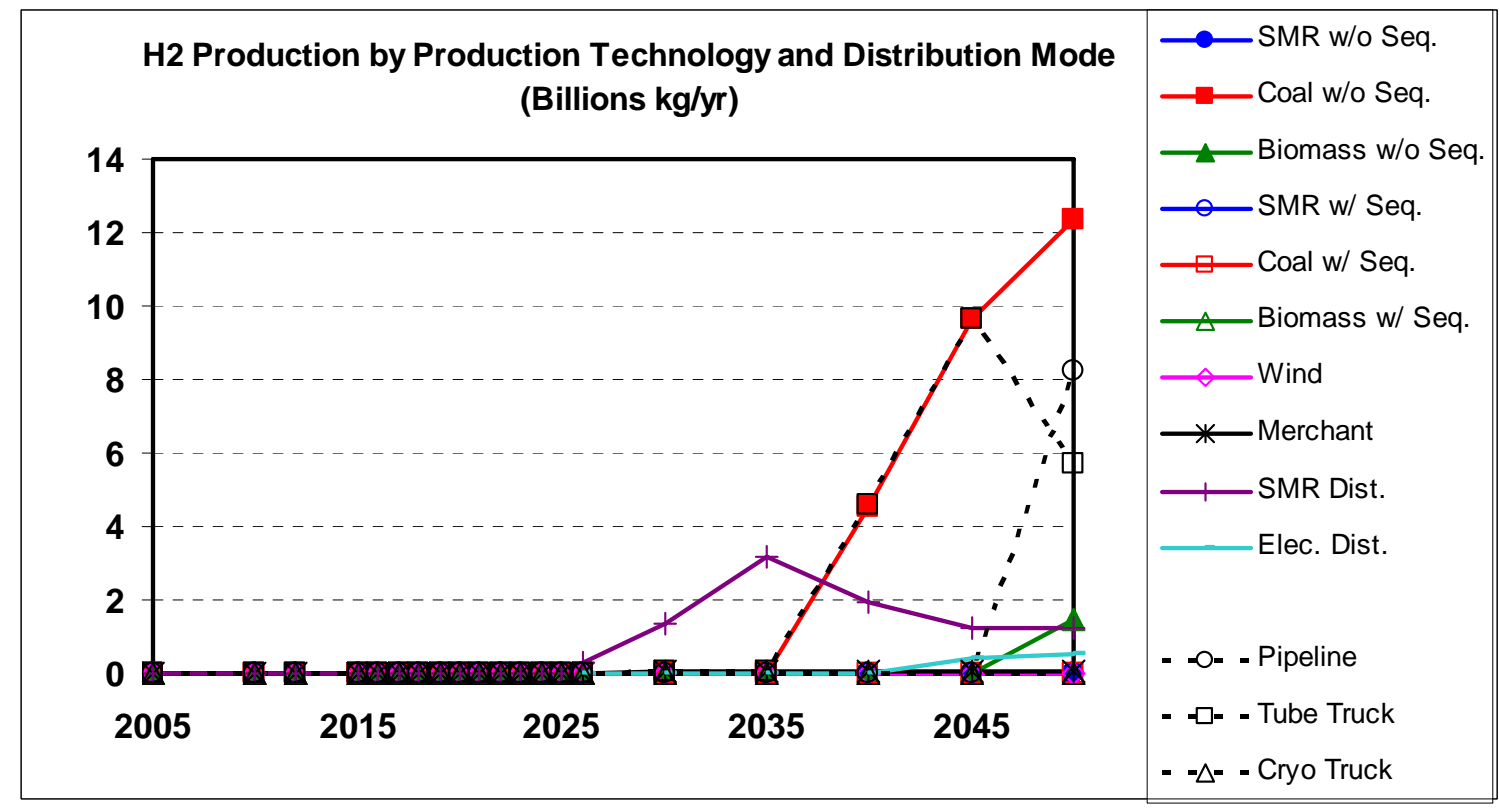

Figure 23. Hydrogen Production Pathways: Medium Density Rest of U.S., Scenario 3, No C Policy (Future \#4) 
In the absence of a strong carbon policy, hydrogen production is relatively carbon intensive. Production via distributed SMR grows rapidly after 2025, eventually to be overtaken by coal gasification without sequestration. In the absence of any incentive to control carbon emissions, hydrogen is produced by the least expensive routes possible. Closer to 2050, there is also a small amount of production from biomass and even a little distributed electrolysis. The $\$ 25 / \mathrm{t} \mathrm{CO}_{2}$ price of carbon causes emissions from production from both biomass and coal to be sequestered (Figure 24). Production from biomass comes on ahead of coal and quickly reaches its maximum output. Sequestration of emissions from hydrogen production via biomass gasification is especially valuable because it results in negative carbon emissions, gaining credits for the owners. Distributed SMR continues to play a significant role despite the fact that its carbon emissions cannot be captured and stored. ${ }^{7}$ For centrally produced hydrogen, pipeline and advanced compressed tube trailer are the dominant delivery modes.

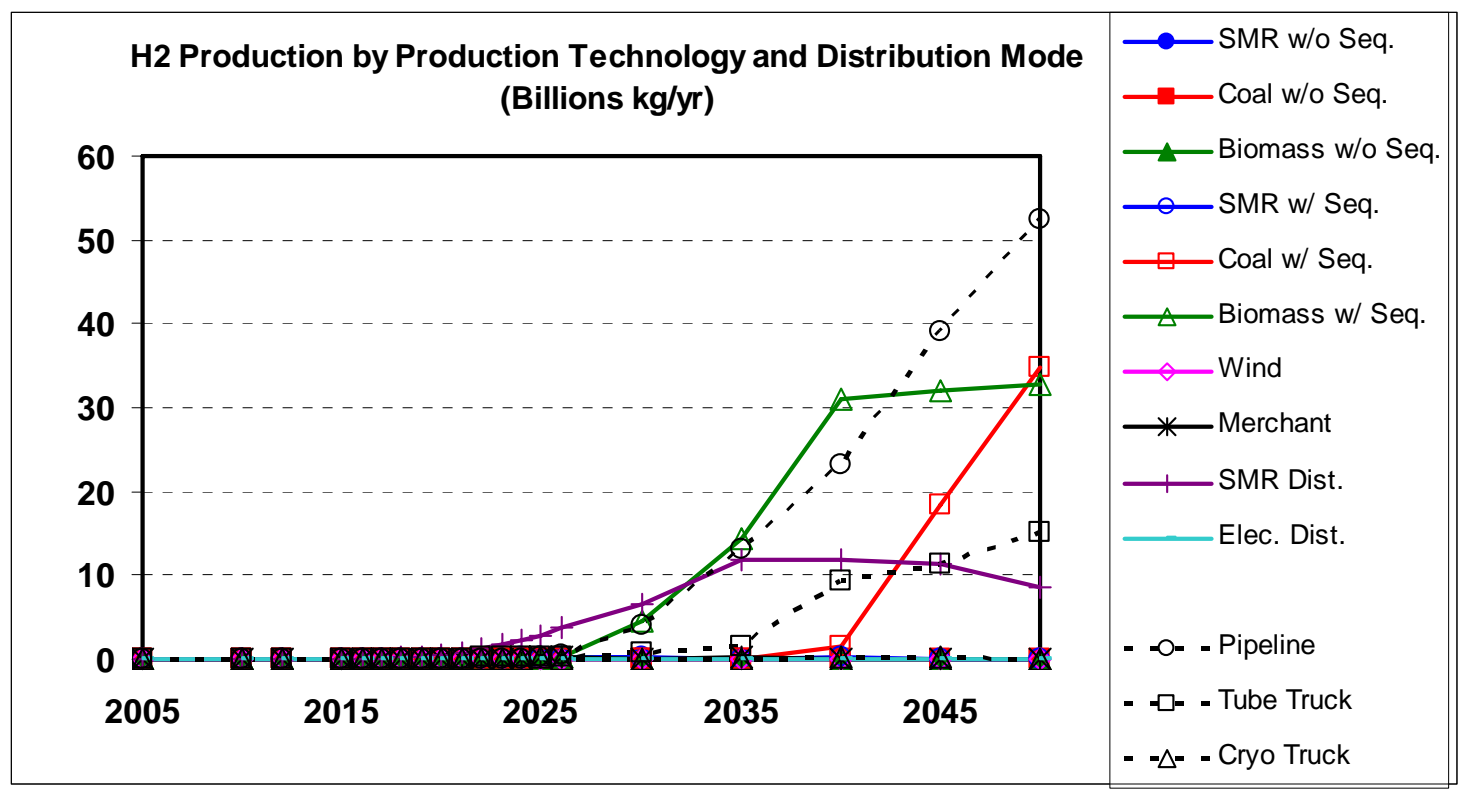

Figure 24. Hydrogen Production Pathways: All U.S., Scenario 3, With C Policy (Future \#8)

The market transformation to hydrogen FCVs combined with strong carbon mitigation policy results in a dramatic reduction in $\mathrm{CO}_{2}$ emissions from light-duty vehicles. The full fuel cycle carbon emissions of Future \#5 (no early transition policy, carbon policy, technology success), Future \#8 (transition Scenario 3, carbon policy, technology success) and Future \#4 (Scenario 3, no carbon policy, technology success) are shown in Figure 25. Carbon emissions from light duty vehicles rise through 2015, then begin to decline as advanced technologies penetrate the market in all three futures. These efficiency-driven reductions cause $\mathrm{CO}_{2}$ emissions from light-duty vehicles to fall through 2035 in all three futures. Only Future \#4, which combines strong carbon policy with a strong market transformation strategy, causes $\mathrm{CO}_{2}$ emissions to continue to decline, reaching about one third of the initial level by 2050.

${ }^{7}$ Additional hydrogen supply beyond that available from existing merchant plants is constrained to be supplied by distributed SMR until 2020. After that date, the constraint is removed and HyTrans solves for the lowest cost production pathways in each region. 


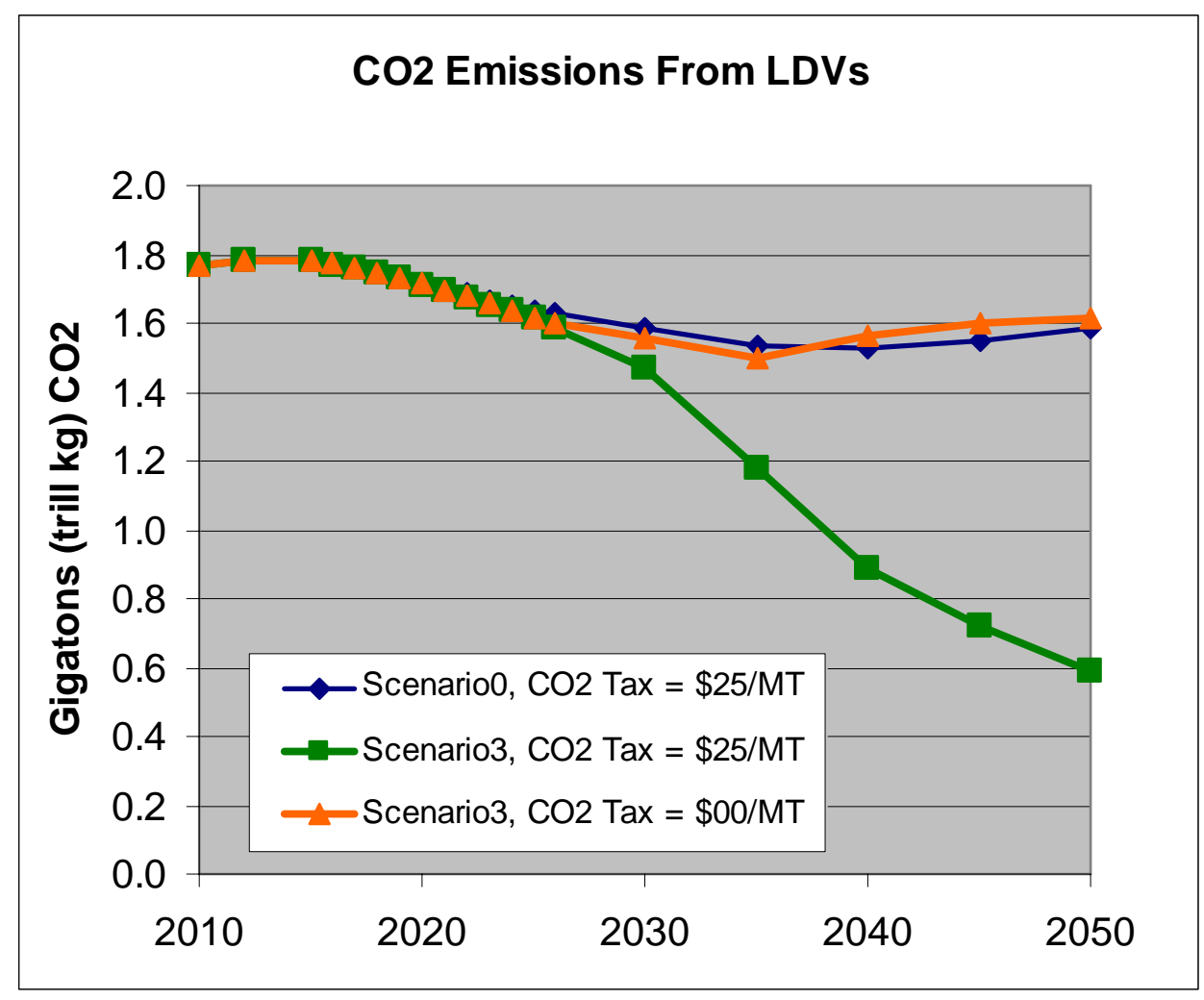

Figure 25. Impacts of Carbon Policy and FCV Market Success on $\mathrm{CO}_{2}$ Emissions from Light-Duty Vehicles (Futures \#5, \#8, \#4)

The biofuels policy case (Future \#11) assumes that biofuels will replace $15 \%$ of gasoline use by 2017, rising to $22 \%$ by 2030 . Because we limit the quantity of biomass available to produce transportation fuels to 35 billion gallons of gasoline equivalent, this limits the amount of biomass available for hydrogen production. As hydrogen vehicles replace gasoline vehicles however, more biomass becomes available to produce hydrogen. On balance, the biofuels policy does not impact the long-run market transformation to hydrogen, but it does change the mix of hydrogen production pathways. There is initially more distributed SMR and less biomass with sequestration. Coal with sequestration also comes on line sooner and reaches a higher level.

We have already seen that technology shortfall holds back the transition to hydrogen. If the goals for fuel cell stack systems are met but the DOE R\&D goals for on-board storage are not met, hydrogen vehicles will apparently still be able to compete successfully against advanced hybrid vehicles (Future \#12). With all the other assumptions of the technology success scenario but an $\$ 10 / \mathrm{kWh}$ cost of on-board storage rather than $\$ 2 / \mathrm{kWh}$, the transition to FCVs continues successfully, as shown in Figure 26. This result suggests that while technology success is critical, there may be some room for less than full achievement of the R\&D goals for on-board hydrogen storage. (As a reminder, this scenario includes a strong carbon policy and assumes high world oil prices, as well.) 


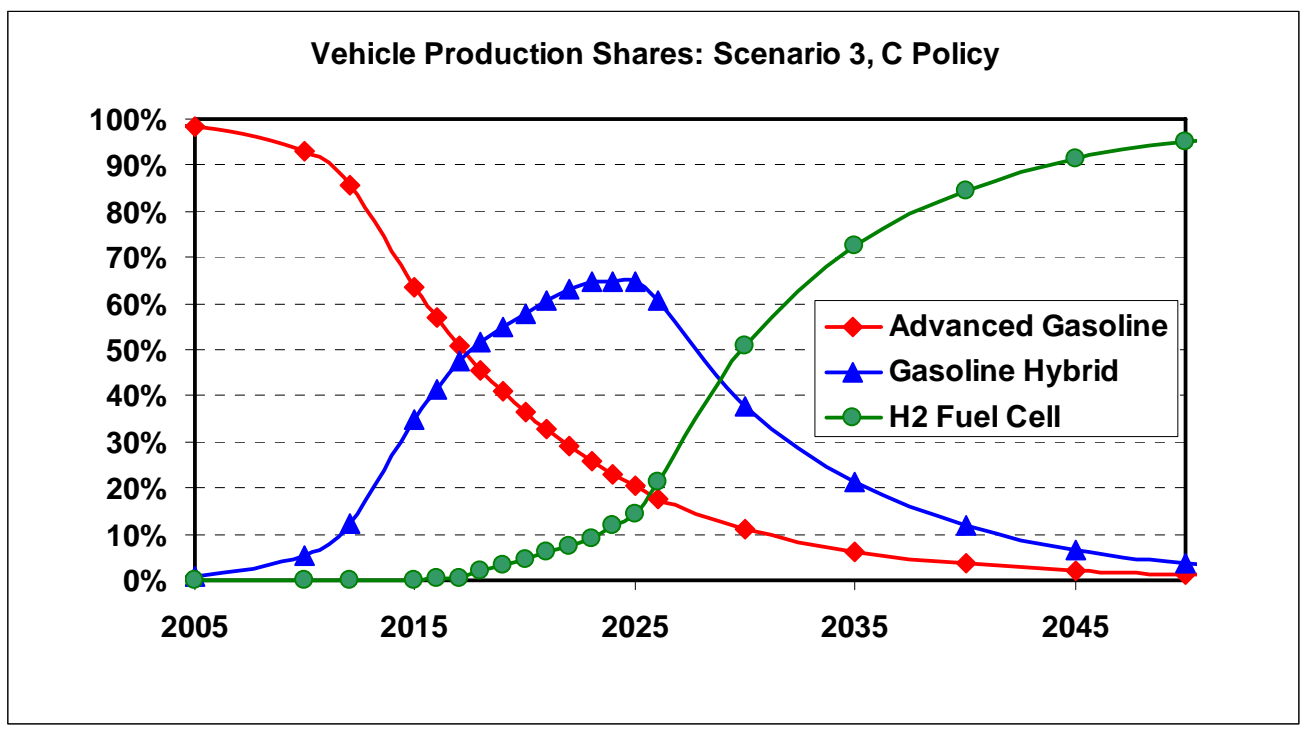

Figure 26. Vehicle Technology Shares, \$10/kWh Storage Costs, Scenario 3 (Future \#12) 


\section{COSTS OF THE EARLY TRANSITION}

The lack of a transition in the "No Policy" scenario showed that overcoming the barriers to transforming the light-duty vehicle market to hydrogen cost more than private agents were likely to want to pay. In the absence of transition policies, nothing happened for forty years. The constraints imposed to create Scenarios 1, 2 and 3 require that either government or industry, or both, are paying the significant excess costs of overcoming the transition barriers. HyTrans calculates these costs but does not say who pays. Each policy case considered in this section (1, 2 or 3) represents a different sharing of the transition costs among government, the automotive industry and hydrogen suppliers. In this section, estimates of the costs to the government of Policy Cases 1, 2 and 3 are presented, followed by a simulation of the cash flow to automobile manufacturers from producing and selling hydrogen FCVs. On the assumption that the government will only share in the cost of the transition to hydrogen if it is to low-carbon hydrogen, all cases presented here assume that the carbon constraining policy is in place (Futures \#6, \#7 and \#8).

The three policy cases examine alternative cost-sharing and vehicle and fuel subsidy programs within the three market transformation scenarios (Table 7). Policy Case 1 includes a 50/50 sharing between government and the auto industry of the incremental cost of hydrogen FCVs, from 2012 to 2025. Incremental costs are calculated as the costs above the price of the FCV's closest competitor, the advanced gasoline-electric hybrid. This policy is similar to the way the Japanese government encouraged the market penetration of hybrid vehicles in Japan. In addition, the government encourages the development of refueling infrastructure by sharing the capital cost of distributed SMR stations according to the following schedule:

- 2012-2017: cost share equal to $\$ 1.3$ million per station

- 2018-2021: cost share of \$0.7 million per station

- 2022-2025: cost share of \$0.3 million per station

The unsubsidized capital cost of distributed SMR stations is \$3.3 million in 2012 for a station of $1,500 \mathrm{~kg} / \mathrm{d}$ nominal capacity. This declines over time by learning-by-doing, eventually reaching $\$ 2$ million per station. The capital cost share schedule above is intended to make the privately borne early costs closer to the long-run mature capital costs. Finally, Policy Case 1 includes a hydrogen fuel subsidy of $\$ 0.50 / \mathrm{kg}$ through 2018 which decreases linearly thereafter to $\$ 0.30$ by 2025.

Policy Case 2 modifies the FCV cost sharing to share not just the incremental but the total cost of FCVs 50/50 between government and industry through 2017. From 2018 to 2025 a tax credit to industry covers $100 \%$ of the incremental cost of FCVs. It is assumed that manufacturers are able to take full advantage of the credit. The infrastructure cost sharing and hydrogen fuel subsidies are also in place in Case 2. Policy Case 3 is identical to Case 2 but adds a $\$ 2,000$ additional tax credit for car buyers from 2018 to 2025. The critical issue with respect to the three incentive policies is how they affect manufacturers' revenue streams from the sale of FCVs and total costs to the government. 


\subsection{COST SHARES BORNE BY GOVERNMENT (THREE SCENARIOS COUPLED WITH THREE POLICY CASES)}

In Policy Case 1, government costs reach $\$ 1$ Billion per year in Scenario 1 (Figure 27a). Cumulative costs through 2025 amount to just over $\$ 8$ billion (Figure 27b). Nearly all of the cost sharing goes to vehicle manufacturers because with only 2 million vehicles on the road at the end of the period, hydrogen consumption is on the order of $1 \%$ of total light-duty vehicle energy use. Vehicle cost-sharing occurs up front at the time of purchase while fuel subsidies are spread out over the life of the vehicle.

Table 7. Hydrogen Fuel Cell Vehicle and Infrastructure Policy Cases

\begin{tabular}{|c|c|c|c|c|}
\hline & & 2012-2017 & 2018-2021 & 2022-2025 \\
\hline \multirow{3}{*}{ Vehicle Cost Sharing } & Case 1: & $\begin{array}{l}\text { 50/50 incremental } \\
\text { cost share }\end{array}$ & $\begin{array}{l}\text { 50/50 incremental } \\
\text { cost share }\end{array}$ & $\begin{array}{c}\text { 50/50 incremental } \\
\text { cost share }\end{array}$ \\
\hline & Case 2: & $50 \%$ total vehicle & None & None \\
\hline & Case 3: & $\begin{array}{l}50 \% \text { total vehicle } \\
\text { cost share }\end{array}$ & None & None \\
\hline \multirow{3}{*}{ Vehicle Tax Credits } & Case 1: & None & None & None \\
\hline & Case 2: & None & $\begin{array}{c}100 \% \text { of incremental } \\
\text { vehicle cost }\end{array}$ & $\begin{array}{c}100 \% \text { of incremental } \\
\text { vehicle cost }\end{array}$ \\
\hline & Case 3: & None & $\begin{array}{c}100 \% \text { of incremental } \\
\text { cost plus } \\
\$ 2,000 / \text { vehicle }\end{array}$ & $\begin{array}{c}100 \% \text { of incremental } \\
\text { cost plus } \\
\$ 2,000 / \text { vehicle }\end{array}$ \\
\hline Station Cost Sharing & All Cases: & $\begin{array}{c}\$ 1.3 \\
\text { Million/Station }\end{array}$ & \$0.7 Million/Station & \$0.3 Million/Station \\
\hline H2 Fuel Subsidy & All Cases: & $\$ 0.50 / \mathrm{kg}$ & $\begin{array}{l}\text { Decreasing starting in } \\
2018 \text { to reach }\end{array}$ & $\$ 0.30 / \mathrm{kg}$ by 2025 \\
\hline
\end{tabular}
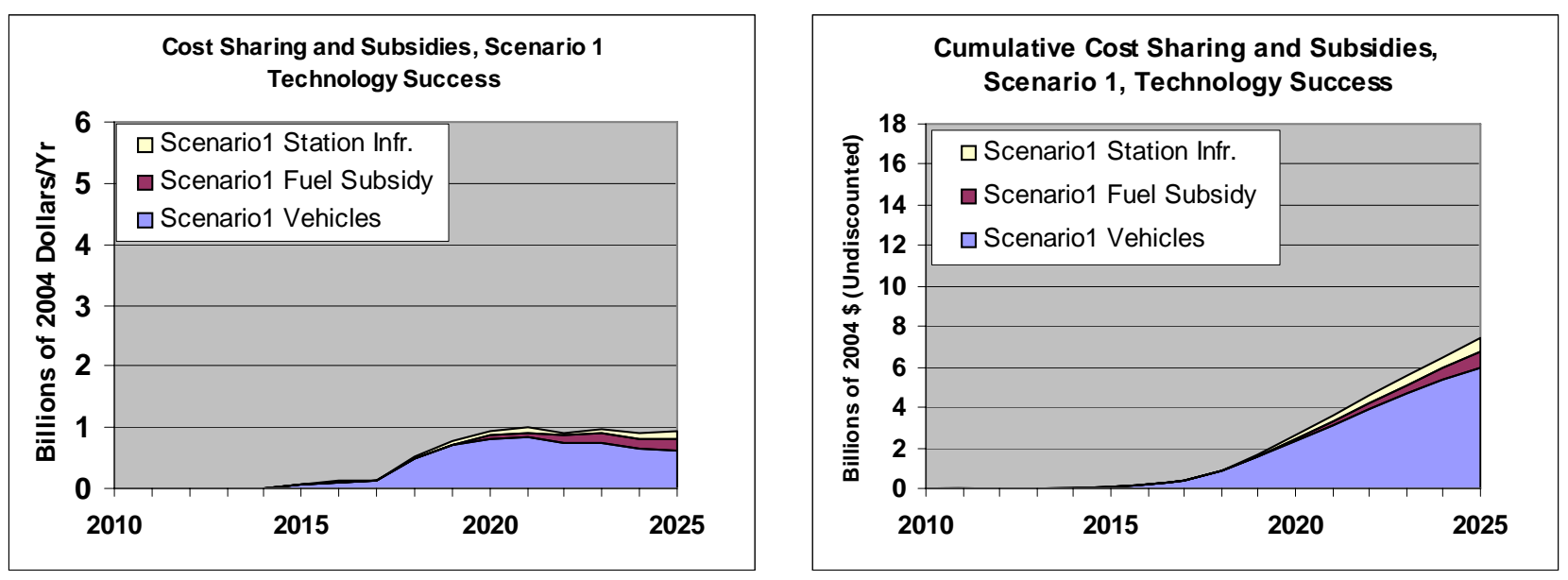

Figures 27a and 27b. Cost to Government of Policy Case 1 in Scenario 1, Annual and Cumulative 
The nearly 5 million vehicles put on the road by 2025 in Scenario 2 double the peak subsidy in Policy Case 1 to $\$ 2$ billion per year (Figure 28a). Cumulative subsidies increase less than proportionately with the number of vehicles because greater learning and scale economies bring production costs down faster in Scenario 2 than in Scenario 1 (Figure 28b). In fact, by 2025, the incremental costs of FCVs are almost zero and so is the government's cost share. Fuel and infrastructure subsidies, on the other hand increase to more than half a billion dollars by 2025 . Most of this is accounted for by the direct subsidy of hydrogen fuel.

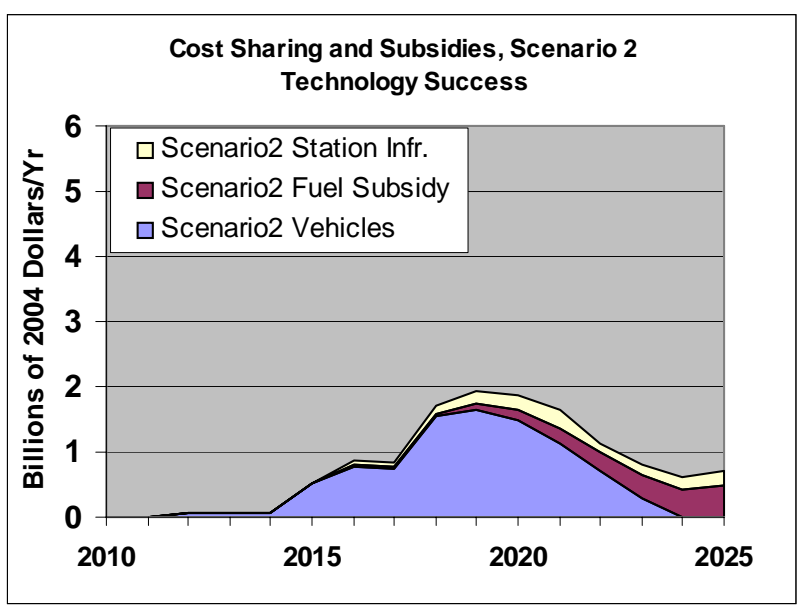

Figure 28a. Annual Cost to Government of Policy Case 1 in Scenario 2

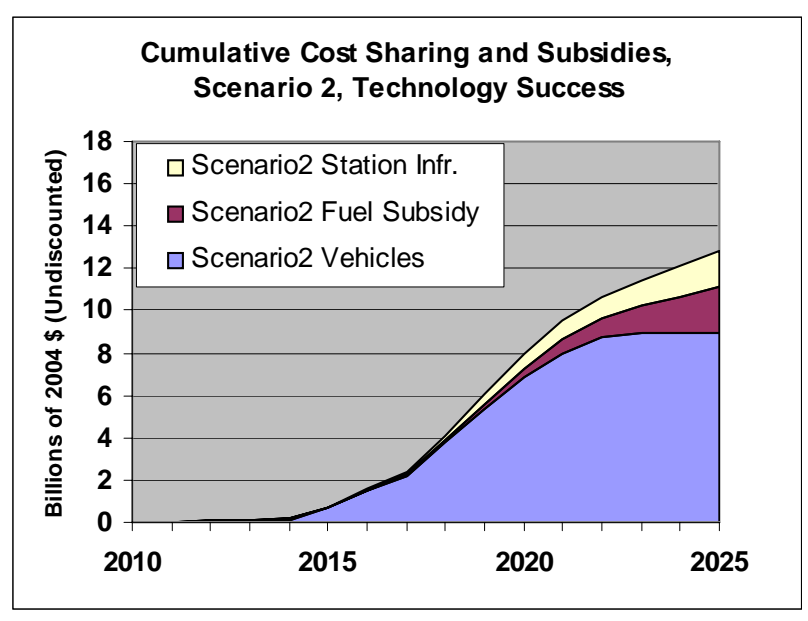

Figure 28b. Cumulative Government Cost Shares, Policy Case 1, Scenario 2

Vehicle stocks rise to almost 10 million vehicles in Scenario 3, and yet government cost-sharing for FCVs is actually a bit lower than in Scenario 2 (Figures 29a and 29b). There are two reasons for this. First, the cost of moving down the learning curve over a given period of time is essentially fixed. Once it is paid, there is no more to pay. Second, Scenario 3 gets to scale economies more quickly than Scenario 2, and this reduces the required subsidy per vehicle. The aggressiveness of Scenario 3 achieves economical production volumes quickly rather than prolonging the cost of low volume production. Fuel and infrastructure subsidies do double, however, simply because there are twice as many hydrogen powered vehicles on the road. As a result, the cumulative cost of Scenario 3 is $\$ 2$ billion greater than Scenario 2.

Sharing half of the full production costs of vehicles to 2017 and shouldering all of the incremental cost from 2018-2015 (Policy Case 2) is considerably more costly to the government than sharing half of the incremental cost (the benefits to manufacturers will be shown below). In Scenario 1, peak costs rise to $\$ 2$ billion per year and cumulative costs are also about twice as large; $\$ 14$ billion is spent through 2025 (Figures 30a and 30b). 


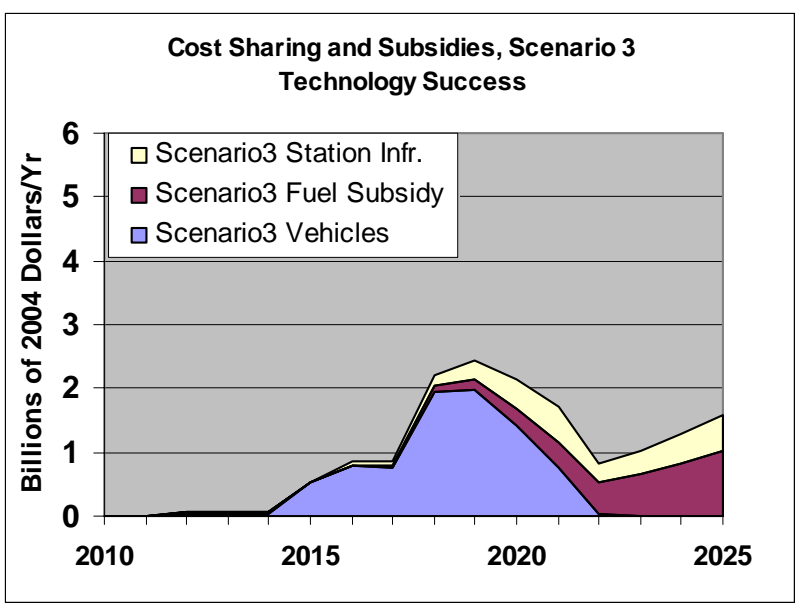

Figure 29a. Annual Cost to Government of Policy Case 1 in Scenario 3

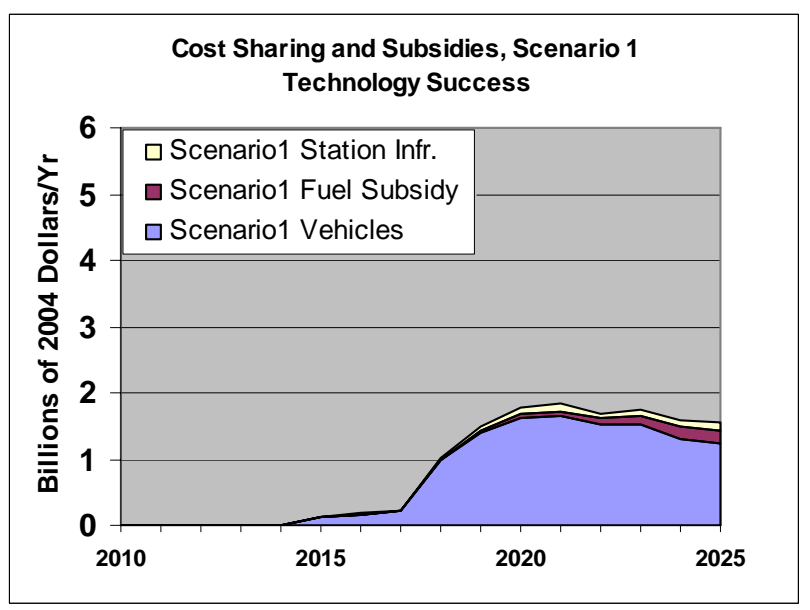

Figure 30a. Annual Cost to Government of Policy Case 2 in Scenario 1

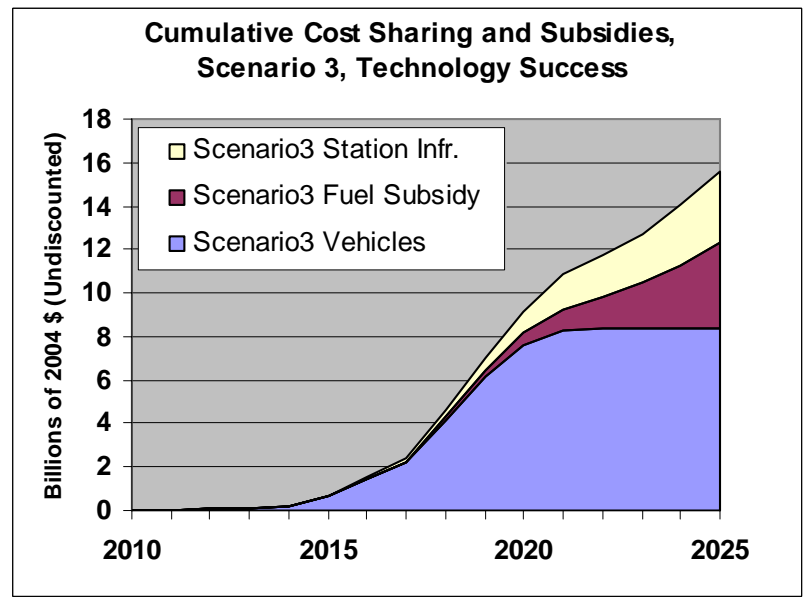

Figure 29b. Cumulative Government Cost Shares, Policy Case 1, Scenario 3

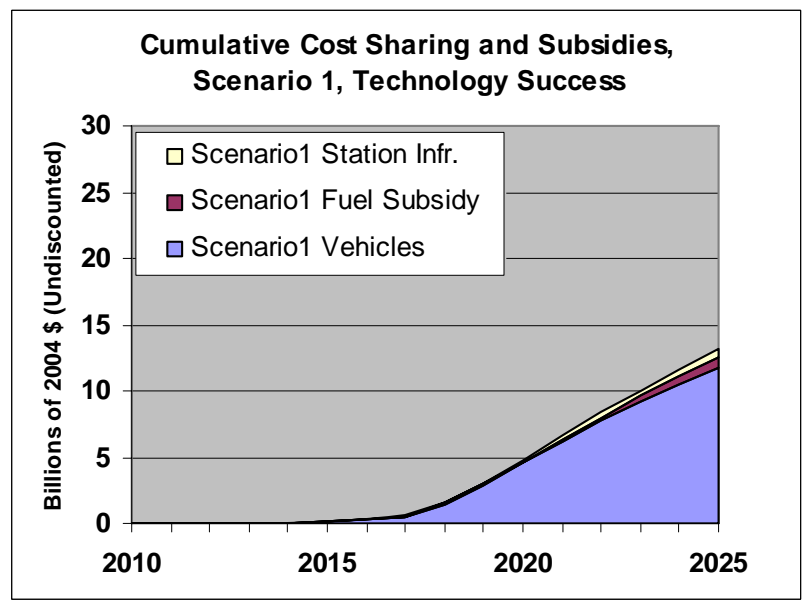

Figure 30b. Cumulative Government Cost Shares, Policy Case 2, Scenario 1

A similar near doubling of costs compared to Policy Case 2 is evident in Scenario 2. Annual costs peak at $\$ 4$ billion and cumulative costs rise to nearly $\$ 25$ billion (Figures 31a and 31b). 


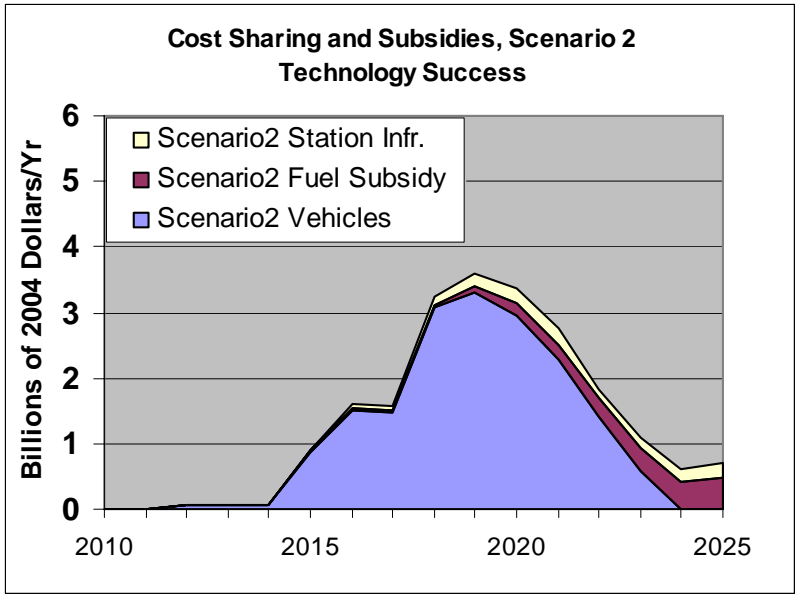

Figure 31a. Annual Cost to Government of Policy Case 2 in Scenario 2

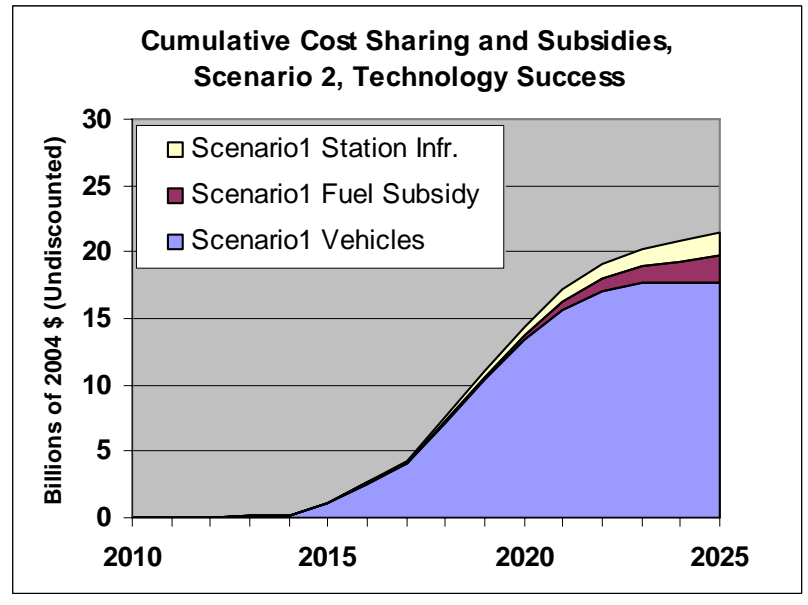

Figure 31b. Cumulative Government Cost Shares, Policy Case 2, Scenario 2

Under Policy Case 2, Scenario 3 costs only marginally more than Scenario 2, because the greater burden of sharing half of total costs is multiplied by a greater number of vehicles (Figures 32a and 32b).

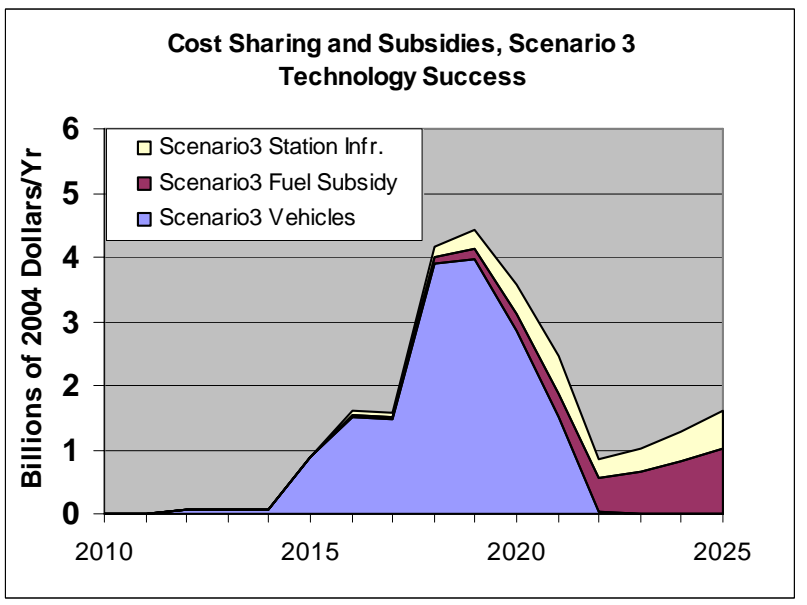

Figure 32a. Annual Cost to Government of Policy Case 2 in Scenario 3

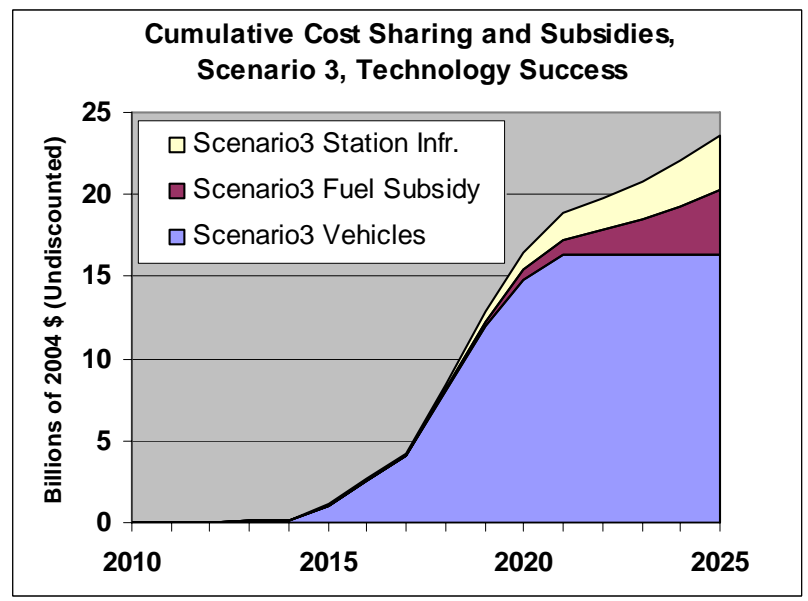

Figure 32b. Cumulative Government Cost Shares, Policy Case 2, Scenario 3

To the policies of Case 2, Case 3 adds a \$2,000 per vehicle incentive beginning in 2018 and continuing to 2025. Growing in proportion to vehicle sales, the annual cost of the incentive approaches \$1 billion in 2025 (Figure 33a). It raises the government's share of total costs through 2025 to $\$ 18$ billion (Figure 33b). 


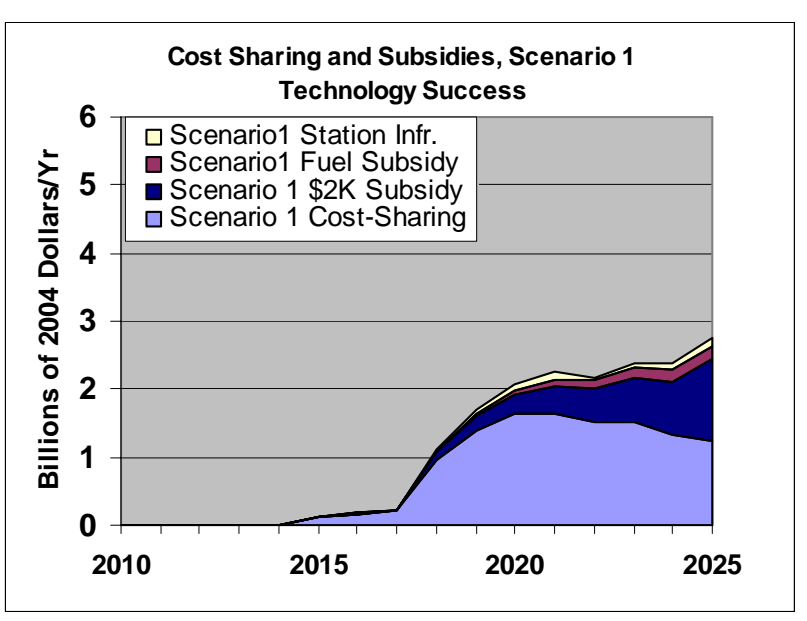

Figure 33a. Annual Cost to Government of Policy Case 3, Scenario 1

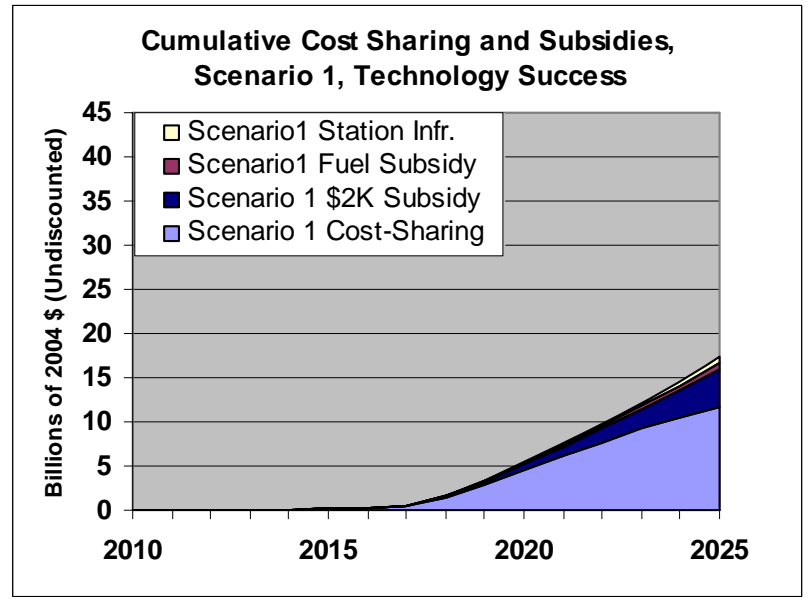

Figure 33b. Cumulative Government Cost Shares, Policy Case 3, Scenario 1

In Scenario 2 the cost of the added incentive amounts to $\$ 2$ billion in 2025, when 1 million new FCVs are sold (Figure 34a and 34b) and boosts the government's cumulative costs to \$35 billion.

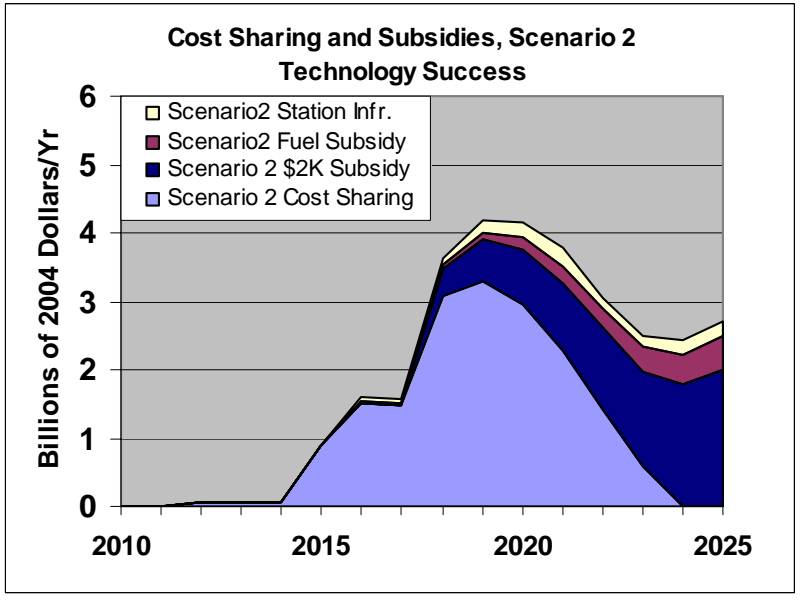

Figure 34a. Annual Cost to Government of Policy Case 3, Scenario 2

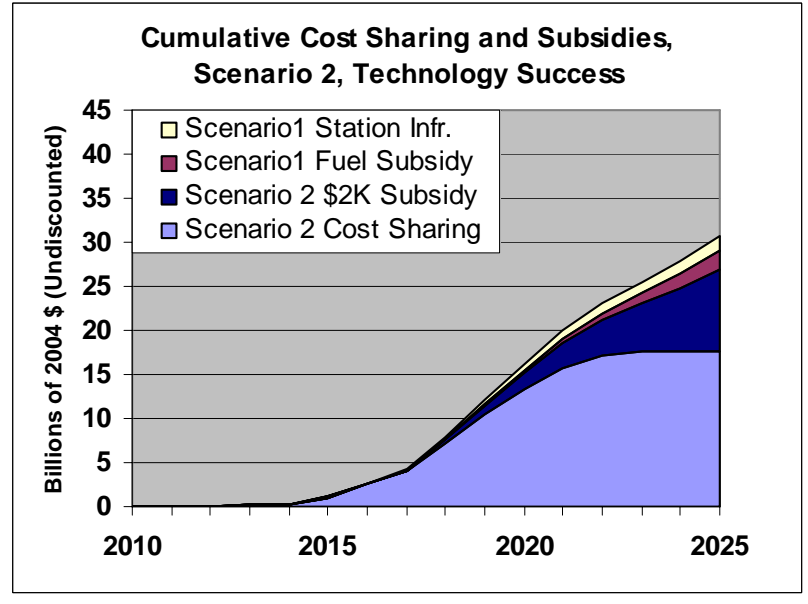

Figure 34b. Cumulative Government Cost Shares, Policy Case 3, Scenario 2

In Scenario 3 the cost of the \$2,000 incentive dominates annual costs in 2025 at about \$5 billion per year. 2025 FCV production is 2.5 million vehicles, and the ambitious scenario deployment schedule has driven incremental vehicle costs to near zero by 2023. In Figure 35a the cost of the incentive can be seen to increase directly with increasing vehicle sales. Cumulative costs of the $\$ 2,000$ incentive alone amount to approximately $\$ 15$ billion by 2025, raising the government's cumulative expenditures to over $\$ 45$ billion for the 15 year scenario (Figure 35b). 


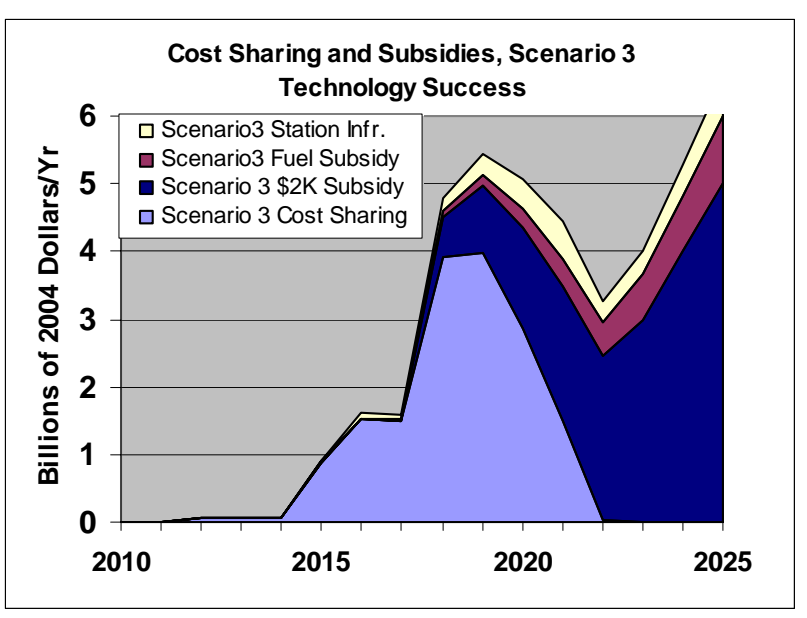

Figure 35a. Annual Cost to Government of Policy Case 3, Scenario 3

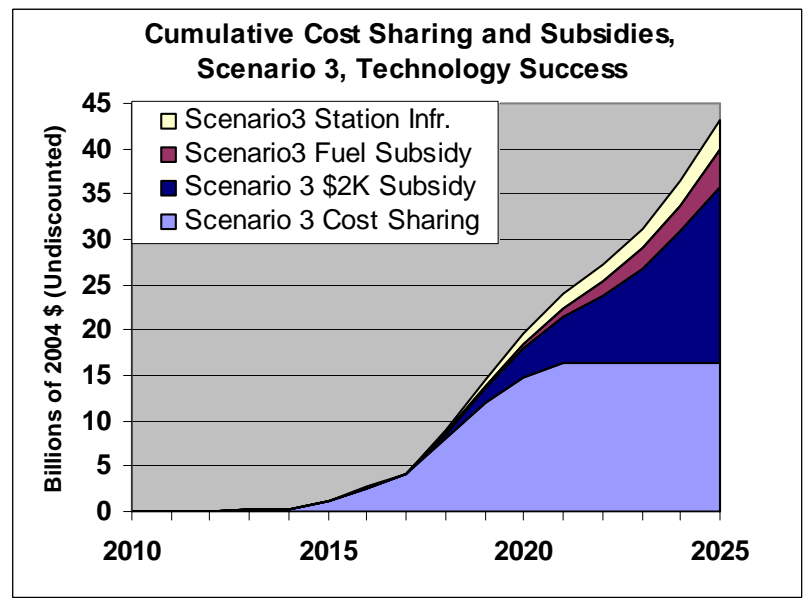

Figure 35b. Cumulative Government Cost Shares, Policy Case 3, Scenario 3

To put these costs in some perspective, U.S. motorists spent $\$ 327$ billion on gasoline in 2005 alone (U.S. DOE/EIA, 2006c, tables 5.11 and 5.24). The U.S. trade deficit in petroleum amounted to $\$ 231$ billion in the same year. In comparison, an expenditure of less than $\$ 50$ billion to achieve a sustainable transition to hydrogen powered vehicles seems small. At this point it is appropriate to remember that this analysis is premised on meeting the DOE technology $\mathrm{R} \& \mathrm{D}$ program goals for hydrogen vehicles, infrastructure and technology. It is also necessary to keep in mind the uncertainties and limitations of this analysis.

\subsection{IMPLIED CASH FLOW FOR VEHICLE MANUFACTURERS}

Motor vehicle manufacturers are bearing significant R\&D costs today and face the possibility of much greater costs to bring hydrogen FCVs to the market in the future. To convey a sense of the magnitude of these potential costs and how they might be affected by the three policy cases, we have constructed a simulation of the industry-wide cash flow from sales of hydrogen FCVs from 2010 to 2025. We call this a simulation since we do not have an estimate of the selling prices for FCVs from 2012 to 2025 and therefore cannot directly estimate the loss or profit per vehicle. The cash flow is approximated by an assumed normal rate of profit, 6.5\% of the long-run (2025) retail price of a FCV, minus the incremental cost of an FCV above the long-run retail price, times the number of FCVs sold, plus whatever government cost sharing is available in the Policy Case in question. In Policy Case 3, the \$2,000 incentive is assumed to be split 50/50 between consumers and manufacturers.

The first Case of interest is no policy sharing or subsidizing of the costs of FCVs in any way (other than government R\&D support). In this case manufacturers bear the full burden of bringing FCVs to the market and driving the market transformation to hydrogen. Initial losses are on the order of a hundred million dollars per year through 2014 (Figure 36). In 2015, FCV sales begin to ramp up in Scenarios 2 and 3. Annual losses quickly reach $\$ 2$ billion per year in 2016. From there they jump to $\$ 4$ billion annually in Scenario 2 and almost $\$ 5$ billion in Scenario 3. By 2020, things begin to improve. In Scenario 3 manufacturers first see a profit in 2023. In Scenario 2 they almost break even in 2025, and in Scenario 1 manufacturers are still facing losses of nearly $\$ 2$ billion annually even in 2025 . Figure 36 illustrates clearly the "valley 
of death,” roughly $\$ 25$ billion in cumulative losses between 2015 and 2022. These losses are a large part of the reason why the transition to hydrogen does not occur in the "No Early Transition Policy Scenario” (Future \#1).

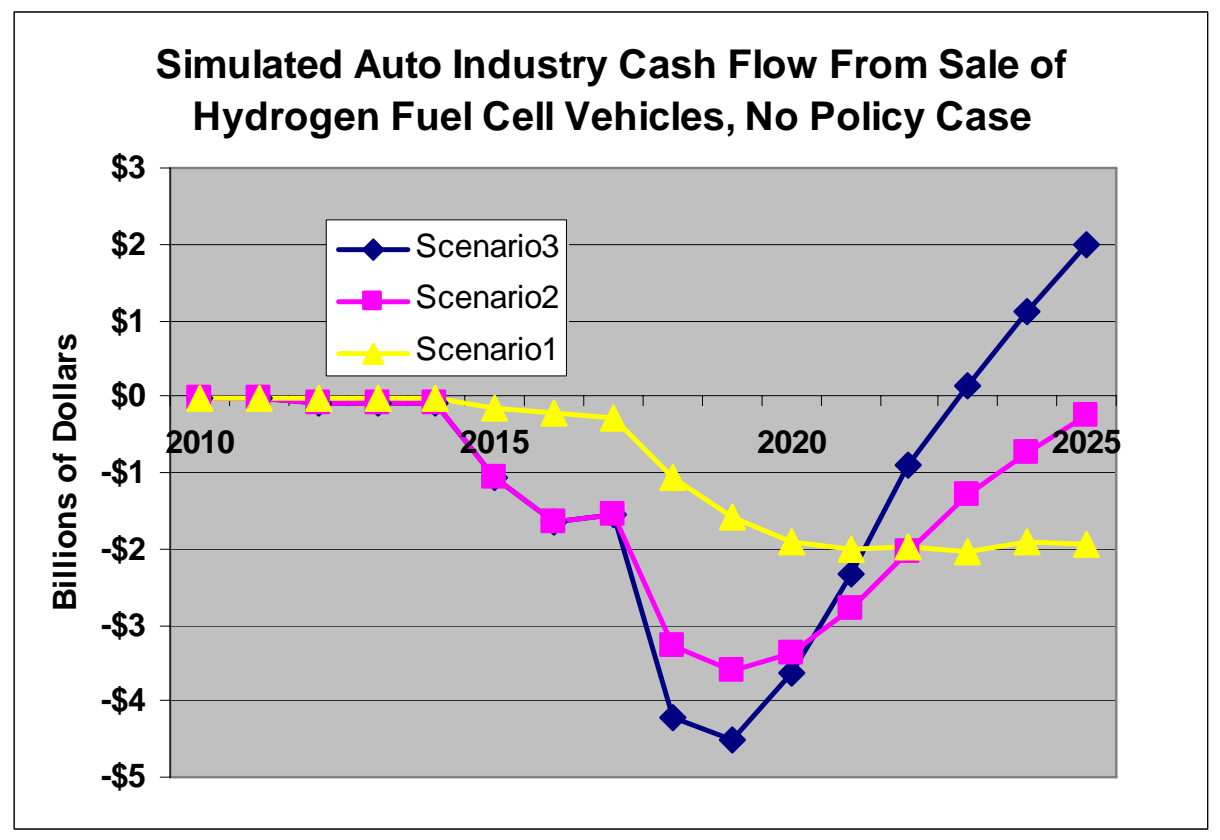

Figure 36. Simulated Industry Cash Flow from Sales of FCVs: No Policy Case

Under Policy Case 1 manufacturers' losses are approximately halved, but the timeline for profitability remains the same (Figure 36). This is because government incentives essentially share half of incremental costs but do not change the time at which they turn positive (Figure 37).

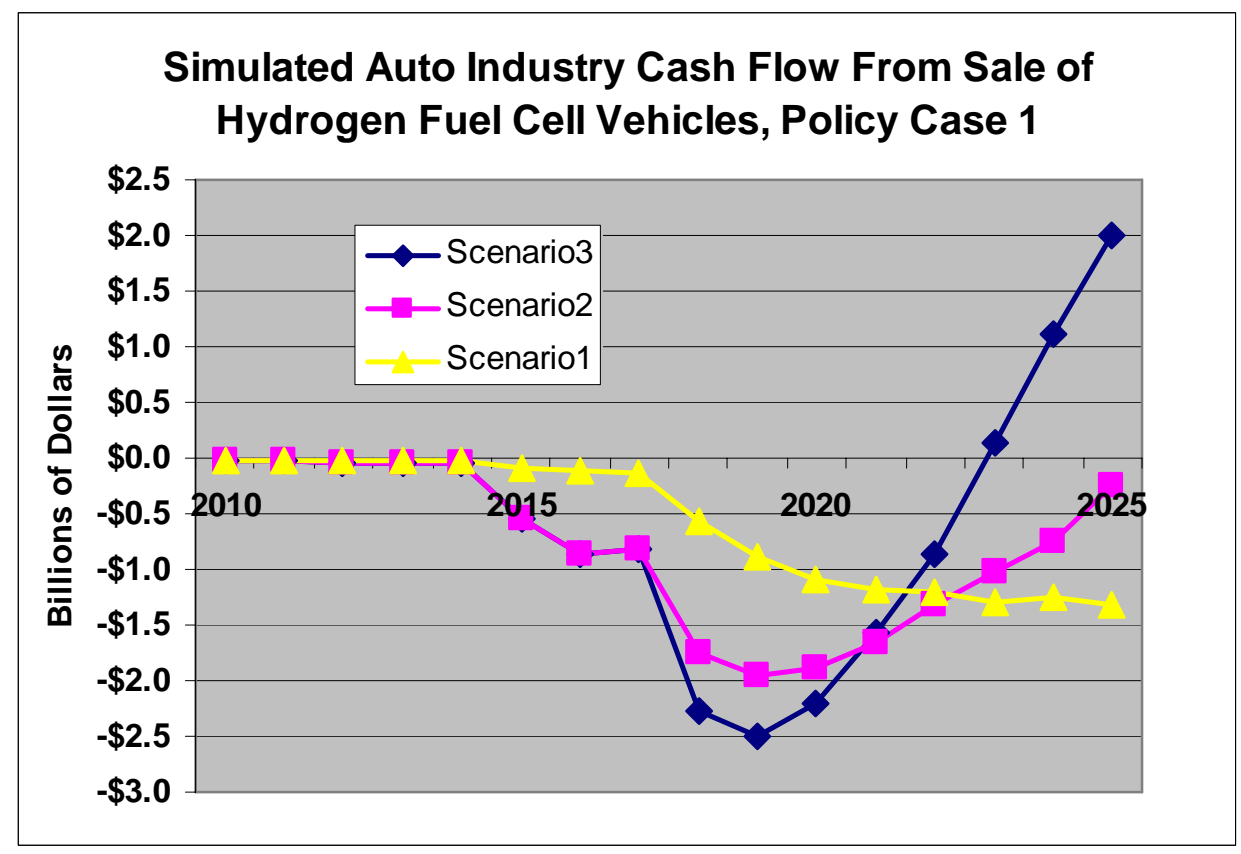

Figure 37. Simulated Industry Cash Flow from Sales of FCVs: Policy Case 1 
Policy Case 2 insures that annual industry-wide losses from hydrogen FCV sales never exceed $\$ 1$ billion per year (Figure 38). Still, net profits don’t arrive until 2023, and later for Scenarios 1 or 2.

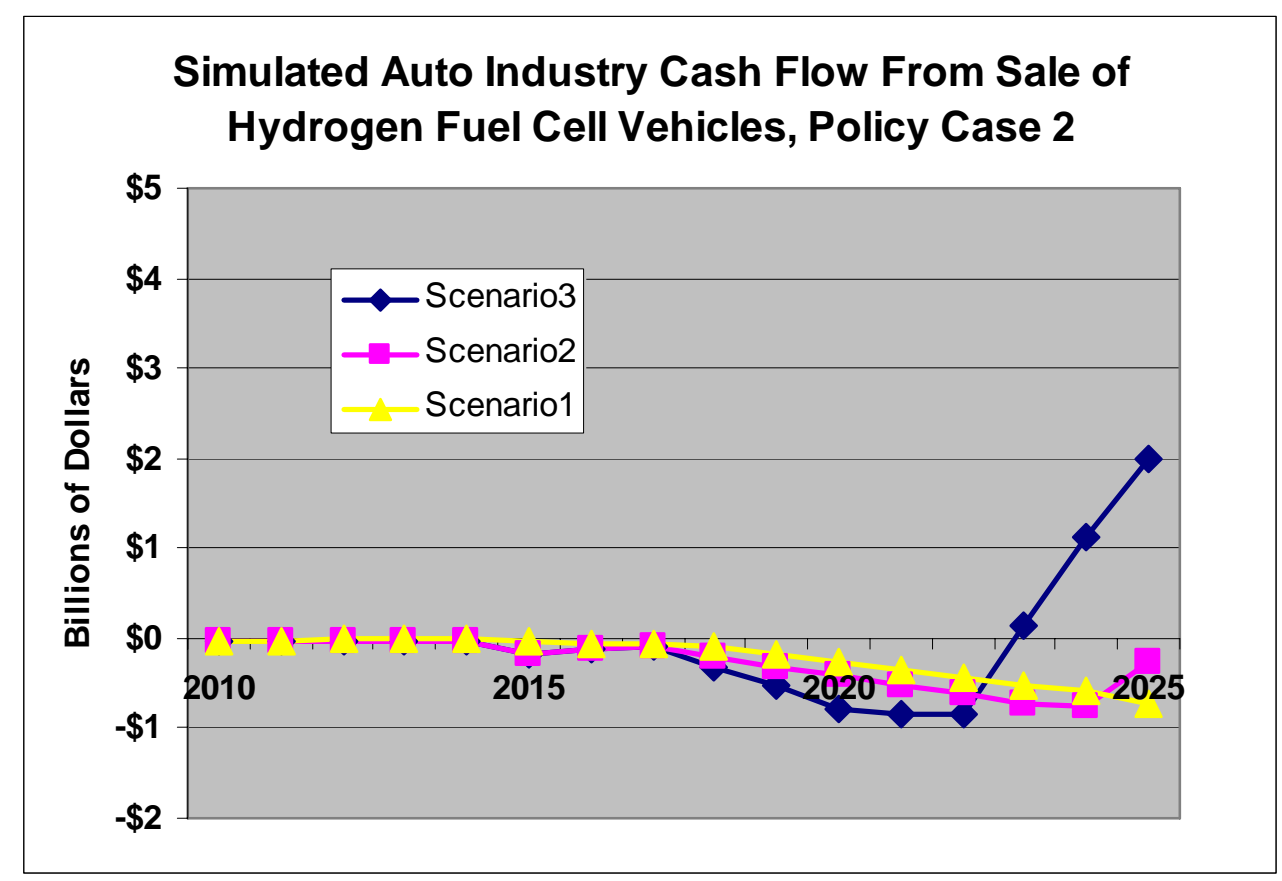

Figure 38. Simulated Industry Cash Flow from Sales of FCVs: Policy Case 2

The extra \$2,000 incentive of Policy Case 3, split 50/50 between customers and manufacturers almost makes Scenarios 2 and 3 profitable by 2018 (Figure 39). However, only Scenario 3 makes more than a billion in annual profits for the industry before 2025.

Of course, the cash flow calculations are simulations and subject to many caveats. At the same time they suggest that plausible policies, at feasible costs, exist that can minimize and even eliminate the very significant market barriers that would otherwise prevent the market transformation to hydrogen. 


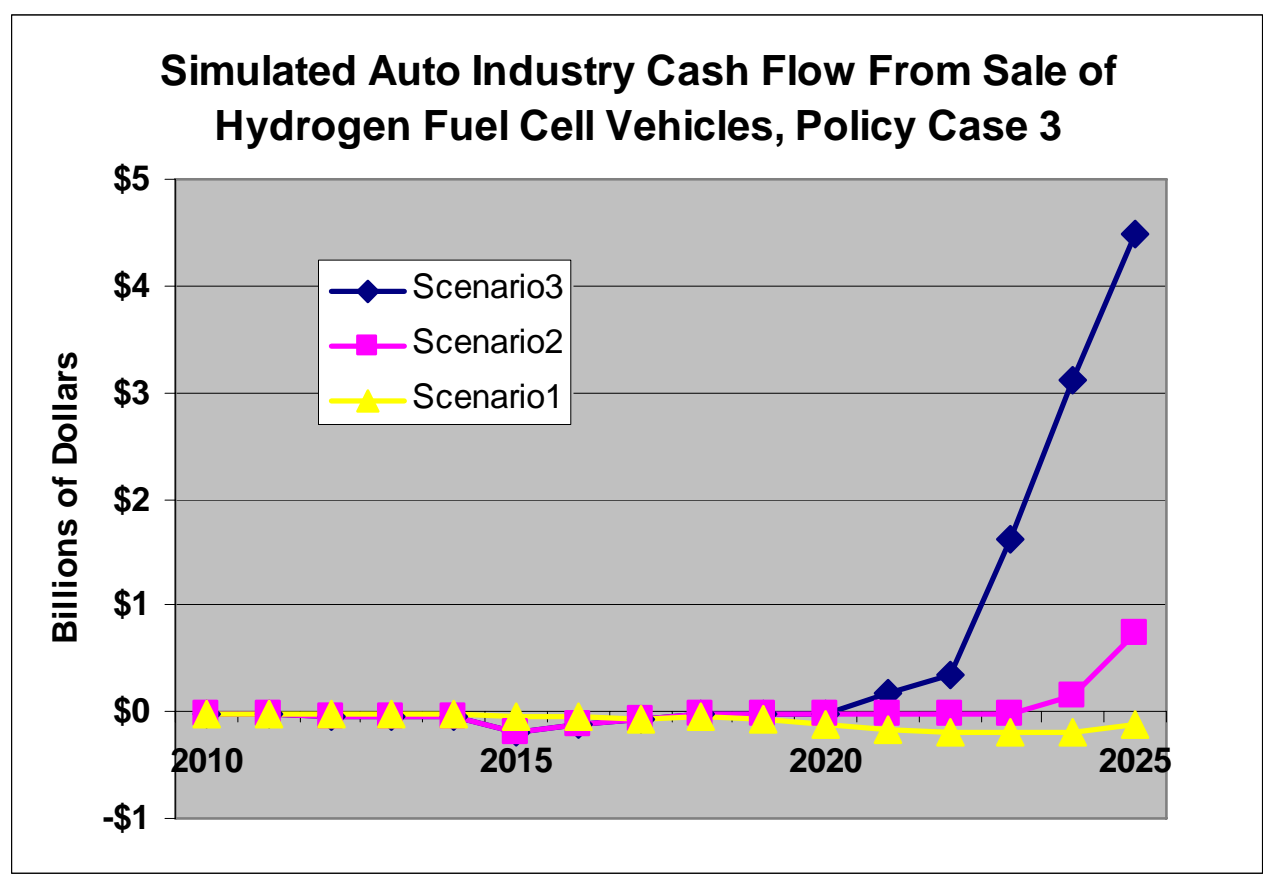

Figure 39. Simulated Industry Cash Flow from Sales of FCVs: Policy Case 3 


\section{COSTS AND SOURCES OF HYDROGEN}

In Scenario 3, the national average costs of hydrogen production and delivery (excluding motor fuel tax and any subsidies) decrease from about $\$ 3 / \mathrm{kg}$ to $\$ 2.50 / \mathrm{kg}$ by 2025 (Figure 40 ). Prior to 2025, all hydrogen comes from either distributed SMR or from existing merchant plants. In 2025 and afterwards, biomass and coal, without sequestration if there is no carbon policy and with sequestration if the carbon policy is in place, become important sources. When delivered by pipeline to well-developed markets, these two sources are competitive with distributed SMR. Outside of the high fuel demand density areas, where pipelines may be inefficient, both biomass and coal-derived hydrogen may be delivered by advanced compressed gas trucks at a higher cost. In some medium and low density areas, hydrogen is provided by distributed generation either via SMR or electrolysis.

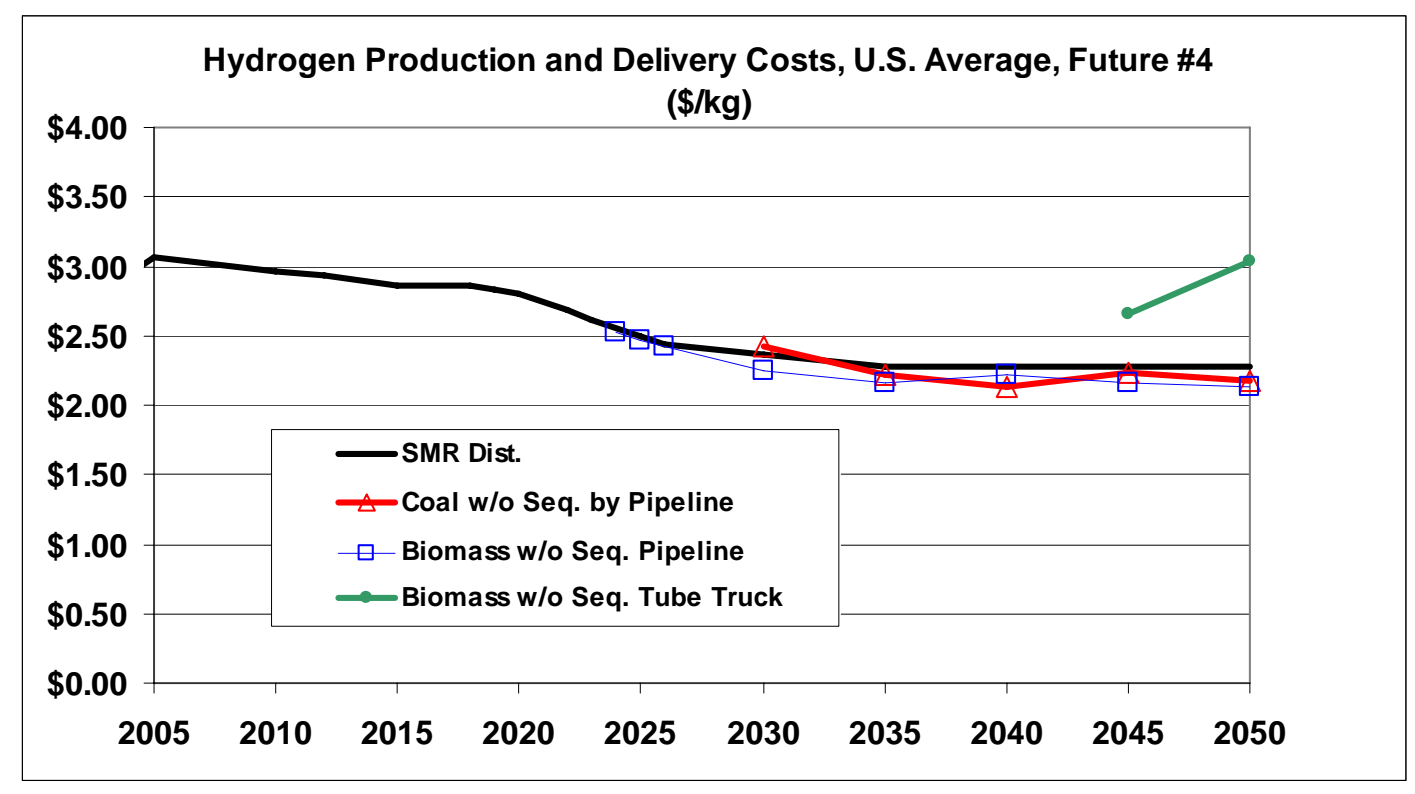

Figure 40. Hydrogen Production Costs in Future \#4, U.S. Average

In Los Angeles, a high-density "Lighthouse" region in the scenarios, before 2025 hydrogen is produced by distributed SMR. After 2025, the growth in hydrogen demand is satisfied more economically by central coal or biomass production, with or without sequestration depending on carbon policy, and distributed by pipeline (Figure 41). 


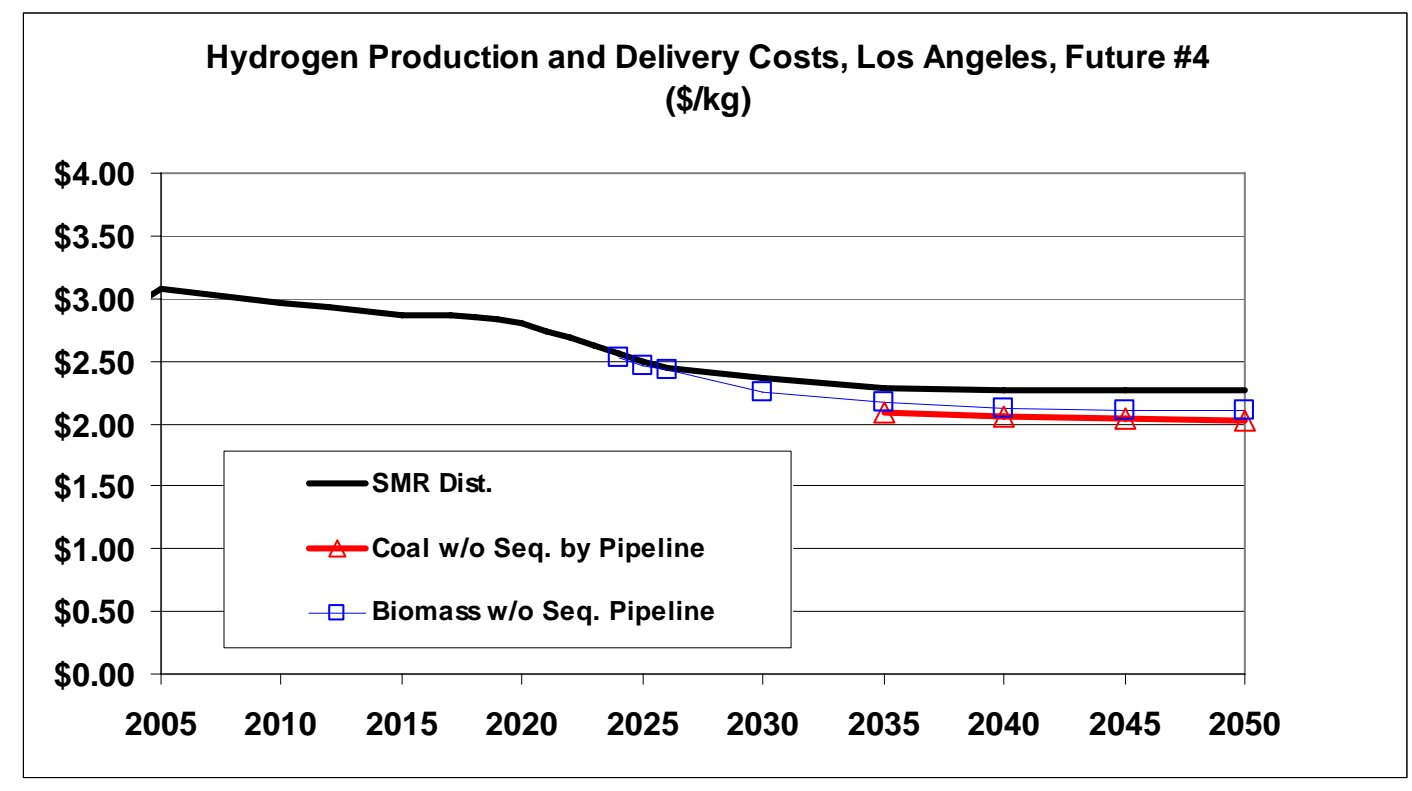

Figure 41. Hydrogen Production Costs in Future \#4, Los Angeles

With gasoline reaching \$3.05/gallon in 2030 (including tax) in the AEO 2006 High Oil Price Projection, hydrogen is the cheaper fuel on the basis of energy content in many regions (Figure 42). The delivered cost of hydrogen at the refueling station, not including taxes or subsidies, starts at about \$3.00 per gallon and declines through 2025 due to learning-by-doing in distributed SMR production.

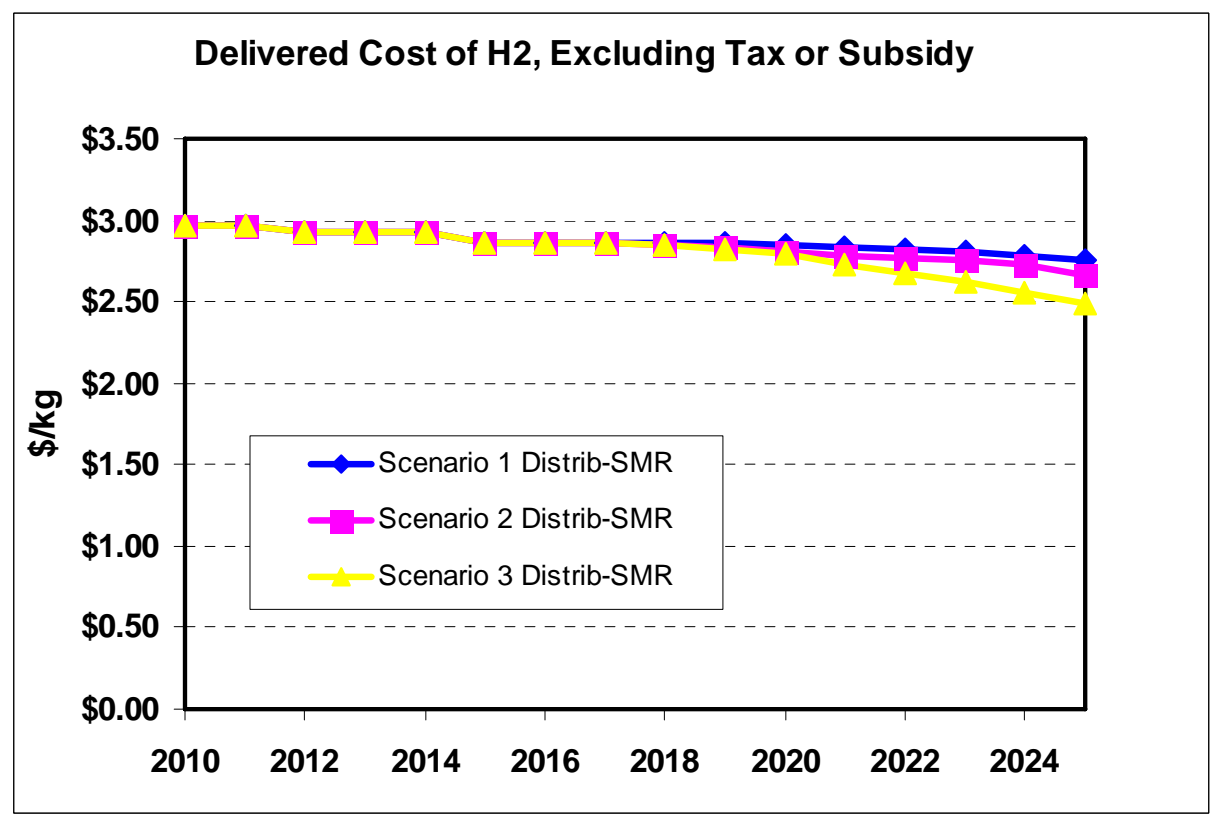

Figure 42. Cost of Hydrogen at the Refueling Station, Excluding Tax and Subsidy 
The policy cases considered include hydrogen fuel subsidies and station capital cost-sharing (see Table 7). The retail price of hydrogen to motorists is significantly reduced in the early stages of the transition by the fuel subsidy that begins at $\$ 0.50 / \mathrm{kg}$ and declines to $\$ 0.30 / \mathrm{kg}$ before ending after 2025. Assuming that the station capital subsidy is passed on to consumers, it would have an even greater impact than the fuel subsidy in the first few years, beginning at nearly $\$ 0.80 / \mathrm{kg}$, decreasing eventually to $\$ 0.18 / \mathrm{kg}$ by 2025 (Figure 43). Note that in all the cases and futures presented in this report, vehicle, fuel, and station subsidies all drop to zero after 2025.

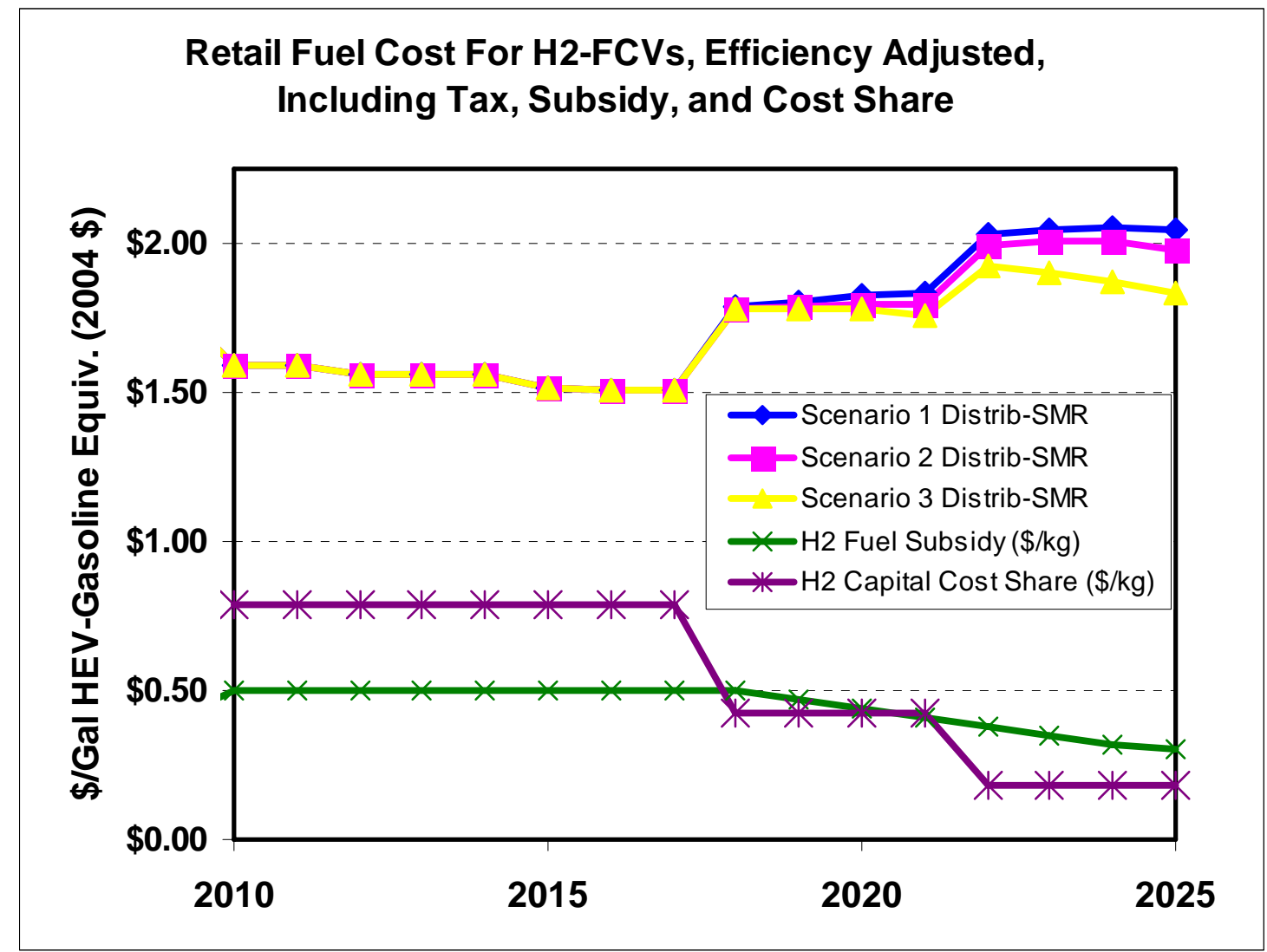

Figure 43. Retail Fuel Cost for Hydrogen Fuel Cell Vehicles, Adjusted for Their Greater Efficiency and Including All Taxes and Subsidies.

The combined effects of fuel subsidies, station cost-sharing and the FCV's higher energy efficiency (see Figure 9) give hydrogen a significant price advantage in terms of cost per vehicle mile over gasoline used in advanced hybrid electric vehicles. Adjusted for the difference in energy efficiency and comparing prices in Scenario 3, gasoline costs about $60 \%$ more per mile than hydrogen in the High Oil Price Case, and 20\% more when the Reference Case is the basis for comparison (Figure 44). 


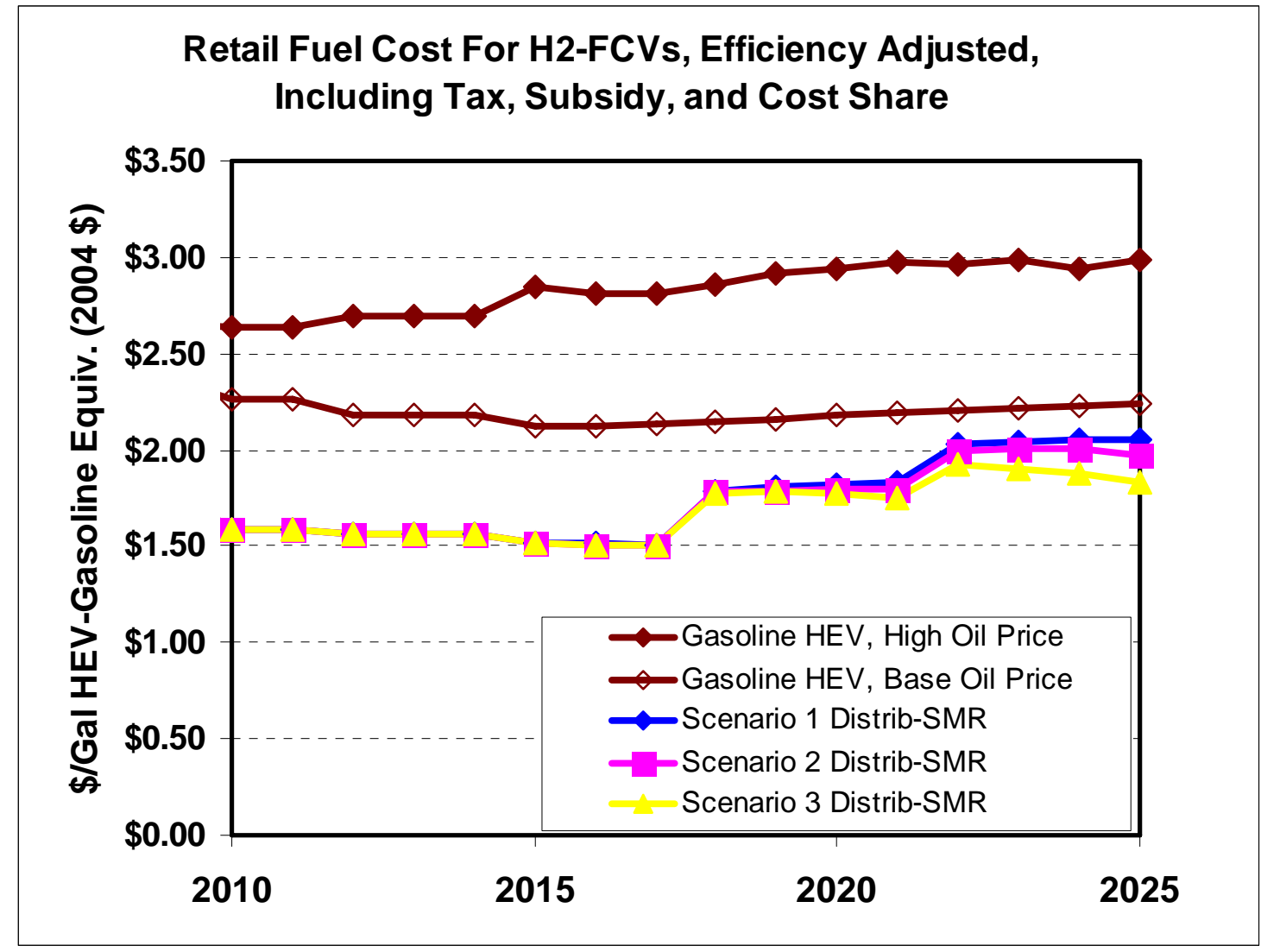

Figure 44. Retail Fuel Cost for Hydrogen Fuel Cell Vehicles, Adjusted for Energy Efficiency and Including Taxes and Subsidies 


\section{THE NEED FOR EARLY TRANSITION POLICIES}

Transition policy appears to be essential to overcome the substantial initial economic barriers to hydrogen powered transportation. This seems to be true even if hydrogen and fuel cell research and development successfully creates technology that is superior to an advanced hybrid ICE vehicle. Establishing a refueling infrastructure in the absence of a ready market for hydrogen fuel, moving down the learning curve for FCV vehicle manufacturing, and achieving both economies of scale and diversity of choice for hydrogen vehicles present private sector investors with the prospect of losses numbered in the billions of dollars for a decade or more before a profitable market materializes. In light of this, public policy intervention to share the costs of the transition to hydrogen appears to be a prerequisite to obtaining the public benefits of clean, secure and sustainable energy for transportation.

Vehicle manufacturers, hydrogen producers and governments cannot be certain of the ultimate success of hydrogen powered vehicles. Yet the sustained participation of all key stakeholders will be critical to a successful transition. Private sector investors will have to wait patiently for a return on their investments. Governments will have to maintain policy continuity regardless of the ups and downs of world oil prices. At the same time, transition policies will undoubtedly have to adapt to changing circumstances. The uncertainties that all parties face will require a continuous monitoring of technological progress and market success and adaptation to surprises as the transition proceeds.

If hydrogen is to be a low-carbon energy source, meaningful carbon mitigation policy also appears necessary. Moreover, carbon constraints must be implemented soon to signal hydrogen producers to invest in renewable production technologies and carbon capture and storage if hydrogen is to be produced from fossil fuels. Hydrogen delivery is also potentially a significant source of carbon emissions because of the large electricity requirements for compression and cooling or for liquefaction. To the extent that this electricity is taken from the grid, there must be time for the utility sector to make major reductions in its carbon intensity. The simulations presented above indicate that policies equivalent to a carbon price starting at \$10/ton in 2010 and rising to $\$ 25 /$ ton of $\mathrm{CO}_{2}$ by 2025 would be adequate to insure climate friendly hydrogen production and delivery (given the degree of technological progress assumed). With strong carbon mitigation policies in place, the transition to hydrogen offers a unique opportunity to drive the $\mathrm{CO}_{2}$ emissions from light-duty vehicles toward zero. 


\section{CONCLUSIONS}

This prospective analysis of the transformation of the automotive market to hydrogen power has produced some potentially valuable insights. If the technology goals of the DOE's vehicle and infrastructure research programs are met, a sustainable transition to hydrogen appears to be achievable, but only if given a strong push by policies that induce the early market penetration of large numbers of hydrogen vehicles. These policies will need to be sufficient to persuade the private sector to bear a share of the risks of the transition. Hydrogen powered transportation is a high-risk, long-term goal that depends critically on the successful development of competitive technology. But if the necessary technological advances are achieved, and strong policies are implemented to manage the transition, then hydrogen fuel cell vehicles together with appropriate policy to constrain greenhouse gas emissions could virtually eliminate both carbon emissions and criteria pollutant emissions from light-duty vehicles.

Uncertainties are inherent in scenario analyses such as this one. It is worth reiterating the key areas of uncertainty to remind ourselves of the limitations of prospective analyses.

- Uncertainty about the extent and rate of technological progress for competing vehicle technologies.

- Uncertainty about future energy market conditions, especially petroleum and feedstock prices.

- Uncertainty about the values consumers attach to vehicle and fuel attributes, including fuel availability and the diversity of choice among makes and models.

- Uncertainty about the response of feedstock costs to the additional demand from hydrogen production.

- Uncertainty about how both market and policy risks will affect the investment decisions of vehicle manufacturers, hydrogen producers and retailers, and consumers.

Despite these uncertainties, the integrated market analysis has produced some valuable insights, albeit insights conditional on the premises of the analysis.

Perhaps the most important finding of this analysis is that given technology success consistent with the DOE's program goals for hydrogen vehicles and infrastructure, and given a concerted effort to initiate the market transformation, a sustainable transition to hydrogen powered lightduty vehicles appears to be achievable. Even in the absence of policy incentives after 2025, hydrogen powered vehicles are able to achieve market dominance in scenarios 1, 2 and 3. By 2050, most new light-duty vehicles could be hydrogen fuel cell vehicles and the majority of fuel used by light-duty vehicles could be hydrogen. Technological success appears to be the single most important factor for achieving a sustainable transition to hydrogen-powered transportation.

Three scenarios representing different rates and geographical concentrations of hydrogen vehicle market penetration and development of refueling infrastructure, plus one null scenario, were analyzed coupled with three policy cases representing alternative ways of sharing the costs of the early transition, plus one null policy case. This report neither endorses nor rejects any particular scenario or policy case. Scenarios 1, 2 and 3 require approximately 2 million, 5 million and 10 million hydrogen vehicles on the road, respectively, by 2025. On the infrastructure side, scenarios 1, 2, and 3 place approximately 1,600, 3,700 and 8,000 refueling stations in 20 
"lighthouse" metropolitan areas by 2025. It appears unlikely that the null (no transition strategy) scenario would by itself produce a transition to hydrogen vehicles in the period 2005 to 2050, even given technology success, unless vehicle manufacturers and fuel providers are willing to voluntarily absorb substantial losses during the transition. Losses by the vehicle manufacturers, who bear the largest share of transition costs through 2025, could easily be billions of dollars per year for as long as a decade.

Given technology success, all three of the early transition scenarios appear to be able to produce a sustainable transition to hydrogen under generally favorable market conditions. The more aggressive scenarios (2 and 3) produce more widespread infrastructure, drive vehicle manufacturing costs down the learning curve and achieve economies of scale faster, and yield a greater diversity of choice of makes and models. To reach the scenario 3 target of 10 million vehicles on the road by 2025, manufacturers will have to aggressively market and promote fuel cell vehicles. Scenario 3 produces the most robust and geographically diverse hydrogen infrastructure. At the end of Scenario 3 in 2025, 15\% of the refueling outlets in the targeted regions offer hydrogen fuel.

The four policy cases illustrate different cost-sharing arrangements between industry and the government. If the industry is required to bear the full cost of the transition, it will incur very substantial losses for more than a decade. On the other hand, policy case 3 assumes the government will bear the majority of the transition costs, greatly reducing industry losses through 2017 and, in scenarios 2 and 3, allowing the industry to achieve profitability by 2018. Again, due to the many uncertainties in this analysis, these dates and numbers should not be considered predictions but rather indicators of the likely relative performance of the alternative policies. In reality, both government and industry will need to closely monitor the progress of the transition and be able to adapt their strategies and policies as it evolves.

Transition to hydrogen vehicles appears to require not only technological success but also strong policy intervention to overcome the natural market barriers to such a dramatic change in vehicle technology and fuel infrastructure. In scenarios run without strong transition policies, there was no transition to hydrogen despite technological success. And while all three of the early transition scenarios examined could produce a sustainable transition to hydrogen, there are reasons to believe that the more aggressive scenarios may be necessary. Both scenarios 2 and 3 drove fuel cell technology down the learning curve and achieved economies of scale in manufacturing. Only scenario 3 achieved a 15\% market share for hydrogen refueling stations in the targeted regions (5\% nationwide) and a substantial diversity of hydrogen powered makes and models (approximately 45) by 2025. This analysis did not explicitly represent the private sector's (firms' or consumers') perception of the riskiness of the transition. The default (typical) industry rates of return of the H2A models were used throughout the analysis. The least aggressive early transition scenario (1) would require an extended period of substantial private and public sector investment without a positive return. The more aggressive scenarios achieved a profitable market more quickly. It seems likely that the most aggressive scenario, by achieving learning and scale economies more quickly, would reduce the risks perceived by vehicle manufacturers and fuel suppliers. Greater early market development would also enhance consumer familiarity and confidence regarding vehicle performance and quality, reducing risks perceived by consumers. 
Unless there is cost sharing by the government, vehicle manufacturers and fuel suppliers are likely to face more than a decade of negative cash flow after the beginning of the market transition in 2012 before a profitable market emerges. With 50/50 cost sharing and possibly other financial incentives, positive cash flow might be achieved in less than a decade and substantial profits might be possible in less than 15 years.

Given technological success, the cost of the transition to hydrogen does not appear to be daunting. Both annually and cumulatively, the added costs are small relative to consumers' expenditures on light-duty vehicle fuel, even in the more aggressive scenarios. In 2005, more than $\$ 325$ billion was spent on motor gasoline in the United States. (U.S. DOE/EIA, 2006a, tables 3.4 and 9.4). In the most aggressive scenario (3) and the most expensive policy case (3), estimated annual government expenditures never exceed $\$ 7$ billion. The cumulative, undiscounted costs to the government through 2025 of the most expensive policy case (3) are $\$ 15-\$ 20$ billion in scenario $1, \$ 30-\$ 35$ billion in scenario 2 and $\$ 45-\$ 50$ billion in scenario 3. Whether the barriers to hydrogen are overcome slowly or rapidly, the cumulative cost of getting down the learning curve, reaching scale economies and establishing an adequate fuel infrastructure are ultimately about the same. The differences in costs among the scenarios Policy Cases are chiefly determined by how much of that cost the government shares with the private sector.

Policies to constrain carbon emissions do not appear to be essential to achieving a transition to hydrogen, but they do appear to be essential to achieving reductions in carbon emissions from the transition. In the absence of strong carbon policy, hydrogen produced in the most costeffective manner is likely to come primarily from fossil resources without sequestration. The result could well be no significant decrease in life-cycle carbon emissions by light-duty vehicles following from the transition to hydrogen. But with carbon constraints equivalent to a carbon price reaching $\$ 25$ per ton of $\mathrm{CO}_{2}$, the carbon emissions from light-duty vehicles could be drastically reduced and eventually virtually eliminated. The transition to hydrogen-powered vehicles creates the potential for carbon-free transportation, but that potential must be combined with strong but reasonable carbon policies in order to be realized. 


\section{REFERENCES}

(DTI) Directed Technologies, Inc. 2007. “Hydrogen Infrastructure Pathways Analysis using HYPRO, Three Scenarios,” unpublished report, by Brian James and Julie Perez, Arlington, Virginia, March.

Leiby, P.N., D.L. Greene, D.C. Bowman and E. Tworek. 2005. "HyTrans: Hydrogen Transition Model Version 1.5,” draft report, Center for Transportation Analysis, Oak Ridge National Laboratory, Oak Ridge, Tennessee, September 30.

Melendez, M. and A. Milbrandt. 2007. "Geographically Based Hydrogen Demand and Infrastructure Deployment Scenario Analysis,” DRAFT report, National Renewable Energy Laboratory, Golden, CO, March.

Rousseau, A. P. Sharer, S. Pagerit and S. Das. 2005. "Trade-Off between Fuel Economy and Cost for Advanced Vehicle Configurations," presented at the EVS 21, $21^{\text {st }}$ Worldwide Battery, Hybrid, and Fuel Cell Electric Vehicle Symposium and Exhibition, Monaco, April 2-6.

(U.S. DOE) U.S. Department of Energy, 2007. "Analysis of the Transition to a Hydrogen Economy and the Potential Hydrogen Energy Infrastructure Requirements", DOE Scenario Analysis Summary Report, draft 5-04-07, Office of Hydrogen, Fuel Cells and Infrastructure Technologies, U.S. Department of Energy, Washington, D.C.

(U.S. DOE/EERE) U.S. Department of Energy, Energy Efficiency and Renewable Energy. 2006. FreedomCAR and Vehicle Technologies Program Multi-Year Program Plan: 2006-2011, Washington, DC, September.

(U.S. DOE/EERE) U.S. Department of Energy, Energy Efficiency and Renewable Energy. 2005. Hydrogen Fuel Cells \& Infrastructure Technologies Program Multi-Year Research, Development and Demonstration Plan: 2003-2010, Washington, DC, January

(U.S. DOE/EIA) U.S. Department of Energy, Energy Information Administration. 2006a. Monthly Energy Review: December 2006, DOE/EIA-0035(2006/12), Washington, DC.

(U.S. DOE/EIA) U.S. Department of Energy, Energy Information Administration. 2006b. Annual Energy Outlook 2006, DOE/EIA-0383(2006), Washington, DC.

(U.S. DOE/EIA) U.S. Department of Energy, Energy Information Administration. 2006c. Annual Energy Review 2005, DOE/EIA-0384(2005), Washington, DC.

Filename: Integrated Analysis of Transition Scenarios_04_23_07.Rev2.doc Printed: 10/24/2007 